\title{
Intergroup relationships in Verreaux's sifakas (Propithecus verreauxi)
}

\author{
Dissertation \\ for the award of the degree \\ "Doctor of Philosophy" Ph.D. Division of Mathematics and Natural Sciences \\ of the Georg-August-Universität Göttingen \\ within the doctoral program Biology \\ of the Georg-August University School of Science (GAUSS)
}

Submitted by

Flávia Koch

From Porto Alegre, Brazil

Göttingen 2015 



\section{Thesis Committee}

Dr. Claudia Fichtel, Behavioral Ecology and Sociobiology Unit, German Primate Center $\mathrm{GmbH}$, Germany

Prof. Dr. Stefan Scheu, J.F. Blumenbach Institute of Zoology and Anthropology, GeorgAugust University Göttingen, Germany

Prof. Dr. Peter M. Kappeler, Department of Sociobiology and Anthropology, Georg-August University Göttingen, Behavioral Ecology and Sociobiology Unit, German Primate Center GmbH, Germany

\section{Members of the Examination Board}

Reviewer: Dr. Claudia Fichtel

Second Reviewer: Prof. Dr. Stefan Scheu

\section{Further members of the Examination Board}

Prof. Dr. Peter M. Kappeler

Prof. Dr. Julia Ostner, Department of Behavioral Ecology, Georg-August University Göttingen, Germany

Dr. Oliver Schülke, Department of Behavioral Ecology, Georg-August University Göttingen, Germany

Prof. Dr. Carel van Schaik, Anthropological Institute and Museum, University of Zurich, Switzerland 



\section{CONTENTS}

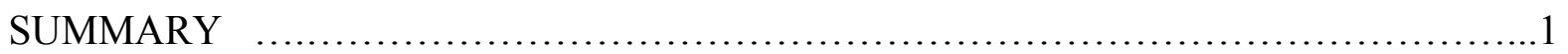

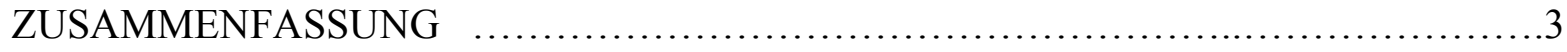

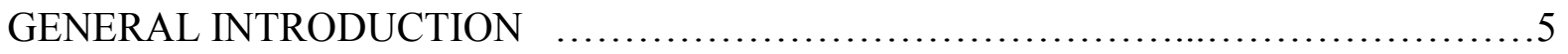

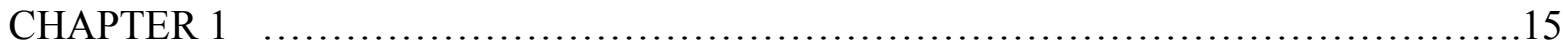

Intergroup encounters in Verreaux's sifakas (Propithecus verreauxi): who fights and why?

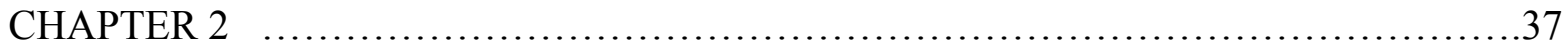

Group encounters in Verreaux's sifakas: the importance of location as a predictor for outcome

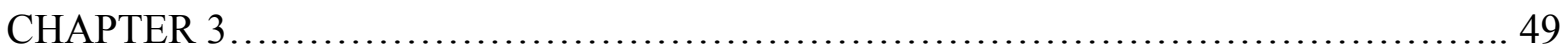

Sex and seasonal differences in diet and nutrient intake in Verreaux's sifakas (Propithecus verreauxi)

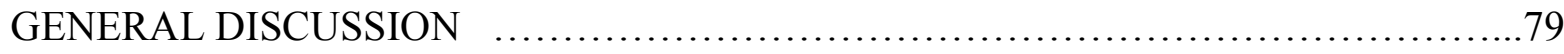

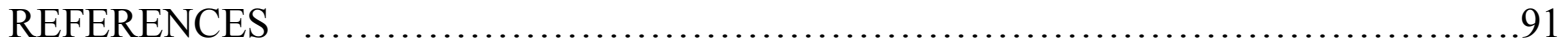

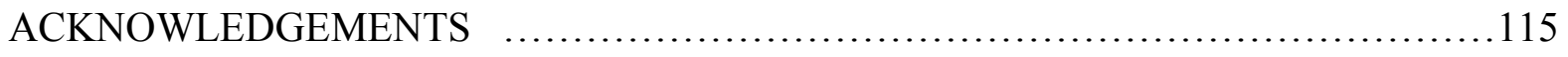

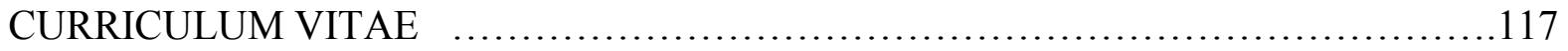

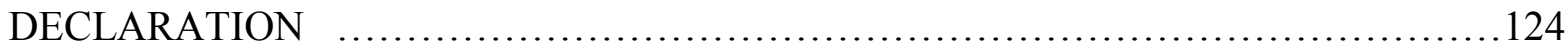





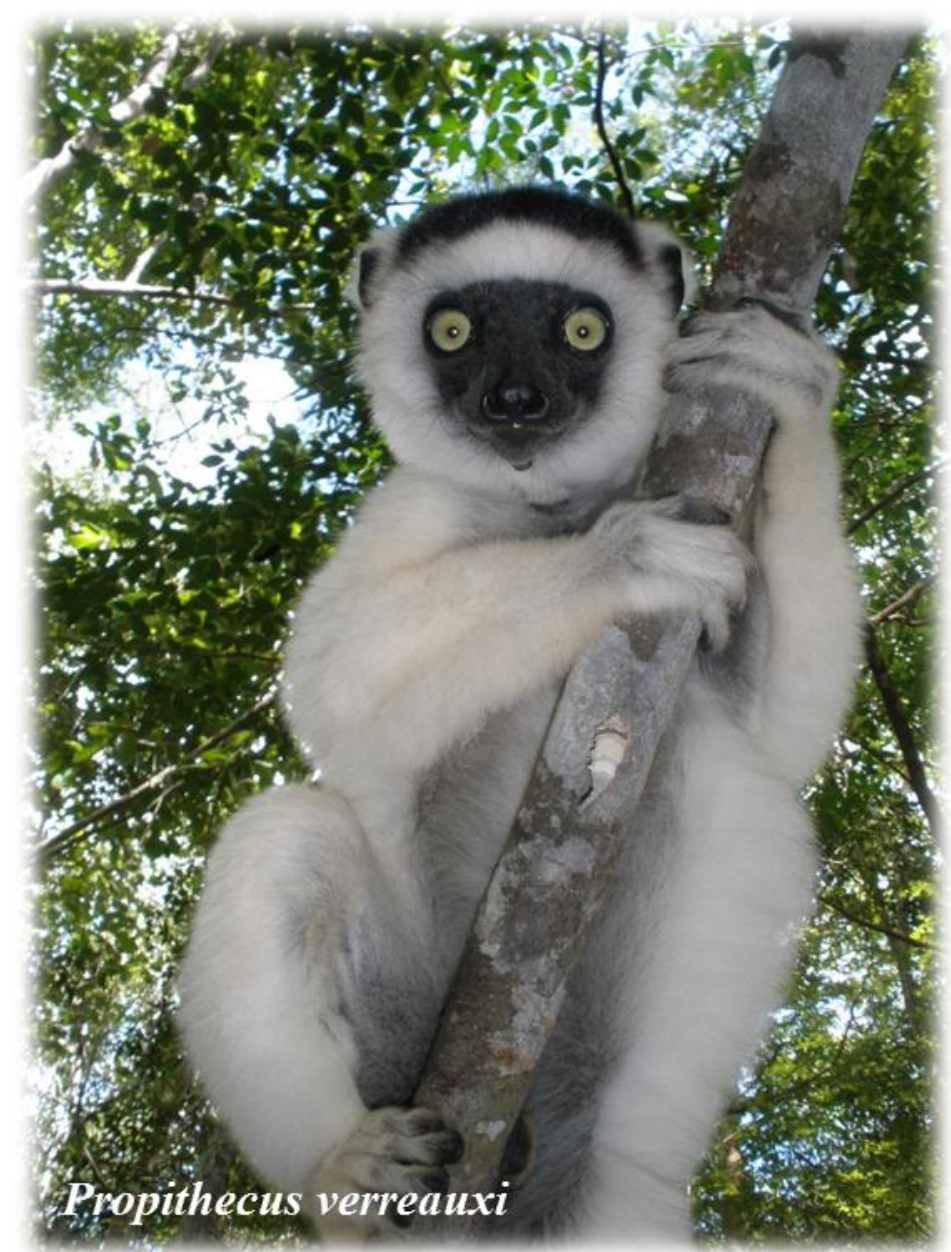

(c) 2013 F.Koch. All rights reserved)

\section{DEDICATION}

This work is dedicated to

Ilka Herzog Koch,

Tenisa Koch,

Fernanda de Vasconcellos Hennemann,

Sofia de Vasconcellos Hennemann,

and to Mo Lefever, with all my love. 



\section{SUMMARY}

How animals achieve collective action for territorial defense and how they establish relationships between neighboring groups has recently become a central topic in the study of animal behavior. The power of a group can be influenced by multiple factors at the group and at the individual level. In this dissertation I investigated aspects of intergroup relationships between eight groups of Verreaux's sifakas in western Madagascar. Detailed behavioral, ecological and demographic data were recorded between 2012 and 2014 to investigate the factors influencing the individual participation, and the predictors for a positive outcome in intergroup encounters. Factors such as sex, age, presence of infants, reproductive stages, and numerical odds were tested as possible predictors for individual participation in group encounters. In the investigation of the predictors for outcome I evaluated the influence of numerical advantage and location of encounter. Furthermore, I investigated the variation of food availability across seasons in the study area, and how the seasonality affected the diet and energy intake of sifaka males and females. According to my results, both sexes participated in group defense. The main incentive for their participation was the effective size of opponent groups (number of individuals participating in the encounter). Free-riding was common in group encounters, and while in males lower rank individuals had higher chances to free-ride, in females the chances of participation decreased with the presence of dependent infants. The location of the encounter was the main predictor for the chances of winning, instead of numerical advantage. Seasonality had a significant impact on the diet of both sexes. Interestingly, females had a higher quality diet than males, which is likely connected with the high costs of reproduction for females. In contrast to the majority of primates, female sifakas are highly involved in group defense. Social dominance, physical power, and the high costs of reproduction in extremely seasonal climates are among the factors connected to the participation of females in group encounters observed in my study. In this study the variable circumstances of each encounter, such as its location and the effective size of the opponent group were the main predictors for the participation and outcome of group encounters. These findings support the hypothesis that other factors than numerical advantage can be critical for the participation and outcome of group encounters. Thus, 
ecological and individual characteristics must be taken into account in order to achieve a better understanding of the relationships between groups.

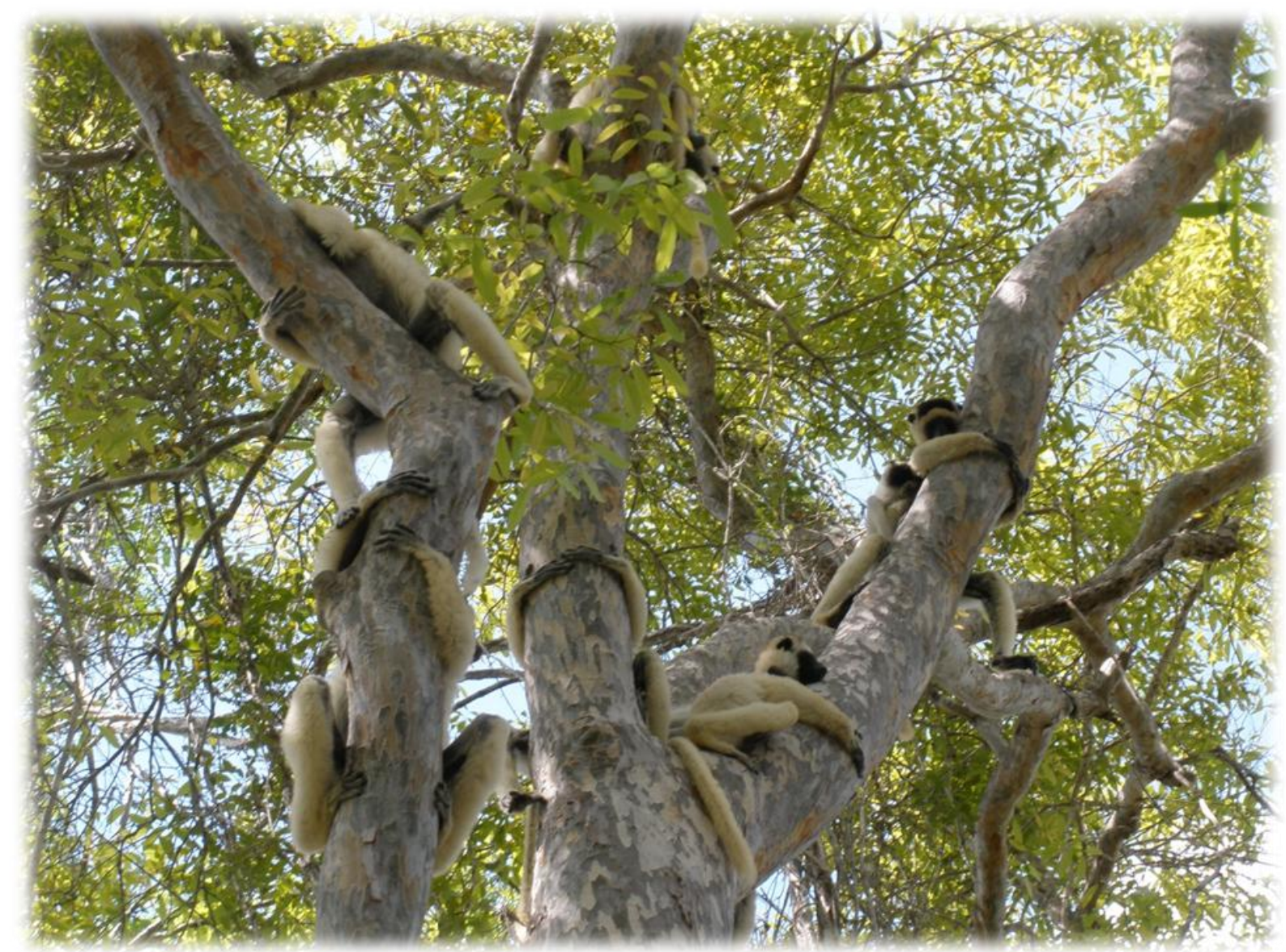

(C) 2013 F.Koch. All rights reserved)

Group of Propithecus verreauxi resting in Kirindy Forest, western Madagascar. 


\section{ZUSAMMENFASSUNG}

Wie Tiere ein kollektives Handeln zur Revierverteidigung erreichen und wie sie Beziehungen zwischen benachbarten Gruppen aufbauen ist in letzter Zeit zu einem zentralen Thema in der Verhaltensforschung geworden. Die Stärke einer Gruppe kann von mehreren Faktoren beeinflusst werden, sowohl auf der Gruppen- als auch auf der Individuenebene. In dieser Dissertation untersuchte ich verschiedene Aspekte der Beziehungen zwischen acht Gruppen von Larvensifakas im Westen Madagaskars. Von 2012 bis 2014 wurden detaillierte Verhaltensdaten, ökologische und demographische Daten aufgenommen, um einerseits die Faktoren zu untersuchen, die die individuelle Teilnahme beeinflussen und anderseits die Prädiktoren zu identifizieren, die den positiven Ausgang einer Zwischengruppenbegegnung vorhersagen. Faktoren wie Geschlecht, Alter, Anwesenheit von Jungtieren, Fortpflanzungsstadien und zahlenmäßige Gewinnchancen wurden als mögliche Prädiktoren für die individuelle Teilnahme an Begegnungen zwischen Gruppen getestet. In der Untersuchung der Prädiktoren für den Ausgang bestimmte ich den Einfluss einer zahlenmäßigen Überlegenheit und des Ortes der Begegnung. Zusätzlich ermittelte ich die saisonalen Schwankungen in der Verfügbarkeit von Nahrung im Forschungsgebiet und wie sich diese Saisonalität auf die Nahrungszusammensetzung und die Energieaufnahme der männlichen und weiblichen Sifakas auswirkt. Meinen Ergebnissen zufolge beteiligen sich beide Geschlechter an der Verteidigung der Gruppe. Der bedeutendste Anreiz für die Teilnahme war die effektive Größe der gegnerischen Gruppe (Anzahl der Individuen, die sich an der Auseinandersetzung beteiligen). Trittbrettfahren war häufig: Während sich bei den Männchen vor allem Tiere mit niedrigem Rang weniger beteiligten, waren es bei den Weibchen vor allem diejenigen mit unselbstständigen Jungtieren. Der Ort der Begegnung war ein essentieller Prädiktor für die Chance einen Konflikt zu gewinnen, im Gegensatz zur zahlenmäßigen Überlegenheit. Die Saisonalität hatte einen signifikanten Einfluss auf die Ernährung beider Geschlechter. Interessanterweise war die Nahrung der Weibchen von höherer Qualität als die der Männchen, was wahrscheinlich mit den für die Weibchen höheren Kosten der Fortpflanzung zusammenhängt. Im Gegensatz zu den meisten Primatenweibchen sind weibliche Sifakas stark an der Gruppenverteidigung beteiligt. Soziale Dominanz, körperliche Kraft und die hohen Kosten der Fortpflanzung in einem Lebensraum 
mit extremen saisonalen Klimaschwankungen gehören zu den Faktoren, die mit der, in meiner Studie beobachteten hohen Beteiligung von Weibchen an Gruppenbegegnungen zusammenhängen. In dieser Studie waren die variablen Umstände einer Begegnung, wie deren Ort und die effektive Größe der gegnerischen Gruppe, die wichtigsten Prädiktoren für die Teilnahme an einer Gruppenbegegnung und für deren Ausgang. Diese Ergebnisse unterstützen die Hypothese, dass andere Faktoren als eine zahlenmäßige Überlegenheit entscheidend für die Teilnahme an einer Gruppenbegegnung und deren Ausgang sein können. Demzufolge müssen ökologische und individuelle Eigenschaften einbezogen werden, um ein besseres Verständnis der Beziehungen zwischen Gruppen zu erreichen. 


\section{GENERAL INTRODUCTION}

Species ranging from ants to primates live in groups. These groups may vary in size and in the stability of their associations, ranging from temporary to stable units (Lott 1991; Lee 1994; Parrish et al. 1997). Living in a group provides collective benefits in terms of safety from predators, enhancement of success in location and maintenance of access to resources, and avoidance of conspecific threat (Wrangham 1980; van Schaik 1983; Janson and Boinski 1992; van Schaik and Kappeler 1993; Palombit et al. 1997; Silk 2002). However, several factors may prevent the formation of groups, imposing fitness costs to group members. Such costs may include increased transmission of parasites and diseases, increased aggression and competition for resources, and increased risk of infanticide (Hoogland 1979; Hoogland 1985; Armitage 1988; Caro 1989; Macdonald and Carr 1989; Davies et al. 1991; Moler and Birkhead 1993; van Vuren 1996).

Animals must compete for limited resources in order to survive and achieve reproductive success. For animals living in groups, competition, either scramble or contest, can take place within and between groups (Janson and van Schaik 1988; van Schaik 1989). Scramble competition can be observed when resources are not monopolizable and animals can equally share a food supply; contest competition is connected to an asymmetric gain of energy among individuals or groups, which can be usually related to dominance relationships between the contestants (Nicholson 1954).

Regarding the competition between groups, it has been shown that in virtually all animal societies, groups of permanently associated individuals compete over access to limited resources (Hölldobler 1981; Black and Owen 1989; Heinsohn and Packer 1995; Crofoot et al. 2008; Harris 2010; Markham et al. 2012). Competition between groups is particularly common among primates. This is because the vast majority of primates live in stable social groups, and they usually exhibit some level of territoriality, due to a high level of home range fidelity that can last over generations (van Schaik 1989; Jolly and Pride 1999). However, despite the common presence of competition between groups, the knowledge on intergroup relationships in primates (and in all taxa) is still very scarce. The widespread lack of quantitative studies on the topic might be due to the fact that intergroup encounters are 
rare events in the daily life of gregarious animals. In fact, the main challenge is to achieve a representative sample size to analyze the various aspects of group interactions (Crofoot and Wrangham 2010). Additionally, several groups must be well habituated to the presence of humans and studied over long periods in order to determine possible dominance relationships between groups. Finally, visibility and group size can be an extra challenge, since individual identification of participants is an important aspect to be considered for the understanding of group encounters. Concerning the terminology, in the literature the interactions between two groups are referred as intergroup encounters, intergroup conflicts, disputes between groups, and group defense. In the present study these terms are used as synonyms, and they all refer to events when two groups meet and a range of aggression can be displayed between them, from peaceful to physical aggression.

A positive outcome in group encounters can result in multiple types of payoffs, including access to mating opportunities and/or food resources (Cheney 1987). However, direct intergroup disputes demand time and energy from all individuals involved in the contest, and they can also involve high risks of serious injuries or even of death (Kelly 2005; Wich and Sterck 2007; Mitani et al. 2010; Scarry and Tujague 2012; Crofoot 2013). It is therefore critical for an individual to measure the balance between potential costs and benefits before the decision of entering in an encounter against another group (Parker 1974; Haley 1994).

One of the main differences in disputes between single individuals versus disputes between groups involving several individuals is the need of cooperation among group members within each social unit. Because group members have different incentives in taking the costs of group defense, individual participation can be highly variable (Boesch and Boesch 1989; Heinsohn and Packer 1995; Nunn and Deaner 2004; Cords 2007; Bonanni et al. 2010; Harris 2010). Although groups can be considered as social units, the decision of participation in group encounters is taken individually by each group member, based on its own balance of the potential costs and benefits in each group encounter.

As a consequence of the variable motivations in participating in group defense, intergroup encounters harbor a high potential for collective action problems, with some individuals reaping the associated benefits without paying the costs of participating (Nunn 2000; Cords 2007; Kitchen and Beehner 2007; Willems et al. 2013; Kao and Couzin 2014; 
Willems and van Schaik 2015). Hence, one of the central questions in behavioral biology remains how cooperation in animals could evolve despite the fact that some individuals benefit more by exploiting other individuals' cooperative actions.

In order to understand how group members cooperate in group defense, two main aspects need to be explored: 1) the factors that influence the individual participation in group encounters, and 2) the predictors for a positive outcome.

\section{Participation}

Many factors can influence the individual participation in group encounters, such as sex, food distribution and availability, social rank, presence of dependent infants, reproductive stage, location of the encounter, and the number of individuals in the opponent group. In mammals, the motivation in participating in group encounters is strongly predicted by sex, because basic differences in the factors limiting reproductive success in males and females: while mating opportunities are the main constraint of males' fitness, food resources are the main constraint for females' fitness (Trivers 1972).

In the vast majority of primates, males are larger (Ralls 1976; reviewed in Key and Ross 1999) and dominant over females, and they tend to be the sex that invests the most in group defense (reviewed in Fashing 2001; Kitchen and Beehner 2007, Table 6 in Chapter 2). Male participation in intergroup encounters has been connected to different purposes including direct (Trivers 1972; Krebs and Davies 1997; Kitchen and Beehner 2007) and indirect mate-defense (the "hired gun" strategy: Rubenstein 1986; Rubenstein and Wrangham 1986), infant-defense in infanticidal species (van Schaik 1996; Steenbeek 1999), or direct resource defense.

According to the direct mate-defense strategy, males should invest more in intergroup encounters when estrous females are present (Cowlishaw 1995; Kitchen et al. 2004) and/or when the overall number of females is high (Cooper et al. 2004; Majolo et al. 2005). In yellow baboons (Papio cynocephalus), for example, males approached and chased neighboring groups more often when estrous females were present in the opponent group (Kitchen et al. 2004). In addition, males have been observed to defend the exclusive access to the females in their own groups by herding them away from another group to prevent extra- 
group copulations (Papio cynocephalus: Kitchen et al. 2004; Macaca fuscata: Majolo et al. 2005).

The indirect mate defense also known as the "hired gun" strategy is usually observed in species with strong sexual dimorphism in favor of males. In these species, females are physically not able to defend access to food or protect their infants from large rival males in opponent groups. Thus, the participation of males is aimed at preventing negative impacts in feeding time for the females in their own group, and/or attempts to infanticide by males from opponent groups. In the latter case, males should be more aggressive to opponents when vulnerable infants are present in their own group (van Schaik 1996; Borries 1997; Fashing 2001; Wich and Nunn 2002; Kitchen et al. 2004). Alternatively, another strategy to avoid infanticide is the avoidance of group encounters: males can lead group movements to prevent encounters with opponent groups when infants are present in their own groups (Kitchen et al. 2003; Harris 2005).

Finally, males can also directly defend access to food. In a strategy called the "resource defense polygyny", males defend high quality areas in terms of availability of food, to attract females. Since females give priority to these areas, because their reproductive success is highly dependent on the quality of habitat (van Schaik and Noordwijk 1988), this strategy functions for males as an indirect form of acquiring mates (Emlen and Oring 1977), and also to improve their own fitness. This strategy is seen among some birds (Hinde 1956), small mammals (Ostfeld 1990), and ungulates (Owen-Smith 1977; Rubenstein 1986).

Although females are usually either bystanders or targets during intergroup conflicts, in some species of mammals, they can be equally or more actively involved in group defense than males (Borries 1993; McComb et al. 1994; Boydston et al. 2001; Korstjens et al. 2005; Cords 2007). According to the socioecological model, philopatric females should cooperatively defend high quality resources that are limited and patchily distributed (Wrangham 1980; van Schaik 1989) or in low availability (Isbell 1991).

Food is a crucial resource for females due to the high costs of reproduction (Trivers 1972; Coelho 1974; NRC, 2003). Indeed, low body condition caused by periods of poor nutrition can force females to skip reproduction or can affect the survival of their offspring, with a severe impact on their fitness (Bercovitch 1987; van Schaik and Noordwijk 1988; Lewis 2005). It is therefore expected that reproductive females are more affected by the 
variance in food availability than males and non-reproductive females (Oftedal 1985; Hemingway 1999; McCabe and Fedigan 2007). Thus, patterns of female sociality coupled with the distribution and availability of food are likely to be the main factors influencing the levels of female participation in intergroup encounters (van Schaik 1989; Cheney 1992; Sterck et al. 1997).

Social rank can also have an important role in individual participation in group defense. In many species higher-ranking individuals invest more in group-defense than lower ranking ones (Fashing 2001; Payne et al. 2003; Kitchen 2004; Cooper et al. 2004; Nunn and Deaner 2004; Williams et al. 2004; Cords 2007; Kappeler et al. 2009; Mares et al. 2012, but see also Decanini and Macedo 2008). Dominant individuals have more to lose in intergroup contests because their social rank assures a superior access to food and mates, and as a result, a higher reproductive output (Mares et al. 2012). Accordingly, individuals that benefit the most should be the main participants in group defense (Cheney 1992; Nunn 2000). Additionally, in some species, such as in ringtailed lemurs (Lemur catta), the better physical condition of dominant individuals can explain the higher frequency of participation of dominant females (Pride et al. 2006).

\section{Outcome}

Previous studies on intergroup relationships identified several predictors for the outcome in intergroup encounters. In principle, the power of a group can be influenced by factors at the group and individual level, though both influence each other mutually. At the group level, the dominance relationship between neighboring groups can be influenced by group size (Cheney 1987; Kitchen 2004; Pride et al. 2006), population density (Horiuchi 2008) and the location of interactions (Pride et al. 2006; Crofoot et al. 2008). For example, wedge-capped capuchins (Cebus olivaceus) exhibit a clear dominance hierarchy between groups, in which dominance is determined by both the number of adult males and the identity of males, because the presence of powerful males in small groups contribute to outrank larger groups with more males but less powerful ones (Robinson 1988).

At the individual level, the balance of power between neighboring groups can be influenced by a range of factors such as group sex ratio (Cheney 1987; Fashing 2001; Wilson 
and Wrangham 2003; Kitchen et al. 2004; Crofoot and Gilby 2012; Markham et al. 2012), relative fighting ability of males (Robinson 1988; Harris 2010), the number of kin in the respective group (Nunn and Deaner 2004) or the numerical odds of the groups involved in the encounter (McComb et al. 1994; Perry 1996; Wilson et al. 2001; Mitani et al. 2002; Kitchen et al. 2004; Crofoot et al. 2008; Bonanni et al. 2010; Benson-Amram et al. 2011; Markham et al. 2012).

Numerical advantage has been pointed as the main factor behind the outcome and participation in group encounters. Indeed, in a variety of species from ants to chimpanzees large groups tend to win encounters over smaller ones (Black and Owen 1989; Hölldobler and Wilson 1990; McComb et al. 1994; Wilson et al. 2001; Kitchen et al. 2004; Crofoot et al. 2008; Brown 2011). Furthermore, large groups are often more capable of defending higher quality home ranges than smaller groups, and females in large groups show higher reproductive success (Pride 2005; Pride et al. 2006; Takahata et al. 2008; but see also Jolly et al. 2002). Gregarious animals can use information about asymmetries in group size between their own group and their opponents to infer the potential risks and their chances of winning the encounter (McComb et al. 1994).

Interestingly, in some species and in certain contexts, other factors can overcome the effect of numerical advantage in the outcome of group encounters. For instance, the location of the encounter has a strong effect in multiple species, including yellow baboons (Papio cynocephalus, Markham et al. 2012), banded mongooses (Mungos mungo, Furrer et al. 2011), and white-faced capuchins (Cebus capucinus, Crofoot et al. 2008). Location is critical because generally animals do not use all portions of their home range with the same intensity. This is due to the fact that the resources are not uniformly distributed across the home range, and/or, some areas can be for exclusive use of one group while other areas overlap with other groups. According to patterns of use and distribution of resources, animals can be more motivated in defending certain areas of their home ranges than others (Maynard Smith and Parker 1976; Crofoot et al. 2008; Markham et al. 2012). 


\section{Why study Verreaux's sifakas?}

Verreaux's sifakas (Propithecus verreauxi) are one of the largest diurnal lemurs in Madagascar. They live in small groups of 3-13 individuals (Nunn 2000; Richard et al. 2002; Kappeler and Schäffler 2008; Kappeler and Fichtel 2012), in which females are philopatric (Richard et al. 1993). They occupy a home range of about 5-10 ha, that varies in size across seasons with larger ranges and longer daily travel path length in the wet season (Carrai et al. 2003; Trillmich et al. 2004; Benadi et al. 2008). Reproduction is seasonal for sifakas, concentrated in a very short period (few days) during the wet season, and very skewed in favor of dominant males, which sire the majority of offspring in their respective groups (Brockman 1999; Kappeler and Schäffler 2008; Mass et al. 2009).

Several features make Verreaux's sifakas a particularly interesting subject to study intergroup relationships. Sifakas are territorial primates that actively defend part of their home range against intruders (Jolly 1966). Each group occupies a home range characterized by a core area that is used exclusively by one group and overlapping areas that are shared by several neighboring groups (Benadi et al. 2008). Encounters between groups are common at feeding sites in overlapping areas of home ranges (Lewis 2005; Benadi et al. 2008). Both sexes participate in intergroup interactions, but usually males are more active than females (Jolly 1966; Richard 1992; Brockman et al. 1998; Benadi et al. 2008; Kappeler et al. 2009). Although groups with more males are more likely to win intergroup encounters, the participation of subordinate males is not reliable (Kappeler et al. 2009), and despite the relatively small groups sizes, collective action problem is an issue for the cooperation among individuals within a group. In addition, the level of aggression in intergroup encounters varies from peaceful and vocal contests to highly aggressive chases (Brockman et al. 1998; Fichtel and Kappeler 2002; Fichtel and Van Schaik 2006; Benadi et al. 2008).

Sifakas also offer a great opportunity to study the patterns of female participation. First, as in the majority of lemurs, females are dominant over males and have priority of access to resources (Richard and Nicoll 1987). Second, in contrast to other primate species where males are physically more powerful than females, in sifakas there is no sexual dimorphism in size. Therefore, females are physically and socially as capable as males are to participate in group defense. 
Finally, Madagascar presents a very challenging seasonal climate, where the availability of food can be extremely variable between years (Jolly 1966; Wright 1999). In some places, such as in the dry deciduous forest, the availability of food drops considerably during the long dry season that can last up to eight months (April to November, Figure 1). During this period sifakas lose body mass and the main item included in their diet is mature leaves (Lewis and Kappeler 2005a). The wet season lasts for only four months (December to March) and, during this period, sifakas have the chance to recover their body condition, since the availability of high quality food, particularly fruits, increases significantly in the forest. This aspect can potentially influence the participation of females in group defense all year round, given their need of both storing and achieving basic nutrition in periods of abundance and scarcity of food, respectively (Richard et al. 2000).

\section{STUDY AIMS}

I studied aspects of ecology and social interactions of eight neighboring groups of Verreaux's sifakas (Propithecus verreauxi) in western Madagascar, in order to achieve the following objectives:

\section{Chapter 1}

The main objective of this chapter was to investigate the factors that influence the individual participation of sifakas in group encounters. I tested the prediction that, due to the similar body size of males and females, and the fact that sifaka females are philopatric and dominant over males, both sexes should participate in group defense. However, only males should increase their participation during the annual mating season when potential mating opportunities in neighboring groups are present (females do mate with non-resident males: Richard 1985). Moreover, I predicted that dominant individuals of both sexes should participate more often in group encounters than subordinates. I also expected that factors such as the presence of dependent infants, the numerical odds in the encounter, food availability, and duration of encounter should influence individual participation. Finally, 
since free-riding occurred in both sexes, I explored the circumstances, such as group size and social status, under which individuals from both sexes free-ride.

\section{Chapter 2}

In order to understand some of the factors influencing the outcome and the potential costs of losing intergroup encounters, we used data from GPS loggers that monitored simultaneously the movements of the eight study groups. In particular, I investigated the effect of numerical advantage and location of encounters (in terms of proximity to intensively used areas) in the outcome of conflicts. I tested two different aspects to check for potential costs of losing group encounters. First, I compared travelling patterns of winner and losers in three different time frames after the encounter. Second, I compared the intensity of use of the encounter area between winners and loser within the month after each encounter.

\section{Chapter 3}

Here I investigated the effect of seasonality, sex, and female reproductive stages in diet patterns of a population of Verreaux's sifakas in a dry deciduous forest in western Madagascar. In this chapter I used data on feeding ecology of adult individuals, coupled with detailed nutritional information of food samples. Under the assumption that the dry season is the limiting period in terms of availability and quality of food, I expected to see a decrease in quality of diet and changes in activity patterns in that period in comparison to the wet season. Moreover, due to the high importance of food for the reproductive success of females, I also investigated diet patterns in different stages of reproduction according to seasonal changes in availability of food. 


\section{CHAPTER 1}

Intergroup encounters in Verreaux's sifakas (Propithecus verreauxi): who fights and why?

With Johannes Signer ${ }^{1}$, Peter M. Kappeler ${ }^{2,3}$, and Claudia Fichtel ${ }^{2}$

1. Department of Wildlife Science, University of Göttingen, Büsgenweg 3, Göttingen, 37077, Germany

2. Behavioral Ecology and Sociobiology Unit, German Primate Center, 37077 Göttingen, Germany

3. Department of Sociobiology and Anthropology, University of Göttingen, 37077, Göttingen, Germany 


\begin{abstract}
Individuals living in groups have to achieve collective action for successful territorial defense. Because group encounters always involve some risks and costs, individuals must base their decision to participate in a given encounter on an evaluation of the trade-off between potential costs and benefits. Since group members may differ in motivation to engage in group encounters, they exhibit different levels of participation. In this study we investigated factors influencing participation in intergroup encounters in Verreaux's sifakas (Propithecus verreauxi). Over a period of 12 months, we studied eight neighboring sifaka groups in Kirindy forest, western Madagascar. We directly observed 71 encounters between known neighboring groups, in which adult females and males participated equally as often. Females participated less often in encounters when they had dependent infants, presumably to reduce the risk of infanticide. Male participation was influenced by social status: dominant males participated in almost every encounter, and males with fewer opportunities to reproduce did free-ride more often. Thus, male participation in encounters is clearly influenced by the incentive of maintaining access to females. The number of actively participating individuals in the opponent group and the duration of the encounter positively influenced participation of both sexes. Finally, both sexes did free-ride and free-riding occurred more often in larger groups. Thus, sifakas seem to base their decision to participate in a given encounter on the actual circumstance of each encounter, suggesting that the complexity in intergroup relationships appears to be the product of the variable circumstances of each encounter.
\end{abstract}

\title{
Introduction
}

Dyadic conflicts over various resources are common in most animal taxa (Riechert 1979; Rood 1986; McComb et al. 1994; Crofoot and Wrangham 2010; Doake and Elwood 2011). Conflicts always involve some risks and costs, including physical aggression that may result in injury or even death (Williams et al. 2004; Kelly 2005). Potential benefits from dyadic competition include access to valuable resources, such as food or mates (Fashing 2001; Crofoot and Wrangham 2010). Thus, animals must base their decision to engage in a given 
encounter on an evaluation of the trade-off between potential costs and benefits (Parker 1974). Selection should therefore have promoted cognitive and behavioral strategies that enhance the ability of individuals in most non-sessile species to assess the value of a disputed resource, their own fighting ability, and the fighting ability of their opponent in order to estimate their chances of winning (reviwed in Arnott and Elwood 2008).

Whereas much theoretical and empirical research has examined dyadic conflicts between individuals (Landau 1951; Parker 1974; Dugatkin 1998), scramble and/or contest competition also occurs between neighboring groups in gregarious species. However, patterns and strategies characterizing intergroup encounters remain poorly understood; perhaps because they exhibit much more complex dynamics. For example, individuals in a group differ in intrinsic (size, physiological condition, age, rank, sex, motivation, personality) and extrinsic (prior experience of winning and losing) traits that determine their current fighting ability (Olson 1965; Heinsohn and Packer 1995; Nunn and Deaner 2004; Harris 2010). Moreover, collective action, such as engaging in intergroup combat, provides opportunities for cheating that feedback upon group performance (Hardin 1968; Rankin and Kokko 2007). Free-riding is indeed a common collective action problem observed in between group encounters (Olson 1965; Esteban and Raz 2001; Willems et al. 2013) that can decrease individual motivation in participating in an encounter (Nunn 2000). The outcome of decision making at the group level is difficult to predict because it reflects the result of multiple, perhaps interdependent individual assessments of the balance between these costs and benefits. However, the observed output, i.e. which individuals participate in the intergroup encounter, can be analyzed in analogy to an individual decision process (Esteban and Raz 2001; Sumpter 2006; Crofoot et al. 2008).

In mammals, individual incentives to participate in a group encounter appear to be strongly predicted by sex because the fitness of males is limited by access to mates, whereas the fitness of females is limited by access to food (Trivers 1972). As a result of this fundamental sex difference, males tend to have higher average incentives to participate in intergroup encounters more often than females; a pattern that has been established empirically (Perry 1996; Fashing 2001; Sicotte and Macintosh 2004; Williams et al. 2004; Kitchen and Beehner 2007; Mares et al. 2012; Willems et al. 2013). Apart from an individual's sex, there appear to be two important additional determinants of variation in 
individual participation in group encounters that we define as follows: the incentive reflects individual motivation, interest, or potential benefits (such as immediate access to a contested resource) that an individual expects from an encounter; whereas the circumstance characterizes the general characteristics of a given encounter, such as the size and identity of the opponent group, the duration of the encounter, the presence of infants (avoidance of infanticide), or general variation in food availability (in species living in seasonal habitats).

High-ranking group members may monopolize a disproportionate share of the immediately available benefits, which may increase their incentive to participate in group encounters compared to low-ranking group mates (Janson 1985; Nunn 2000; Kitchen et al. 2004; Cooper et al. 2004; Majolo et al. 2005). For instance, in species with pronounced male reproductive skew, dominant males may have stronger incentives to participate in group encounters because they have priority of access to mates (Cooper et al. 2004). Similarly, some individuals may not participate in an encounter because they expect to obtain few or none of the potential benefits. In chimpanzees, for example, the participation of males in border patrols increases according to the benefits those males can expect from the encounter (Watts and Mitani 2001). Thus, individual incentives vary, and they may do so for very different reasons (low prospects and free-riding generally predict no or rare participation).

The effects of the particular circumstances of an intergroup encounter on the probability of individual participation remain less well understood, however. First, the quality, and hence the value of a given part of a group's home range can vary (e.g. in food availability) so that the particular location of an encounter can also influence individual participation in group defense (Wilson et al. 2001; Crofoot and Gilby 2012). Second, the size and power of the opposing group can influence individual participation in group encounters because it factors into the assessment of the costs of an encounter (Parker 1974). For example, individual participation of female lions in territorial disputes increases if they have a numerical advantage over the other group (McComb et al. 1994). The importance of differences in group size is reflected by the observation that large groups tend to indeed defeat smaller ones (Black and Owen 1989; Holldobler and Wilson 1990; McComb et al. 1994; Wilson et al. 2001; Kitchen et al. 2004; Crofoot et al. 2008; Brown 2011). The duration of encounters can also influence individual participation. Since long encounters are physically more demanding than shorter ones, it can be predicted that the number of 
participants increases with the duration of the encounter (Enquist and Leimar 1987). However, individual participation may also be negatively correlated with the size of one's own group (Olson 1965; Esteban and Raz 2001; Pride et al. 2006); perhaps because of greater opportunities for free-riding (Nunn 2000).

We set out to study patterns and determinants of individual variation in the propensity to participate in intergroup encounters in Verreaux's sifakas (Propithecus verreauxi), a group-living primate from Madagascar. Verreaux's sifakas are a suitable and interesting species to test factors influencing individual participation in group encounters for several reasons. First, they exhibit interesting territorial behavior, characterized by partial home range overlap with neighboring groups and core areas for exclusive use (Jolly 1966; Benadi et al. 2008). Second, they live in relative small groups of about $6 \pm 2$ individuals, which provide an opportunity to study the role of collective action in small groups, where each individual represents a significant proportion of total group size. Third, sifakas lack sexual size dimorphism, and females are dominant over males in dyadic agonistic interactions (Jolly 1966; Richard and Nicoll 1987), offering an opportunity to study differences in male and female participation, regardless of physical superiority of one sex.

In a field study of eight neighboring groups of Verreaux's sifakas, we tested the prediction that, due to the similar body size of males and females, and the fact that sifaka females are philopatric and dominant over males, both sexes should participate in group defense. However, only males should increase their participation during the annual mating season when potential mating opportunities in neighboring groups are present (females do mate with non-resident males: Richard 1985). Moreover, we predicted that dominant individuals of both sexes should participate more often in group encounters than subordinates. We also expected that factors such as the presence of dependent infants, the numerical odds in the encounter, food availability, and duration of encounter should influence individual participation. Finally, since free-riding occurred in both sexes, we explored the circumstances, such as group size and social status, under which individuals from both sexes free-ride. 


\section{Methods}

\section{Study site and species}

The study was conducted in Kirindy Forest, a dry-deciduous forest in western Madagascar $\left(44^{\circ} 39^{\prime} \mathrm{E}, 20^{\circ} 03^{\prime} \mathrm{S}\right)$, a field site operated by the German Primate Center (Kappeler and Fichtel 2012) and situated within a forestry concession managed by the Centre National de Formation, d'Etudes et de Recherche en Environment et Foresterie (CNFEREF). The regional climate is characterized by pronounced seasonality, with a long dry season of up to 8 months from April to November, and a short wet season between December and March. As part of an ongoing long-term project, animals are habituated and individually marked with combinations of colored nylon collars and pendants or color-coded radio collars (Kappeler and Fichtel 2012).

Two observers, (F. Koch and M. Razafindrasamba, a Malagasy field assistant), conducted one hour continuous focal observations (Altmann 1974) on the adults in two different groups simultaneously, resulting in 1480 hours of observations distributed between March 2012 and April 2013. The inter-observer reliability was established during the pilot study from August to October 2011, when F. Koch and M. Razafindrasamba conducted behavior observations together. The size of the eight study groups ranged between three and eight individuals (Table 1), with one adult female and one to three adult males per group, with the exception of group J, in which two adult females were present. During the study period, eight out of nine females gave birth. Infants were considered dependent until they reached the age of three months, and individuals between three months and four and half years were defined as juveniles (Kappeler and Fichtel 2012). 
Table 1. Variation in group size and composition between the eight study groups from March 2012 to April 2013.

\section{Group Range group size}

\begin{tabular}{ll}
\hline C & 3-5 (1 adult female, 1 juvenile female, 1-3 adult males) \\
E & 5-8 (1 adult female, 1 juvenile female, 1-3 adult males, 1-3 juvenile males $)$ \\
F & 4-6 (1 adult female, 1 -2 juvenile females, $2-3$ adult males $)$ \\
F1 & 5 (1 adult female, 1 juvenile female, 2 adult males, 1 juvenile male $)$ \\
G & 4-5 (1 adult female, 1 juvenile female, 1-4 adult males $)$ \\
H & 3-4 (1 adult female, $1-2$ adult males, 1 juvenile male $)$ \\
J & 6-8 (2 adult females, $1-2$ juvenile females, $3-4$ males $)$ \\
L & 3-5 (1-2 females, $2-3$ males $)$ \\
\hline
\end{tabular}

\section{Group encounters}

Intergroup encounters were operationally defined as follows: an encounter began when the nearest members of two groups were at a distance of 50 meters or less from each other, and it ended when they were again at a distance of more than 50 meters. Details of group encounters were recorded with a digital voice recorder (Olympus WS 650S) and subsequently transcribed. The following details on group encounters were recorded: date, time the encounter started and ended, presence of dependent infants, and identity of individuals participating actively in the encounter from the focal and opponent group. Active participation was considered when individuals showed one of the following behaviors during the encounter: scent marking, urinating/defecation, vocalizing, chasing, and physical aggression.

We divided the level of aggression in four categories: 1) when there was no interaction and no vocalization, 2) when the only interaction between the groups was vocal and at least one individual produced loud calls, i.e., "tchi-faks" (Fichtel and Kappeler 2002), 3) when at least one individual from one group chased one or several members of the other group, and 4) when at least one individual from one group displayed physical aggression towards a member of the opponent group, such as chasing, grappling or biting an opponent. 
We used two different approaches to infer group size: the total group size that refers to the total number of individuals in the group, and the effective group size that refers to the number of individuals active in the encounter (excluding the free-riders).

\section{Food availability}

We registered the monthly phenology of 693 trees distributed throughout the home ranges of the study groups, representing 163 species from 44 families. A semi-quantitative method to infer food availability by assigning scores ranging from zero to four for availability of each item (young leaves, mature leaves, fruits, flowers), with zero representing total absence of the item, and four representing 100\% availability of the item (Fournier 1974). We averaged the scores of food availability per month for each item (young leaves, mature leaves, fruits, and flowers), and then across items to have a total score for food availability per month.

\section{Statistical analyses}

All analyses were conducted in R (R, version 3.1.2; R Development Core Team, 2015) and were based on data from the perspective of the focal group. To compare the rate of encounters per month between the dry and the rainy season, we used a Generalized Linear Model with the rate of encounters as the dependent variable and season (dry or rainy) as the independent variable. We used binomial Generalized Linear Mixed Models (GLMM, Baayen et al. 2008), from the package lmer4 (Bates et al. 2014), to investigate whether individual participation (yes or no) was influenced by sex or age; individual nested in group dyad identity (identity of the two opponent groups) was included as random factors.

To investigate whether the effective size of the focal group (number of active individuals in the focal group) was affected by the effective size of the opponent groups (number of active individuals in the opponent group) and by the duration of the encounter, we used a Poisson GLMM with effective group size of focal group as response variable and effective group size of the opponent group and duration of the encounter explanatory variables. Individual identity nested in dyad identity was included as random factor.

We used a binomial GLMM to examine whether the participation of males and females was influenced by the total and effective group size of the opponent group, and 
tested the two variables in two different models due to the correlation between these variables. We fitted both models, compared the AIC values and selected the model with the best fit, i.e. the model that took into account the effective size of the opponent group. However, due to the theoretical relevance of both models we present and discuss the results of both models.

In order to investigate factors that influence female participation we used a binomial GLMM, with participation as response variable and the presence of dependent infant as explanatory variable, controlled by individual identity nested in dyad identity. To investigate factors that influence male participation we used a binomial GLMM, with participation as response variable and social status and mating season (yes or no) as explanatory variables, individual identity nested in dyad identity were used as random factor. Social status as explanatory variable was included only for male participation because seven out of eight groups harbored only one adult female. Social status of males was based on the outcome of dyadic agonistic interactions following the classification in Kappeler et al. (2009): Dominant (D): male that is not related to the dominant female, has higher access to the female(s), and are likely to sire the majority of offspring in the group (Kappeler and Schäffler, 2008); Natal Subordinate (NS): males that were born in the group, and therefore directly related to the dominant female; Non-Natal Subordinate (NNS): males that immigrated into the group and are neither related to the dominant female nor to the dominant male; and Related (R): males that are related to the dominant male, but not to the resident females.

For all models, we checked the relevant assumptions and verified the significance of the full model (including the predictors and control factors) to the null model (only with the control factors) using the R function ANOVA.

\section{Results}

\section{General characteristics of intergroup encounters}

We observed 88 direct encounters between neighboring groups of sifakas. However, all the following results are based on the analyses of 71 encounters, which involved only the known groups within our eight study groups (Figure 1). On average sifakas had $6( \pm 3)$ encounters per month. 


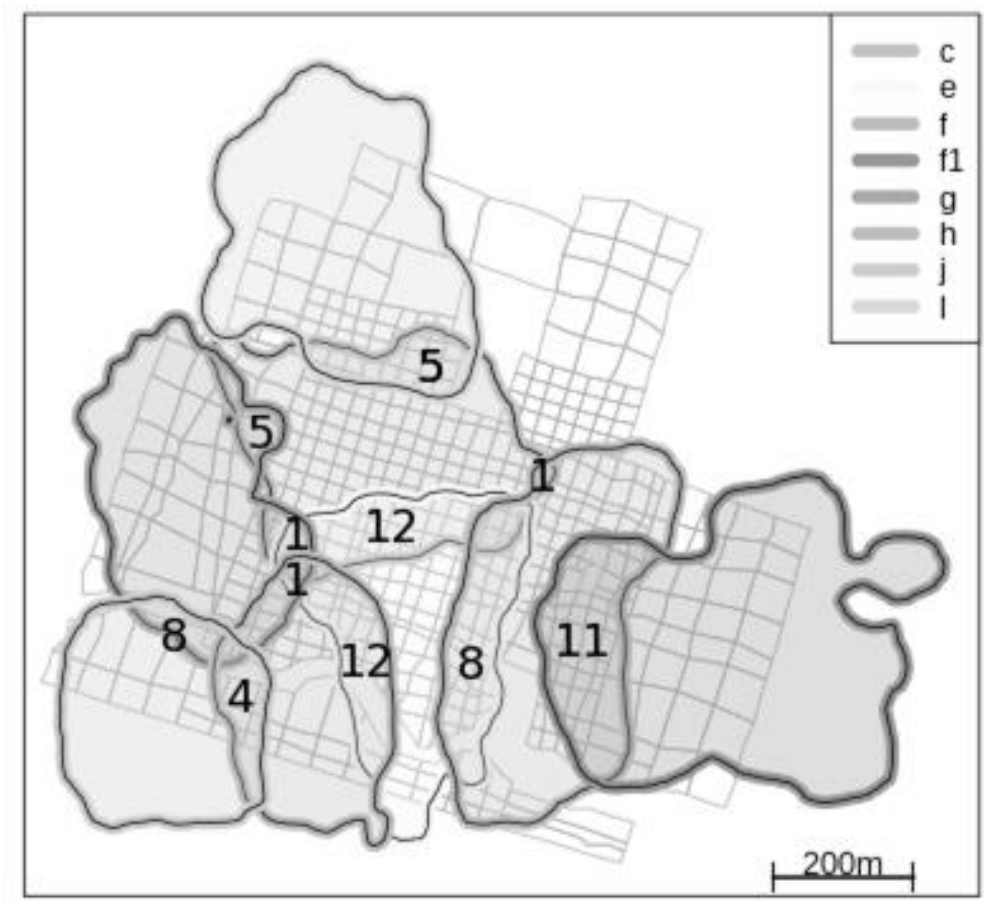

Figure 1. Home ranges of the 8 groups of sifakas; annual overlap areas between neighboring groups are based on $95 \%$ kernels. The numbers represent the number of observed encounters between each dyad.

The encounters lasted on average for $23 \pm 22$ minutes and the majority of them $(72 \%)$ reached the category three of aggression, including chases between individuals of the opposing groups. On average, $64 \pm 48 \%$ of adult females and $71 \pm 45 \%$ of adult males participated in inter-group encounters, indicating that both sexes did free-ride regularly. Freeriding by adult individuals occurred in $72 \%$ of intergroup encounters. The frequency of encounters did not differ between the rainy and the dry season (Table $2 \mathrm{a}, \chi^{2}=0.47$, $\mathrm{df}=1$, $\mathrm{P}=0.49$ ). Adult individuals participated in encounters more often than subordinates in both sexes and females participated as often as males (Table $2 \mathrm{~b}, \chi^{2}=13.51, \mathrm{df}=2, \mathrm{P}=0.001$ ). 
Table 2. Results of the GLM testing seasonal differences in encounter rate (a), and results of the binomial GLMM testing the influence of sex and age classes (adults and juveniles) on the probability of participation in a group encounter (b).

\begin{tabular}{lllll}
\hline a) GLM: seasonal differences in encounters & & & \\
\hline Fixed effects & Estimate & Std. Error & Z value & $\operatorname{Pr}(>|\mathrm{z}|)$ \\
(Intercept) & 1.92 & 0.13 & 14.30 & 0.001 \\
Wet season & -0.42 & 0.27 & -1.61 & 0.12 \\
b) GLMM: influence of sex and age on participation & & & \\
Fixed effects & Estimate & Std. Error & Z value & $\operatorname{Pr}(>|\mathrm{z}|)$ \\
(Intercept) & 0.82 & 0.28 & 2.92 & 0.003 \\
Sex & 0.25 & 0.32 & 0.76 & 0.44 \\
Age (juveniles) & -1.17 & 0.35 & -3.27 & $<0.001 * * *$ \\
\hline
\end{tabular}

\section{Participation in intergroup encounters}

On the group level, the effective size of the focal group was influenced by the effective size of the opponent group and by the duration of the encounter (Table $3 ; \chi^{2}=48.41, \mathrm{df}=2$, $\mathrm{P}<0.001$, Figure 2). When more individuals actively participated in an encounter from the focal group, the more individuals participated in the opponent group. Additionally, the duration of encounters had a positive effect on the number of participants, with more individuals participating in longer encounters.

Table 3. Results from the Poisson GLMM testing the relation between the number of individuals active in the focal group with the duration of the encounter, and the number of individuals active in the opponent group.

\begin{tabular}{lllll}
\hline Fixed effects & Estimate & Std. Error & $\mathbf{Z}$ value & $\operatorname{Pr}(>|\mathbf{z}|)$ \\
\hline (Intercept) & 0.51 & 0.11 & 4.83 & $<0.001$ \\
Effective size opponent group & 0.12 & 0.03 & 4.30 & $<0.001 * * *$ \\
Duration of encounter & 0.27 & 0.07 & 3.67 & $<0.001 * * *$ \\
\hline
\end{tabular}




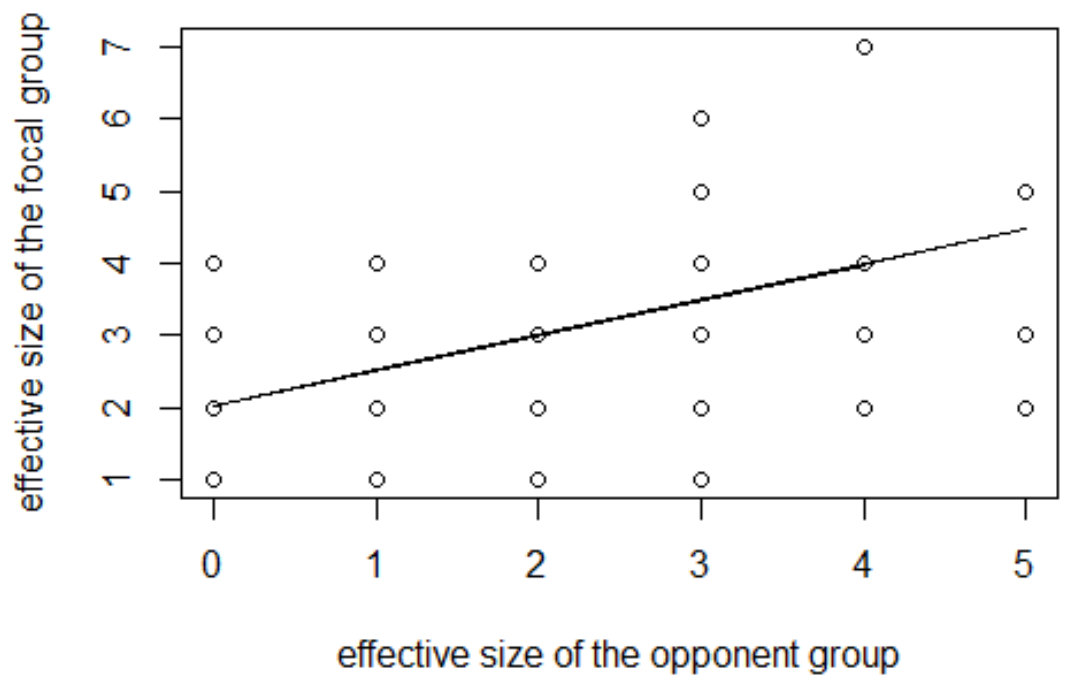

Figure 2. Participation on the level of effective group size. Relation of the number of actively participating individuals in the focal group and the opponent group.

On the individual level, participation of females and males was positively influenced by the effective group size of the opponent group $\left(\chi^{2}=33.57, \mathrm{df}=3, \mathrm{P}<0.001\right.$, Table $\left.4 \mathrm{a}\right)$; individuals were more likely to participate when more members of the opponent group participated actively in the encounter. Interestingly, the probability of individual participation was lower in larger groups, thus large groups indeed offered more opportunities for freeriding than smaller ones (Table 4a). Food availability did not influence individual participation (Table 4a). By running the model with the same parameters, but exchanging the effective size of the opponent group by the total size of the opponent group, there was no influence of total group size on individual participation (Table $4 \mathrm{~b}, \chi^{2}=8.17, \mathrm{df}=3, \mathrm{P}=0.04$ ), suggesting that individuals base their decision to participate on how many individuals from the opponent group actively participated. Females participated less often in group encounters when they had dependent infants $\left(\chi^{2}=4.42, \mathrm{df}=1, \mathrm{P}=0.03\right.$, GLMM: Estimate: 0.85; Std. error: $0.42, \mathrm{P}=0.04)$. 
Table 4. Results of the binomial GLMM testing the influence of a) the effective group size of the focal group, the effective group size of the opponent group and food availability on the probability of individual participation in inter-group encounters. b) model with the total group size of the focal and opponent group instead of effective group size.

\begin{tabular}{lclll}
\hline a) GLMM: effective group size of the opponent group \\
\hline Fixed effects & Estimate & Std. Error & Z value & $\operatorname{Pr}(>|\mathrm{z}|)$ \\
(Intercept) & 0.91 & 0.79 & 0.15 & 0.25 \\
Total size focal group & -0.29 & 0.11 & -2.55 & $0.01 *$ \\
Food availability & -0.21 & 0.61 & -0.35 & 0.72 \\
Effective size opponent group & 0.59 & 0.13 & 4.50 & $<0.001 * * *$ \\
b) GLMM: total group size of the opponent group & & \\
Fixed effects & Estimate & Std. Error & $Z$ Z value & $\operatorname{Pr}(>|\mathrm{z}|)$ \\
(Intercept) & 2.23 & 0.90 & 2.47 & 0.01 \\
Total size focal group & -0.29 & 0.10 & -2.81 & $0.004 * *$ \\
Food availability & -0.11 & 0.57 & -0.20 & 0.84 \\
Total size opponent group & -0.01 & 0.11 & -0.12 & 0.90 \\
\hline
\end{tabular}

Participation by males was influenced by individual social status $\left(\chi^{2}=18, \mathrm{df}=1\right.$, $\mathrm{P}=0.001$, Table 5). Dominant males participated in almost all $(91 \pm 28 \%)$ encounters and did so more often than related and non-natal subordinate males (Figure 3), suggesting that males with reduced opportunities to reproduce free-ride more often. Participation of males was not affected by mating season. 
Table 5. Results of the binomial GLMM testing the influence of social status (NNS: nonnatal subordinate males, NS: natal subordinate males, R: subordinate males that are related to the dominant males but not to the group females) and the mating season on the probability of adult males to participate in group encounters.

\begin{tabular}{llllll}
\hline Fixed effects & & Estimate & Std. Error & $\mathbf{Z}$ value & $\operatorname{Pr}(>|\mathbf{z}|)$ \\
\hline (Intercept) & & 1.91 & 0.38 & 4.99 & $<0.001$ \\
Social status & NS & -0.32 & 0.74 & -0.43 & 0.66 \\
& NNS & -1.94 & 0.60 & -3.27 & $0.001 * *$ \\
& R & -1.59 & 0.46 & -3.46 & $<0.001 * * *$ \\
Mating season & & 0.27 & 0.54 & 0.51 & 0.61 \\
\hline
\end{tabular}

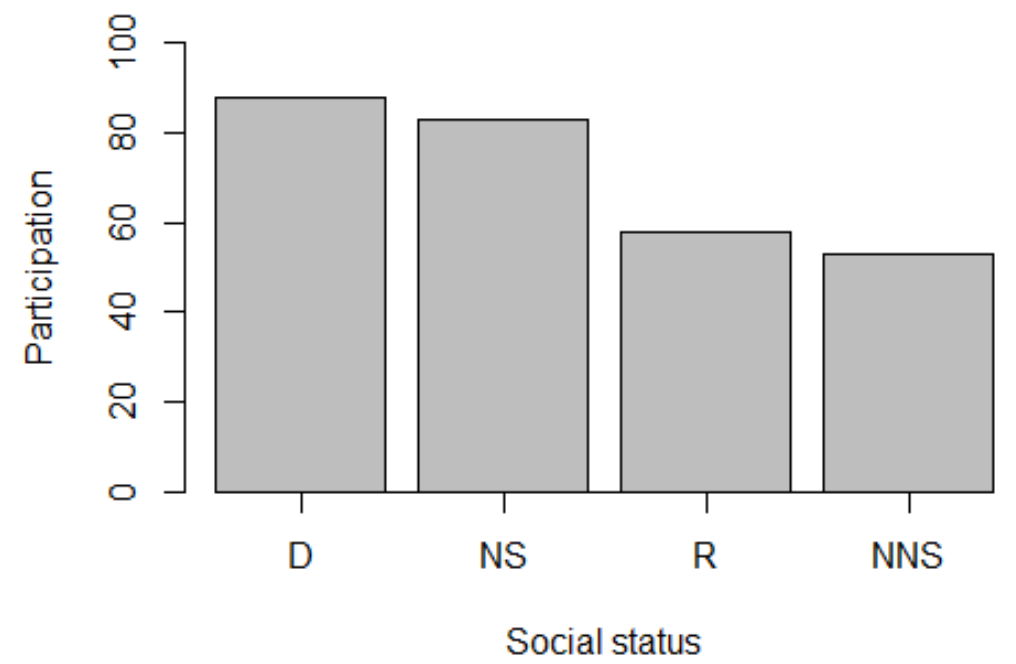

Figure 3. Percentage of male participants in group encounters according to their social status. D: dominant males, NS: natal subordinate males, R: subordinate males that are related to the dominant male, NNS: non-natal subordinate males. 


\section{Discussion}

In this study, we show that both adult female and male Verreaux's sifakas are regularly involved in aggressive intergroup encounters throughout the year. The incentive to participate in both sexes was not influenced by variation in food availability but by group size. In addition, male and female participation were influenced by different factors, i.e., social status and presence of infants, respectively. Moreover, Verreaux's sifakas seem to base their decision to participate or to free-ride also on the circumstance of an encounter, i.e., the number of active opponents. We discuss these incentives and circumstances below and place them in a comparative context.

\section{Sex and participation in intergroup encounters}

Males and females have different incentives in engaging in group defense, and depending on the nature of the encounter, the participation of one sex can be more pronounced than the other (Trivers 1972; Wrangham 1980). In contrast to other mammals such as hyenas and lions, in the majority of primates, males participate more often in group encounters than females (reviewed in Table 6). However, in some primates female participation can be similar or even superior to the participation of males, as for example in blue monkeys (Cercopithecus mitis: Cords 2007), ringtailed lemurs (Lemur catta: Jolly et al. 1993), or black-tufted marmosets (Callithrix penicillata: Decanini and Macedo 2008). The type of social organization, i.e. whether species are organized into multi-male multi-female groups, one male groups or pairs (Kappeler \& van Schaik 2002), does not appear to explain sex differences in participation. In Verreaux's sifakas, females and males participated equally often in group encounters. A combination of factors, including male-male competition over mating opportunities, the lack of sexual size dimorphism, and the social dominance of females over males, may contribute to this pattern.

The common pattern of higher male participation observed in primates is in line with the mating defense hypothesis, which predicts that the main incentive for participation of males is either to defend group females or to get access to females of other groups (Wrangham 1980; van Schaik et al. 1992). In line with this hypothesis, dominant males in some species achieve higher reproductive success and participate more often in intergroup 
encounters than subordinate males (Perry 1996; Gese 2001; Kitchen et al. 2004; Cooper et al. 2004; Van Belle et al. 2014). Particularly during the mating season, dominant males are expected to invest more in conflicts to protect access to females and to prevent extra-group copulations. In two populations of Japanese macaques (Macaca fuscata), males behaved more aggressively during the mating season in the population in which intergroup mating occurred. Therefore, defending female mates in the mating season was more beneficial for this population than for another one in which extra-group copulations were not observed (Saito et al. 1998).

In our study, dominant males participated more often than subordinate males throughout the year, and the probability of participation of males was not affected by the mating season. The mating season in Verreaux' sifakas is relatively short, concentrated in two months in which females are receptive for a few days (Brockman 1999; Mass et al. 2009). Dominant males consort females during the mating season, peaking during the short period when females are receptive (Mass et al. 2009). Male reproductive success in sifakas is highly skewed in favor of the dominant male, which indicates that guarding females is a good strategy for the dominant males. Moreover, the asynchronous estrus of females within groups allows dominant males to monopolize reproduction in their own group, resulting in high reproductive skew in favor of the dominant males (Kappeler and Schäffler 2008). Because rates of extra-group paternities are very low in our study population (Kappeler and Schäffler 2008), dominant males are apparently guarding females of their own group effectively and seem to forgo potential mating opportunities during intergroup encounters which also bear the risk of leaving group females unguarded. Similarly, in banded mongooses (Mungos mungo), dominant males guard the breeding females in their own group instead of actively chasing intruders (Cant et al. 2002). Since male reproductive success in sifakas is highly skewed in favor of the dominant male, showing its presence and physical power to males in neighboring groups that may potentially try to take over the group, may explain the high participation of dominant males in encounters all year round. Similarly, in meerkats (Suricata suricatta), where male reproductive success is also highly skewed, dominant males often participate in encounters to keep prospector take-overs away, suggesting that actively repelling potential take-overs can be as crucial as preventing extra-group copulations for the reproductive success of dominant males (Mares et al. 2012). 
Female participation in contests between groups is expected when food resources are economically defendable (Wrangham 1980). Food is the limiting factor for the fitness of females due to the high energetic demands of reproduction (Trivers 1972; Coelho 1974; Wrangham 1980). Indeed, access to high quality food can influence the chances of producing more viable offspring, whereas poor nutrition can induce females to skip reproduction, or compromise the chances of survival of their infants (Bercovitch 1987; Richard et al. 2000; Lewis and Kappeler 2005a; McCabe and Fedigan 2007). In Verreaux's sifakas, however, food availability did not influence participation in intergroup encounters. Also, the rate of encounters did not differ between the wet and dry season, when food is more or less available, respectively. Since Madagascar's ecosystems are characterized by pronounced seasonality, coupled with strong climatic unpredictability (Dewar and Richard 2007), and relatively low fruit productivity as well as nutritional content of fruits (Ganzhorn et al. 2009), both sexes may invest equally in resource defense. Furthermore, it has been suggested that female sifakas can be considered as capital breeders (Richard et al. 2000; but see also Lewis and Kappeler 2005b), and therefore expected to compete continuously for food in order to survive and to store nutrients (Richard et al. 2000).

\section{Intersexual dimorphism and dominance}

In the majority of mammals, males are larger than females (Ralls 1976). Since group encounters are physically demanding, being the less powerful sex can increase the risks and costs of injuries for females, and decrease the motivation in participating in group defense. Accordingly, females in species with pronounced sexual dimorphism in favor of males are rarely engaged in group encounters (Cheney 1981). Moreover, in species in which males are dominant over females, the lack of dominance can also result in reduced access to the benefits of the disputes, presumably decreasing the motivation of females in joining group encounters even more (Cheney 1981, but see Hill 1994; Cords 2007). In baboons (Papio cynocephalus) and white-faced capuchins (Cebus capucinus), for example, females are much smaller and socially subordinate to males, and as a consequence, they normally do not contribute to group defense because of their limited physical power and the unbalanced access to benefits (Perry 1996; Crofoot 2007; Markham et al. 2012). However, in sifakas there is no sexual size dimorphism; therefore males and females have similar physical power 
(Richard and Nicoll 1987; Young et al. 1990; Kappeler 1991), and possibilities to contribute to group defense. The fact that females are as powerful as males can be crucial in intergroup encounters in relatively small groups, where the number of adults in each group is relatively low $(\sim 3)$, and in this case the participation of females can be decisive for the outcome of the conflict.

Furthermore, female sifakas are dominant over males and have priority of access to resources. Hence, they may have more incentives to participate in group encounters because they can access a larger portion of benefits from it (Cheney 1987; Cords 2007; Kappeler et al. 2009; Willems et al. 2013; Van Belle et al. 2014). Female dominance over males is considered as an adaptive behavioral mechanism that provides adult females with feeding priority, which in turn is assumed to be beneficial or even required under the energetic stress females experience while reproducing during Madagascar's annual lean season (Jolly 1984; Young et al. 1990; Wright 1999). Similarly, in ringtailed lemurs (Lemur catta), where females are also dominant over males, females participate regularly and even more often than males in intergroup encounters (Jolly et al. 1993; Nakamichi and Koyama 1997; Nunn and Deaner 2004).

\section{Circumstances of intergroup encounters}

Despite the difference in incentives for males and females in participating in intergroup encounters, the particular circumstances of each encounter, such as the size of the groups involved, can play an important role in the individual decision of joining the conflicts. In both sexes, participation was influenced by the effective size of the opponent group, i.e., the number of actively participating individuals in the opponent group. The capacity of assessing the number of individuals in the opponent group has been observed in several other species of mammals, such as black howler monkeys (Alouatta pigra), chimpanzees (Pan troglodytes), lions (Panthera leo), and spotted hyenas (Crocuta crocuta), and revealed that individual participation in group defense is dependent upon numerical assessment of the opponent group (McComb et al. 1994; Wilson et al., 2001; Kitchen 2004; Kitchen 2006; Crofoot et al. 2008; Benson-Amram et al. 2011).

The number of active individuals in the opponent group may serve as an estimate of the power of the opponent group and the risks of the encounter (Arnott and Elwood, 2008). 
The variance in the number and identity of participants creates unpredictability and more challenges for the groups to assess the power of their opponents, especially in fission-fusion societies in which the total size of parties varies from encounter to encounter. For Taî chimpanzees (Pan troglodytes verus), for example, it has been suggested that this uncertainty allows small parties to attack much larger ones (Boesch et al. 2008). During our study, Verreaux's sifakas' group size varied between three and eight individuals. Although neighboring groups differed in total group size between 0 and $130 \%$, absolute group size had no effect on the outcome of intergroup encounters. Thus, the unpredictability of who will participate in intergroup encounters suggests that Verreaux's sifakas do not benefit per se from living in larger groups (Kappeler et al. 2009; Port et al. 2011).

In principle, the duration of encounters increases as the differences in contestant's power decrease, and the outcome takes longer to be decided due to the lack of clear asymmetries between opponents (Enquist and Leimar 1983). In that sense, individuals can decide to participate during an ongoing conflict in order to counterbalance the asymmetry to facilitate a favorable outcome. In sifakas, the number of actively participating individuals in the focal group was also a response to the duration of the encounter. The longer the encounter lasted, the more individuals joined, suggesting flexibility in the decision of participating.

\section{Collective action problems and the role of free-riding in small groups}

Collective action problems (CAP: Olson 1965) occur whenever collective action creates a public good (such as a territory) and the selfish interests of group members are not in line. Natural selection will favor free-riders over cooperators, as they reap the benefits of access to the good without risking the costs of producing it (Nunn 2000). In the context of territorial defense, some individuals can be less cooperative than others and still get their share from the benefits of collective actions, thereby undermining group-level cooperation (Nunn, 2000; Nunn \& Deaner, 2004). CAPs in territorial defense have been reported in several mammals (Heinsohn \& Packer 1995; Gese 2001; Bonnani et al. 2010) and appear to be common in primates (van Schaik 1996; Nunn 2000, Kitchen \& Beehner 2007; Willems et al. 2013; Willems \& van Schaik 2015), where they occur in the context of territorial advertisement (Kitchen 2004; van Belle et al. 2014, van Belle 2015) and actual intergroup encounters 
(Nunn \& Deaner 2004; Harris 2010; Crofoot \& Gilby 2012). Comparative analyses across primates also indicated that CAPs are less likely to occur in species that are either cooperative breeders, in which the dominant sex is philopatric or that live in relatively small groups with only few individuals of the dominant sex (Willems et al. 2013; Willems \& van Schaik 2015). Although Verreaux's sifakas live in relatively small groups with only few individuals of the dominant sex, and females are philopatric, free-riding of adult individuals occurred regularly, i.e. in $72 \%$ of observed encounters and was more common in larger groups. Also, in ringtailed lemurs (Lemur catta) females in larger group free-ride more often than females in smaller groups, suggesting that the opportunity to free-ride increases with group size (Nunn and Deaner 2004; Pride et al. 2006).

Sifaka females did not cooperate in intergroup defense when they had dependent infants. Encounters are highly aggressive events in which infants might be harmed and exposed to infanticidal males (van Schaik 1996). Infanticide has been reported several times in Propithecus (Erhart and Overdorff 1998; Morelli et al. 2009), including our study site (Lewis et al. 2003; Kappeler and Fichtel 2012). Another important aspect is that sifakas lactate during the peak dry season, when the availability of food is low, so that energetic constraints resulting from the energetic demands of lactation may restrict female participation in group encounters (Harrison, 1983). In blue monkeys (Cercopithecus mitis: Cords 2007), white-faced capuchins (Cebus capucinus: Crofoot and Gilby 2012), and ringtailed lemurs (Lemur catta: Nunn and Deaner 2004), females were also less often engaged in encounters between groups when they had infants.

Male free-riding was influenced by social status, with males having fewer opportunities to reproduce free-riding more often. This is in line with other studies showing that subordinate males free-ride more often in the context of group defense (Perry 1996; Gese 2001; Cooper et al. 2004; Crofoot \& Gilby 2012; Scarry 2013; Kitchen et al. 2004, van Belle et al. 2014). Occasional participation of subordinate males might be due to the fact that they may try to avoid potential physical costs of losing a fight. For example, in white-faced capuchins (Cebus capucinus) losing groups travelled over longer distances than the winning group (Crofoot 2013). Hence, all group members have to pay these costs and, therefore, subordinate individuals might not share the same benefits of winning the encounter as the dominants, but they will certainly pay for at least some of the costs of losing it. In Verreaux's 
sifakas, it is puzzling why these free-riders are tolerated in the group: on the one hand, they fight with dominant males over access to females in the mating season, but, on the other hand, they do not provide any long-term benefit in terms of infant survival, take-over risks by strange males, or territorial defense (Kappeler et al. 2009; Port et al. 2012). Since subordinate males are not costly in terms of intragroup feeding competition, their occasional participation in encounters between groups might be sufficient to be tolerated in their own group (Kappeler et al. 2009).

In conclusion, the complexity in the relationships between groups appears to be the product of the variable circumstances of each encounter, which are determinant for the patterns of individual participation. In this complex and dynamic context, factors such as the total group size do not necessarily lead to clear and stable patterns of individual participation and dominance between groups. Therefore, it is important that future research includes also the circumstances of each particular encounter, such as the consideration of the effective group size instead of the total group size as a predictor for the power of each opponent. In addition, sex differences in participation are yet not well understood. Although, in the majority of primates males participate more often than females, the pattern of equal or even higher participation of females in some species is still puzzling (Table 6). Since the type of social organization, i.e. whether species are organized into multi-male multi-female groups, one male groups or pairs, does not appear to explain sex differences in participation, more research is required. In lemurs, at least, equal or higher participation of females can be explained by female dominance and the lack of sexual size dimorphism. 
Table 6. Level of female participation in group encounters in primate species. Social organization: $\mathrm{OM}=$ one adult male per group, $\mathrm{MMMF}=$ multi-male and multi-female organization, and PAIR $=$ one adult male and one adult female.

\begin{tabular}{|c|c|c|c|}
\hline $\begin{array}{l}\text { PARTICIPATION OF FEMALES } \\
\text { IN COMPARISON TO MALES }\end{array}$ & PRIMATE SPECIES & REFERENCES & $\begin{array}{l}\text { SOCIAL } \\
\text { ORGANIZATION }\end{array}$ \\
\hline & Cercopithecus diana & Hill 1994 & $\mathrm{OM}$ \\
\hline \multirow[t]{4}{*}{ HIGHER } & Cercopithecus mitis & Cords, 2007 & $\mathrm{OM}$ \\
\hline & Lemur catta & Nunn \& Dreaner, 2004 & MMMF \\
\hline & Propithecus verreauxi & present study & MMMF \\
\hline & Macaca thibetana & Zhao, 1997 & MMMF \\
\hline \multirow[t]{15}{*}{ SIMILAR } & Callithrix penicillata & Decanini \& Macedo, 2008 & PAIR \\
\hline & Cercocebus galeritus & Kinnaird, 1992 & MMMF \\
\hline & Cercopithecus ascanius & Brown, 2013 & $\mathrm{OM}$ \\
\hline & Cebus capucinus & Perry, 1996 & MMMF \\
\hline & Colobus guereza & Fashing, 2001 & $\mathrm{OM}$ \\
\hline & Pan throglodytes & Williams 2004 & MMMF \\
\hline & Macaca foscata & Majolo et al., 2005 & MMMF \\
\hline & Colobus polykomos & Korsjens et al., 2005 & $\mathrm{OM}$ \\
\hline & Gorila beringei & Robins \& Sanyer, 2007 & $\mathrm{OM}$ \\
\hline & Alouatta pigra & van Belle, 2015 & MMMF \\
\hline & Presbitis sp. & van Schaik et al., 1992 & $\mathrm{OM}$ \\
\hline & Hylobates lar & Bartlett, 2003 & MMMF \\
\hline & Gorila gorila & Sicotte, 1993 & $\mathrm{OM}$ \\
\hline & Papio ursinus & Cowlishaw, 1995 & MMMF \\
\hline & Presbitis thomasi & Steenbeek, 1999 & $\mathrm{OM}$ \\
\hline \multirow[t]{13}{*}{ LOWER } & Hapalemur griseus & Nievergelt et al., 1998 & PAIR \\
\hline & Cercopithecus aethiops & Cheney, 1981 & MMMF \\
\hline & Saguinus mystax & Garber et al., 1993 & MMMF \\
\hline & Cebus olivaceus & Robinson, 1988 & MMMF \\
\hline & Macaca maurus & Okamoto \& Matsumura, 2002 & MMMF \\
\hline & Macaca sylvanus & Mehlman \& Parkhill, 1988 & MMMF \\
\hline & Macaca radiata & Cooper et al., 2004 & MMMF \\
\hline & Sapajus nigritus & Scarry, 2013 & MMMF \\
\hline & Chiropotes sagulatus & Shaffer, 2013 & MMMF \\
\hline & Colobus vellerosus & Sicotte \& Macintosh, 2004 & $\mathrm{OM}$ \\
\hline & Pithecia pithecia & Thompson et al., 2012 & PAIR \\
\hline & Lophocebus albigena & Brown, 2013 & MMMF \\
\hline & Papio cynocephalus & Markham et al., 2012 & MMMF \\
\hline
\end{tabular}




\section{СНAPTER 2}

Group encounters in Verreaux's sifakas: the importance of location as a predictor for outcome

With Johannes Signer ${ }^{1}$, Peter M. Kappeler ${ }^{2,3}$, and Claudia Fichtel ${ }^{2}$

1. Department of Wildlife Science, University of Göttingen, Büsgenweg 3, Göttingen, 37077, Germany

2. Behavioral Ecology and Sociobiology Unit, German Primate Center, 37077 Göttingen, Germany

3. Department of Sociobiology and Anthropology, University of Göttingen, 37077, Göttingen, Germany 


\begin{abstract}
Intergroup competition is a complex interaction and several factors can influence the outcome of encounters. We studied the influence of numerical advantage and location of encounter on the chances of winning an encounter in eight neighboring groups of Verreaux's sifakas: Propithecus verreauxi. Location, rather than the numerical advantage of a group in a given encounter, influenced the probability of winning an encounter, suggesting that the combination of higher motivation of residents in defending intensively used areas and collective action problems in intruders may explain this pattern. Thus, in gregarious animals the variable circumstances of each encounter and individual features can overcome group characteristics and predict the chances of winning an intergroup encounter.
\end{abstract}

\title{
Introduction
}

In group-living species, several factors can influence the outcome of group encounters, with numerical advantage being the main predictor of the chances of winning (Cheney 1987; McComb et al. 1994; Cant et al. 2002; Kitchen and Beehner 2007). Indeed, from insects to primates, larger groups tend to defeat smaller ones (Hölldobler 1981; Cheney 1987). However, collective action problems and residence-effect can diminish the power of larger groups, and as a consequence, other factors such as location of encounters can be a critical influence to the outcome of group encounters (Crofoot et al. 2008; Mares et al. 2012; Markham et al. 2012).

Since the economic value of areas within home ranges varies according to the availability of resources, it is expected that animals show variable levels of motivation in defending each area (Crofoot et al. 2008; Harris 2010; Furrer et al. 2011). The intensity of use of certain areas indicates the high value that residents attribute to these areas (Maynard Smith and Parker 1976; reviewed in Leimar and Enquist 1984). For that reason, residents tend to be more motivated in defending intensively used areas against intruders, which can influence the outcome in their favor in encounters around these locations (Haley 1994; Crofoot et al. 2008). 
After a decided encounter, winners will enjoy the potential benefits of the access to the contested resource (e.g., food, mates), while losers will have to pay for the costs of defeat. Costs can include alteration in travelling parameters (distance, speed, and sinuosity), including higher energetic demands (Crofoot 2013); or even the permanent loss of access to important parts of their home range (Robinson 1988). Because the determinants of winning and the costs of losing intergroup encounters have only been studied in a few primate species, we investigated these aspects in eight neighboring groups of Verreaux's sifakas ( $P$. verreauxi), which occupy overlapping home ranges with exclusive core areas (Benadi et al. 2008) and evolved group-living independently from anthropoid primates (Shultz et al. 2011)

\section{Methods}

\section{Study site and species}

The study was conducted from March 2012 to May 2014 in Kirindy Forest, western Madagascar (4439'E, $\left.20^{\circ} 03^{\prime} \mathrm{S}\right)$. We inferred intergroup encounters in eight neighboring groups from spatial data. One individual per group was equipped (during capture that followed the procedures described in Springer and collaborators, 2015) with a GPS logger (E-OBS Digital Telemetry), recording locations each 15 minutes from 4:30 am to 8:30 pm (Table 1). We based these settings because sifakas are diurnal (Erkert \& Kappeler, 2004), and social groups are known to be cohesive in their movements (Trillmich et al., 2004). We estimated total home range size (95\% isopleth), core areas (50\% isopleth) with kernel density home ranges (reference bandwidth, Worton 1989) based on relocations that were recorded one month prior to the encounter using the package $\mathrm{rhr}$ in program $\mathrm{R}(\mathrm{R}$ Development Core Team 2015; Signer and Balkenhol 2015). 
Table 1. Number of GPS locations (one location each 15 minutes) and days in which the groups were equipped with GPS loggers during the study period from March 2012 to May 2014.

\section{Groups Locations Days with GPS logger}

\begin{tabular}{lll}
\hline $\mathbf{C}$ & 33060 & 551 \\
$\mathbf{E}$ & 29100 & 485 \\
$\mathbf{F}$ & 27120 & 452 \\
$\mathbf{F 1}$ & 21360 & 356 \\
$\mathbf{G}$ & 30180 & 503 \\
$\mathbf{H}$ & 32160 & 536 \\
$\mathbf{J}$ & 31860 & 531 \\
$\mathbf{L}$ & 10740 & 179 \\
\hline
\end{tabular}

\section{Encounters}

Intergroup encounters were inferred as follows: an encounter began when the nearest members of two groups were at a distance of $42 \mathrm{~m}$ or less from each other, and ended when they were again at a distance of more than $42 \mathrm{~m}$. Based on 71 empirical observations of group encounters we calculated the mean distance between the two groups over the encounter duration. We then averaged the distance over all encounters resulting in an encounter distance of $42 \mathrm{~m}$. We defined the beginning of an encounter when the groups were $42 \mathrm{~m}$ or less apart from each other. The end of an encounter was defined when the groups were for more than one hour more than $42 \mathrm{~m}$ apart from each other. We set one hour as a time limit to infer an encounter from the GPS data because observed group encounters lasted on average $23 \pm 22$ minutes. For each encounter we mapped an encounter area, which was defined as a buffer around all relocations that belonged to one encounter for both 
participating groups. The buffer width was the encounter distance $42 \mathrm{~m}+1 \mathrm{~m}$, since it had to be more than $42 \mathrm{~m}$ not to be considered an encounter. To infer the winner and the loser of encounters we randomly assigned the groups of being a focal or opponent in each group encounter. The winner of the encounter was the group that had the higher number of relocations (GPS points) within the encounter area within the hour that followed the encounter. Additionally we estimated kernel density home ranges (reference bandwidth (Worton et al. 1989), no standardization was performed) with relocations that were recorded one month prior to the encounter using Program R (CRAN) and package rhr (Signer and Balkenhol 2015). We then calculated the overlap between core areas (50\% Isopleth) and the encounter area. The winner of the encounter was the group that had the highest number of relocations (GPS points) within the encounter area during the hour following the encounter.

\section{Location}

To examine if the location had an effect on the outcome of encounters, we calculated the proportion of overlap (based on the number of GPS relocations) between the encounter area and the core area of each group within a month before the encounter, which we called proportion of invasion. We included the data from a month before the encounter for the analyses of proportion of invasion because sifakas switched their core areas, defined here as intensively and exclusively used areas, each two to three weeks (Figure 1). Accordingly, a higher proportion of invasion of one group reflects a higher overlap between the encounter area and the core area compared to the opponent. 


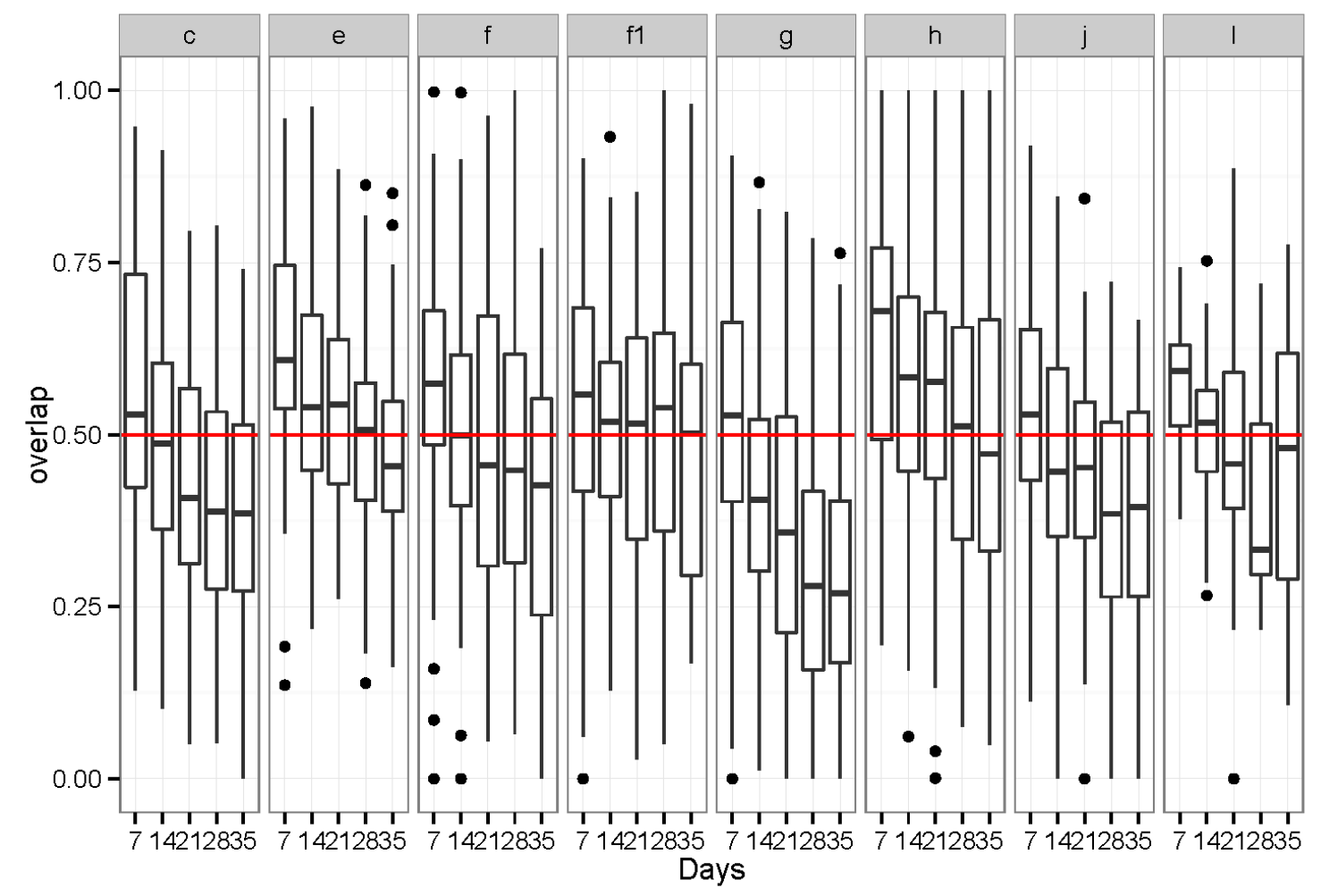

Figure 1. Weekly changes in the proportion of overlap between the current and the former core area for each study group. Less than $50 \%$ of overlap means a switch of position of the current core area in relation to the position of the former one.

\section{Costs of defeat}

The comparison of travelling parameters (distance, speed, sinuosity) between winners and losers within one, two, and three hours after the encounter was used to infer the short term costs of defeat. The distance travelled was inferred through the sum of consecutive step lengths within one, two or three hours after the encounter; speed was calculated by dividing distance by time, and sinuosity by dividing distance by the straight line distance between the first and last relocation within the time frame. To analyze long term costs in losing an encounter, we compared the intensity of use (density of GPS points) of the encounter area between winners and losers during one month after the encounter, which we called the postencounter effect. 


\section{Statistical analyses}

We used a binomial test to investigate whether one group of a given dyad won encounters more often than expected by chance. Binomial Generalized Linear Mixed Models (GLMM) from the package lmer4 (Bates et al. 2014) were used to investigate the effect of relative group size (group size of the focal group minus group size of the opponent group) and proportion of invasion (arcsine square root transformed) on the outcome of group encounters. Dyadic identity was used as a random factor. Wilcoxon signed rank test was used to investigate potential costs of losing an encounter such as the alteration in travelling costs and the post-encounter effect. All statistical analyses were performed in $\mathrm{R}$ version 3.1.2 ( $\mathrm{R}$ Development Core Team 2015) and for each encounter we randomly selected one group as the focal subject for the analysis.

\section{Results}

We recorded 759 encounters among eight neighboring groups, of which 624 were decided. Sifakas did not exhibit clear intergroup dominance relationships (Table 2). The probability of winning a group contest was not influenced by numerical advantage, but by the location of encounters, with the proportion of invasion of intensively used areas predicted the probability of winning an encounter (Figure 2, $\chi^{2}=49.03, \mathrm{df}=2, \mathrm{P}<0.001$, Table 3). 
Table 2. Total number of encounters between the 8 neighboring groups of sifakas, and the frequency of won encounters for each group of the two opponents.

\begin{tabular}{|c|c|c|c|c|c|}
\hline $\begin{array}{c}\text { ID } \\
\text { Group } \\
1\end{array}$ & $\begin{array}{c}\text { ID } \\
\text { Group } \\
2\end{array}$ & $\begin{array}{l}\text { Number of } \\
\text { encounters }\end{array}$ & $\begin{array}{c}\text { Frequency } \\
\text { of winning } \\
\text { Group } 1\end{array}$ & $\begin{array}{c}\text { Frequency } \\
\text { of winning } \\
\text { Group } 2\end{array}$ & $\begin{array}{c}\text { Binomial } \\
\text { test } \\
\text { p-value }\end{array}$ \\
\hline $\mathbf{C}$ & $\mathbf{E}$ & 148 & 64 & 84 & 0.118 \\
\hline $\mathbf{C}$ & $\mathbf{F}$ & 17 & 9 & 8 & 1 \\
\hline $\mathbf{C}$ & $\mathbf{G}$ & 51 & 16 & 35 & 0.011 \\
\hline $\mathrm{C}$ & H & 1 & 0 & 1 & NA \\
\hline C & $\mathbf{L}$ & 13 & 7 & 6 & 1 \\
\hline $\mathbf{E}$ & $\mathbf{F}$ & 69 & 36 & 33 & 0.81 \\
\hline $\mathbf{E}$ & $\mathbf{G}$ & 10 & 5 & 5 & 1 \\
\hline $\mathbf{E}$ & H & 79 & 42 & 37 & 0.653 \\
\hline $\mathbf{F}$ & F1 & 82 & 27 & 55 & 0.003 \\
\hline G & $\mathbf{H}$ & 15 & 10 & 5 & 0.032 \\
\hline $\mathbf{G}$ & $\mathbf{J}$ & 59 & 23 & 36 & 0.118 \\
\hline $\mathbf{G}$ & $\mathbf{L}$ & 4 & 1 & 3 & NA \\
\hline $\mathbf{H}$ & $\mathbf{J}$ & 76 & 40 & 36 & 0.731 \\
\hline
\end{tabular}




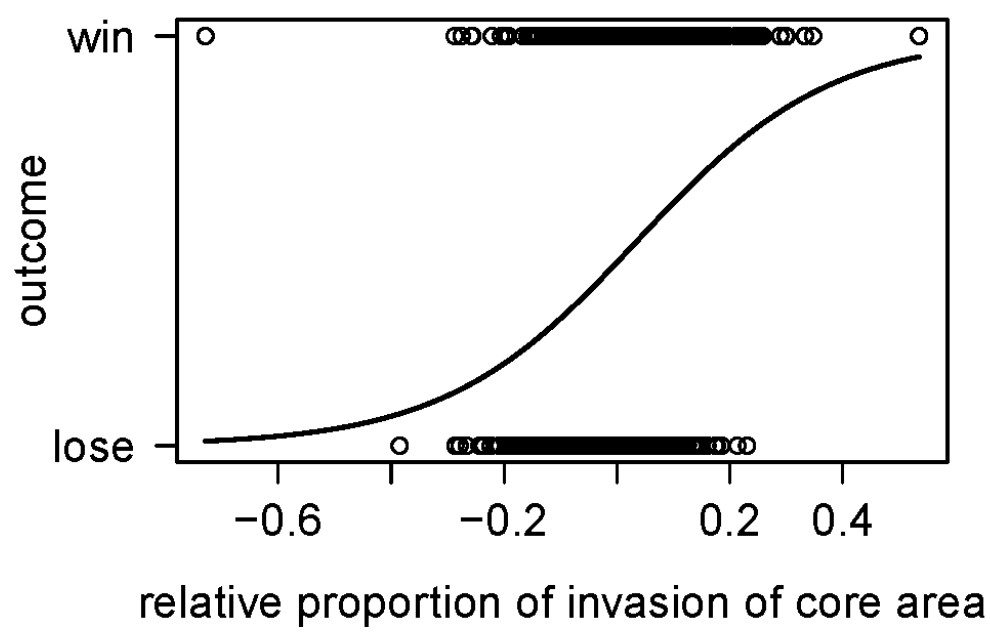

Figure 2. Effect of proportion of invasion of intensively used area on the outcome of group encounters.

Table 3. Binomial Generalized Mixed Model on the proportion of invasion of the core area and the numerical advantage on the probability of winning the encounter.

\begin{tabular}{lllll}
\hline Fixed effects & Estimate & Std. Error & $\mathrm{Z}$ value & $\operatorname{Pr}(>|\mathbf{z}|)$ \\
\hline (Intercept) & -0.06 & 0.08 & -0.72 & 0.47 \\
Proportion of invasion & 5.54 & 0.86 & 6.43 & $0.001 * * *$ \\
Relative group size & 0.04 & 0.05 & 0.92 & 0.35 \\
\hline
\end{tabular}

The loser of an encounter travelled for longer distances $(\mathrm{V}=36, \mathrm{P}=0.008)$, straighter $(\mathrm{V}=1, \mathrm{P}=0.01)$, and with higher speed $(\mathrm{V}=36, \mathrm{P}=0.008)$ than the winner (Figure 3$)$, but only within the first hour after the encounter (Figure 3). Losers used the encounter area less often than winners within a month after the encounter, suggesting that losing involves long-term costs $(\mathrm{V}=33, \mathrm{P}=0.04)$. 

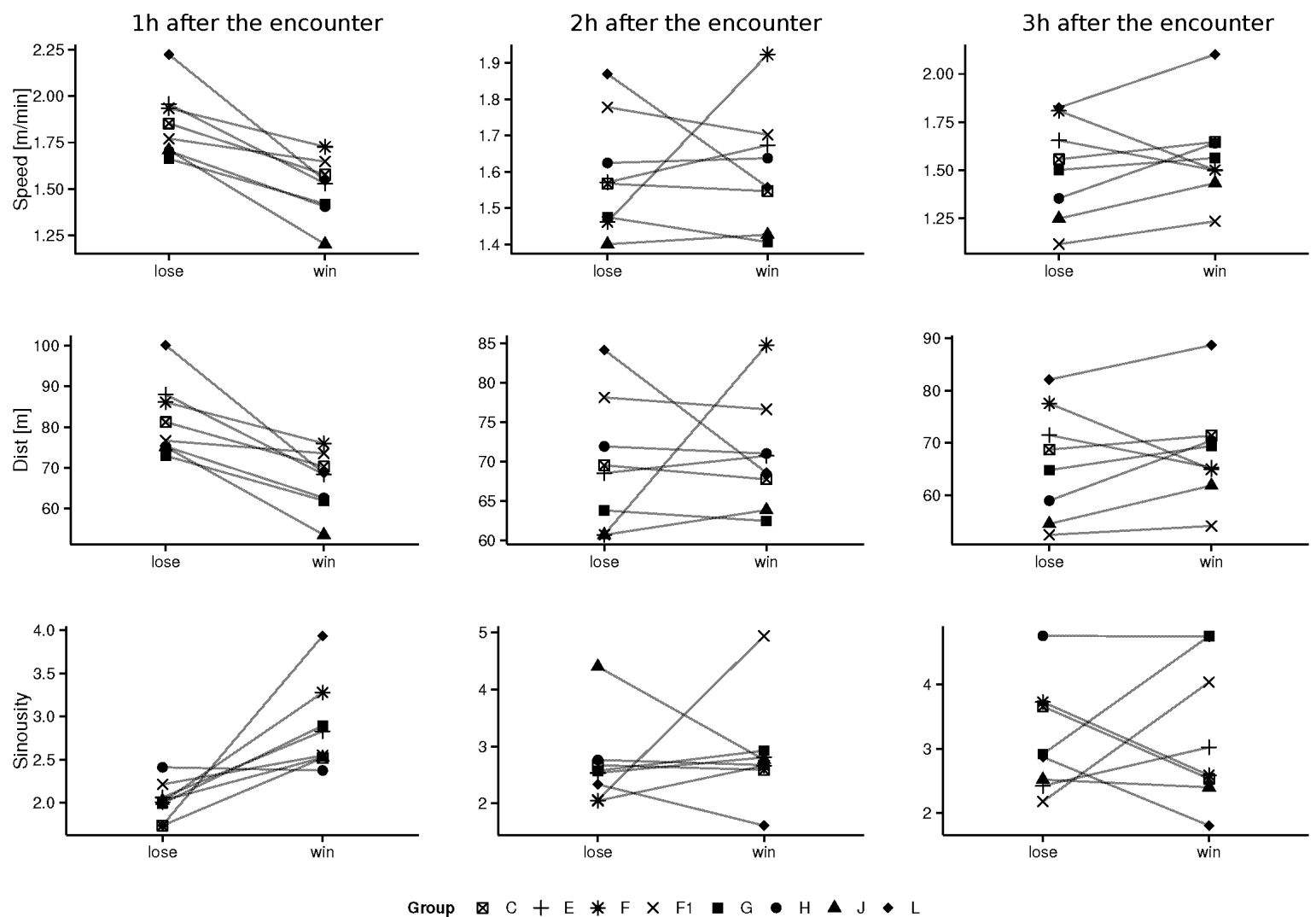

Figure 3. Travel parameters (speed, distance, and sinuosity) of each study group after winning and losing intergroup encounters in different time frames.

\section{Discussion}

Our results show that numerical advantage did not affect the outcome of encounters. When the potential benefits of group encounters are not equally shared among all group members, some individuals may decide not to participate in encounters (Nunn and Deaner 2004). In sifakas, dominant individuals of both sexes enjoy better access to resources, and the presence of free-riders among subordinates is common (Richard and Nicoll 1987; Kappeler and Schäffler 2008; Kappeler et al. 2009). Hence, the lack of effect of numerical advantage might be due to collective action problems (Koch et al. submitted). In fact, a better predictor of the power of groups and their chances of winning is probably the number of actual participants in each encounter, rather than differences in total group size (Crofoot et al. 2008). 
In several species of mammals the location of the encounter influence the outcome of encounters in favor of residents (Crofoot et al. 2008; Furrer et al. 2011; Markham et al. 2012). Indeed, residents are more familiar with the distribution and availability of resources in the disputed area, which creates an asymmetry in resource-holding power (RHP) between contestants in favor of the residents (Haley 1994). In sifakas, this residence-effect was the main predictor for winning an encounter. Resident groups, thus, are able to overcome other asymmetries in RHP, such as numerical disadvantage, and still win encounters in areas of residence (Crofoot et al. 2008). Moreover, residents have also higher costs from losing an encounter than intruders, due to the high attributed value to the area, and are therefore expected to free-ride less often and to be more motivated than intruders (Maynard Smith and Parker 1976).

Potential costs of losing an intergroup encounter are rarely studied. In white-faced capuchins (Cebus capucinus), losers had higher travel costs than winners (Crofoot 2013). Sifakas also showed alteration in travelling parameters, but the effect was present only within the first hour after the encounter. In that hour, losers travelled on average $15 \mathrm{~m}$ more than winners. However, the distance covered after defeat is still within the average hourly activity range $(71 \pm 43 \mathrm{~m})$. Thus, the variation in travelling parameters observed probably does not represent a major physical cost and it is most likely explained by the retreat of the losers to their own core area.

Another potential cost of losing an encounter is the inability of using the resources within the encounter area after the encounter. For instance, in yellow baboons (Papio cynocephalus), losers used the encounter area less often than winners (Markham et al. 2012). Sifakas also showed a post-encounter effect, in which losers used the encounter area less often than winners in the month after the encounter. In contrast to other species that are highly motivated in defending space despite the level of use, such as white-faced capuchins (Crofoot et al. 2008), sifakas are highly motivated in defending intensively used areas, likely due the availability of specific food resources. Therefore, the inability of accessing the encounter area after losing an encounter can represent the inability of accessing important resources.

Our results agree with the assumption that variable circumstances of group encounters, such as the location, are crucial for the outcome of encounters (Crofoot et al. 
2008; Markham et al. 2012). Since variable conditions can affect the participation in encounters, we can reaffirm that the dilemma between cooperation and competition in gregarious animals occurs at the individual level. Therefore, future studies should investigate individual characteristics and environmental conditions to reach a better understanding of the dynamics in intergroup competition. 


\section{СHAPTER 3}

Sex and seasonal differences in diet and nutrient intake in Verreaux's sifakas (Propithecus verreauxi)

With Jörg U. Ganzhorn ${ }^{1}$, Jessica M. Rothman ${ }^{2,3}$, Colin A. Chapman ${ }^{4}$, and Claudia Fichtel ${ }^{5}$

1. Animal Ecology and Conservation, University of Hamburg, Martin-Luther-King Platz 3, 20146 Hamburg, Germany

2. Department of Anthropology, Hunter College, City University of New York, New York, NY, USA

3. New York Consortium in Evolutionary Primatology, New York, NY, USA

4. Department of Anthropology and McGill School of Environment, McGill University, Montreal, QC, Canada

5. Behavioral Ecology and Sociobiology, German Primate Center, Kellnerweg 4, 37077 Göttingen, Germany 


\section{Abstract}

Seasonal variation in food availability can be especially demanding for females, because of the high energetic costs of reproduction. Therefore, females must adapt the particular demands of the different reproductive stages to the seasonal availability of resources. Madagascar has a highly seasonal climate, where food availability can be extremely variable. We investigated the impact of seasonality on the diet composition and nutrient intake of female and male sifakas (Propithecus verreauxi) in a dry deciduous forest in western Madagascar. We were interested in seeing how females adjust their diet to the different energy demands of their reproductive stages. Our results show that seasonality impacted the quality of diet of both sexes. The dry season (Apr-Oct) was the scarcest period in relation to the availability of high quality (i.e., with energy content) food items, which impacted the nutrient intake of males and females in that season. The wet season (Nov-Mar) was the recovering period when sifakas accessed the highest quality diet in terms of energy intake, mostly due to the high availability of fruits, which dominated the diet composition in that season. Females spent more time feeding, and had a higher intake of macronutrients than males. Concerning the reproductive stages, females significantly increased the intake of nutrients during the period of late lactation. This is likely due to the high energetic demands, since the comparison with the diet of males from the same time revealed that indeed females had a higher intake of nutrients than males during that reproductive stage. This finding rules out the possibility that the boost in diet was only reflecting the rise of food availability in the forest. The pattern of the diet of sifakas in our study indicates that they are following a capital breeder strategy, with females having better access to resources in order to store enough nutrients to cope with the reproduction costs in periods of low food availability.

\section{Introduction}

Fluctuations in food availability are a major challenge faced by primates living in seasonal climates. Species adopt different behavioral and/or physiological strategies to survive in those conditions (Knott 1998; Hemingway 1999; van Schaik and Brockman 2005). 
One of these strategies is to switch from preferred to fallback food that are still available during times of food scarcity (Lambert 2007; Marshall and Wrangham 2007; Vogel et al. 2009; Altmann 2009; Marshall et al. 2009). Fallback foods are defined as widely available foods consumed by animals only when more preferred resources are scarce (Peters and O'Brien 1994; Marshall et al. 2009). It has been demonstrated that some primates, such as howler monkeys (Alouatta palliata) and gorillas (Gorilla gorilla), show preference for fruits whenever they are available, but switch to leaves when fruit availability decreases (Milton 1980; Stanford and Nkurunungi 2003). Similarly, chimpanzees switch their diet composition to more abundant fruits, such as figs, whenever more preferred fruits are not available (Wrangham et al. 1996; Doran 1997).

Primates also adjust their activity patterns to seasonal fluctuations in food availability (Doran 1997; Gursky 2000), spending more time traveling and searching for food when it is scarce (e.g., Tarsius spectrum). Another possibility is to adopt a conservative strategy, increasing resting time and avoiding behaviors that demand high energy in periods of food scarcity to minimize energy demands (Milton 1980; Strier 1992; Milton 1998). Alternatively, in other species, animals spend longer time feeding to compensate the poor quality of food available during lean seasons (Dunbar 1988; Hemingway 1999). Beside this, other primates have morphological and/or physiological adaptations to deal with seasonal variability in availability of food, such as specific adaptation of the digestive tract (Bauchop and Martucci 1968), seasonal changes in digestive efficiency, torpor or hibernation (Schmid and Kappeler 1998; Ganzhorn et al. 2003; Dausmann 2014).

The impact of seasonality can vary between males and females, due to differences in energy requirements (reviewed in Key and Ross 1999). Reproduction, in particular the lactating stage, is highly demanding for females (Coelho 1974; NRC 2003). Therefore, it is expected that reproductive females are more affected by the variance in food availability than males and non-reproductive females (Oftedal 1985; Hemingway 1999; McCabe and Fedigan 2007). As a result, they must seasonally adjust their diet composition to changes in food availability in order to guarantee their reproductive success (Jolly 1984; Key and Ross 1999; Dunham 2008). For instance, to assure adequate nutrition, pregnant females spend more time feeding than non-pregnant ones (Lee 1984; Boinski 1988; Hemingway 1999), select higher quality diets (McCabe and Fedigan 2007) or ingest larger amounts of food (Hemingway 
1999; Rothman et al. 2008). In green monkeys (Cercopithecus aethiops), lactating females adopted an energy conservation strategy during periods of food scarcity, in which they increased the time resting, and avoided excessive activity in competition with others over food (Harrison 1983).

In many mammalian species, including primates, males are typically larger than females (Ralls 1976; reviewed in Key and Ross 1999) and have to cope with higher costs of body maintenance (Key and Ross 1999). However, in some species there is little sexual dimorphism, including the majority of Lemuriformes (Jolly 1984; Kappeler 1990; Kappeler 1991). Interestingly, the absence of sexual size dimorphism may be energetically advantageous to males, since they are exempt from costly maintenance of a larger body size (Richard 1992), while females still cope with the costs of reproduction (Jolly 1984). Another interesting trait of lemurs is the phenomenon that females are typically dominant to males and have priority of access to food (Jolly 1984; Richard and Nicoll 1987; Kappeler 1990; Dunham 2008). This fact has been related with the highly seasonal climate of Madagascar, where the availability of resources can be extremely variable. Thus, through the social dominance, females ensure the access to enough resources for their survival and reproduction (Jolly 1984; Richard and Nicoll 1987; Wright 1999).

Sifakas are one of the largest diurnal lemurs in Madagascar. They include large amounts of leaves in their diets, and rely on anatomical adaptations such as high molar crests, enlarged stomach, and elongated cecum and colon (Hill 1953) to digest a fibrous diet. The fact that Madagascar is a highly seasonal environment, particularly in the dry deciduous forests, where the majority of trees lose their leaves during the dry season, raises important questions of how availability and quality of food influences the diet and activities of folivores. Furthermore, despite the fact that sifakas are seasonal breeders with a short mating season (Brockman et al. 1998; Mass et al. 2009), adult females are highly charged with reproduction year round, spending six months pregnant and another six months lactating (Jolly 1984; Kappeler and Fichtel 2012). This high involvement with reproduction, coupled with the lack of male parental care, and the fact that infants are born in the season of low food availability contributes to the high reproductive costs for sifaka females (Jolly 1984).

A study on Edward's sifakas (Propithecus edwarsi) indeed documented important differences between the diet of males and females. However, those sex differences in diet 
were not more pronounced between reproductive stages (Hemingway 1999). Norscia and collaborators (2006) showed that seasonality had a high impact on the diet and activity patterns of Verreaux's sifakas (Propithecus verreauxi). This study, conducted in a deciduous forest in western Madagascar, showed that lemurs adopted a conservative strategy to save energy in periods of food scarcity. However, the data available in both studies did not include nutritional and potential sex differences respectively.

To build on this past research, we investigated the effect of seasonality, sex, and female reproductive stages in diet patterns of a population of Verreaux's sifakas in a dry deciduous forest in western Madagascar. Under the assumption that the dry season is the limiting period in terms of availability and quality of food, we tested the following hypotheses concerning the impact of food seasonality in both sexes: 1) sifakas will spend more time resting and less time feeding in the dry than in the wet season, and 2) there will be a decrease in energy intake during the dry season in comparison to the wet season. With respect to the high energy demands of female reproduction and seasonality we postulate that: 3) females will spend more time feeding on fruits, flowers, young leaves and mature leaves than males, 4) females will consume higher quality diets in terms of intake of energy and storable nutrients than males, and 5) if the timing of lactation is synchronized with the time of highest food availability and quality (Wright 1999), then we expect that females will consume higher quality foods during lactation than during gestation.

\section{Methods}

\section{Study site and subjects}

The study was conducted in the forest concession of Kirindy /CNFEREF, a dry-deciduous

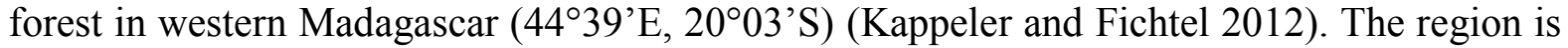
characterized by high seasonality, with a long dry season from April to early November, and a short wet season between mid-November and the end of March (Sorg and Rohner 1996).

We observed the behavior of 23 habituated adults (nine females and 14 males), of eight neighboring groups of Verreaux's sifakas from March 2012 to April 2013. However, 
given that not all 23 individuals were present in all seasons (due to dispersal or death), in the present study we used only data only from focal individuals that were present in all seasons for a better comparisons of diet between sexes and seasons. Therefore, our sample size was nine adult females and nine adult males distributed among the eight groups. For the comparison between reproductive stages among females our sample size was seven adult females, because one female did not give birth and another female lost the infant shortly after given birth.

Two observers conducted simultaneous observations of the adults in two different groups. All groups were followed every month, and each focal individual was observed continuously for one hour using the focal animal sampling (Altmann 1974). Each observer followed one group in the morning and a different group in the afternoon, thereby focals in four different groups were observed a day. Observations of focals and groups followed a rotation system that alternates the orders of observation to achieve full statistical days for all individuals. In total we registered 1064 hours of observation, with an average of 61 hours ( \pm 3) for each focal. The sifakas are habituated and individually marked with combinations of colored nylon collars and pendants or color-coded radio collars, respectively (Kappeler \& Fichtel 2012). Group size ranged from three to eight individuals, with one to two adult female and one to three adult males per group.

We categorized the reproductive stages of females into pregnancy and lactation based on visual observations. We used nursing behavior as the criterion to classify a female in the lactation category. We determined pregnancy period retrospectively after each infant was born. Because gestation is known to be ca. six months in length (Jolly 1984), one can determine the total gestation period once the infant is born. Since the estrus in sifaka females is synchronized (Mass et al. 2009), all females give birth around the same time (within a month). In the case of females in our study we have data on the exact day that each infant was born, since all groups are monitored on a daily basis as part of the long term data collection. In our study the first infant was born in 20/06/2012 and the last infant was born in 21/07/2012.

\section{Feeding behavior}


During focal observations, we recorded the food type (young or mature leaves, unripe or ripe fruits, open flowers or flower-bud, barks, and seeds), the tree species, and the location of the tree with a GPS (Garmin ${ }^{\circledR}$ GPS 60CSx). Given the high diversity in diet of sifakas we were not able to collect samples of all foods they fed on. For that reason we only collected samples from "important food resources", which were defined as foods eaten by a focal individual consecutively for more than five minutes (the focal should be feeding on the same type of item from the same tree). For these IFR we also estimated the bites per minute (whenever it was possible to visualize). The trees with IFR were individually marked for subsequent measurement of DBH, estimation of height and canopy size, and collection of samples for the nutritional analyses. The collection was performed on the same day, or within a maximum of three days after the feeding was recorded, and whenever possible, from the same tree from which sifakas were feeding. All IFR were sampled regardless if the same species had been collected already (since foods can be intra-specifically variable in nutritional content, Chapman et al. 2003), resulting in 1143 plant samples that could be used for chemical analyses (see below). When nutritional and intake information for certain foods were not available, we followed the method used by Irwin and collaborators (2014), using the average of all samples from the same species and food item to replace missing values.

The availability of food was based on monitoring phenology once a month of 690 trees from 166 species distributed in 47 families along transects using a semi-quantitative method (Fournier 1974). Using this method, scores of availability for each food item ranged from 0 to 4 , where 0 was the complete absence of the item and 4 represented its maximum abundance $(100 \%)$. We calculated the average of the scores from all trees for each item per month to infer its availability. To investigate if sifakas selected their diet based on the availability of items, we performed a Spearman correlation between the importance of items in the diet (based on time spent feeding) per month and its availability (based on the scores of abundance of food items).

\section{Processing samples and chemical analyses}


The samples were processed, weighed, and prepared for drying by placing them in paper bags and storing them in containers filled with dried ECO silica (non-toxic, $1.3 \mathrm{~mm}$ pearls with color indicator Roth ${ }^{\circledR}$ ) where they stayed until they were completely dried (i.e., water content did not change). The containers were inspected at least twice a day to control for possible mold. The silica gel was oven dried and replaced on a daily basis. Before drying, fruit pulp was sliced into small pieces, and seeds (in case sifakas ate the seeds) were dried separately from the pulp of the fruits to optimize drying.

After samples were dried, they were ground in an analytical mill (IKA, A11) through a 1-mm screen, and stored in plastic tubes. The samples were analyzed for neutral detergent fiber (NDF-ANKOM fiber analyzer), nitrogen (Kjeldahl), ash (combustion) and fat (ether extract) (Naumann and Bassler 1976; van Soest et al. 1991; Voigt et al. 2004; Donati et al. 2009) following standard chemical procedures. A comparison of methods is provided by Ortmann and collaborators (2006) and Rothman and collaborators (2011).

Due to the large sample size we applied near infrared spectroscopy (NIRS) (Foley et al. 1998; Stolter et al. 2006; Rothman et al. 2009) in the Department of Zoology of the University of Hamburg (Germany). NIRS models were developed with the Quant 2-method using partial least squares (PLS) regression with the software Opus NT Version 2.02 (Bruker GmbH, Germany). We used cross-validation (jack-knifing, internal validation) and test-setvalidation (external validation) to test the accuracy of the developed NIRS models (Appendix A). Standard NIRS procedures use the same data for generating the NIRS models and to test them. Though these procedures are used routinely, they can result in erroneous estimates when applied to samples that had not been used in model development (Stolter et al. 2006). We therefore applied the NIRS models to another test set of samples that had not been used for model development (independent test set validation; following Stolter et al. (2006). The original NIRS model were only used when the concentrations predicted by the NIRS model deviated less than $10 \%$ from the results obtained by wet chemical analyses of the independent test set (Stolter et al. 2006).

We estimated crude protein as nitrogen $* 6.25$. Non-structural carbohydrates were calculated following the formula (Irwin et al. 2014b):

$$
\mathrm{TNC}=100-(\text { fat }+ \text { crude protein }+ \text { fiber+ash })
$$


The calculation of energy from non-structural carbohydrates, fiber, protein, and fat were based on the conventional conversion values of $4 \mathrm{kcal}$ per gram protein, $4 \mathrm{kcal}$ per gram of non-structural carbohydrates, and $9 \mathrm{kcal}$ per gram of fat (NRC 2003). In the case of fiber, we used a conversion factor of $1.2 \mathrm{kcal}$ per gram, instead of $4 \mathrm{kcal}$, since we subtracted 1 kcal which is lost to the anaerobic microbes processing the fermentable fractions, plus the coefficient of digestibility for fiber $(40 \%)$. This measure has flaws as the errors of each analysis accumulate in the calculation (Rothman et al. 2011), but the final values are simply used for comparative analyses. A specific value for digestibility of fiber is currently not available for Verreauxs' sifakas. Therefore, the digestibility coefficient for fiber used in this study was $40 \%$ of $3 \mathrm{kcal}$, and it was based on a study, which investigated digestibility in two species of Propithecus (P. coquereli and P. tattersalli) in captivity (Campbell et al. 1999). Leaves were not analyzed for "fat" as ether extracts from leaves are very low. For leaves, we set the concentrations for "fat" $=0$. We calculated the nutrient concentration per food sifakas fed on based on the percentage of dry matter. "Fiber" was analyzed as Neutral detergent fiber. This measure includes hemicellulose and proteins associated with the cell wall. Some of these components might be digestible by sifakas. Therefore, high NDF-concentrations are considered to represent high energy content. All analyses of nutrient intake were based on grams per hour of time spent feeding.

\section{Statistical analysis}

For the statistical analyses, we pooled the content of samples that each focal fed on in each hour of observation, and then calculated the means for the various behavioral categories or nutrients per hour and per season. We included in the analyses only the focal individuals that were present in all seasons ( $\mathrm{N}=18$ individuals, nine males and nine females). Linear Mixed Models: LMM (Baayen et al. 2008) in R (version 3.1.2, (R Development Core Team 2015), from the package lmer4 (Bates et al. 2014) were applied to investigate the influence of sex and season on time spent feeding and resting and nutrient intake. Sex and seasons were the predictors, and time spent feeding or resting, intake (measured in grams) of non-structural carbohydrates (TNC), crude protein (CP), and fiber (FIBER), were our response factors. Since the availability of food in Kirindy Forest drops gradually (Lewis and Kappeler 2005b; 
Norscia et al. 2006) we divided the wet and dry seasons into: early dry season (April to July), late dry season (August to October), early wet season (November to December), and late wet season (January to March) to investigate seasonal patterns in more detail. The analyses were done separately for each macronutrient; therefore each LMM had the intake from a particular macronutrient, for instance crude protein, as a response variable, and sex and season as the explanatory factors. Squared root and log transformations were applied to variables that were not normally distributed in order to achieve normality. Figures are representing the original data without transformation, which were used only for the statistical models. All models were controlled for focal and group identity by integrating them as random factors (individual ID nested in group ID). For the LMMs, P values were obtained with the Rpackage lmerTest (Kuznetsova et al. 2013). We checked all the relevant assumptions (multicollinearity, and existence of influential cases) for each linear mixed model, and we verified the significance of the full model (including the predictors and controlled factors) to the null model (only with the controlled factors) using ANOVA.

Non-parametric tests (Friedman and Wilcoxon Signed Rank Test) were applied for the comparison between sexes and seasons on time spent resting, and also on feeding time on different food items: flowers (FL), fruits (FR), young leaves (YL), and mature leaves (ML). In order to correct for multiple testing, we reduced the value of $\mathrm{P}$ from 0.05 to $0.008(0.05 / 6)$ using the method "Bonferroni" in the "p-adjust" function from the package "Stats" (version 3.1.0) in R. With respect to the reproductive stages we split the categories of gestation and lactation in a more detailed classification, as follows: early pregnancy (February to April), late pregnancy (May to July), early lactation (August to October), and late lactation (November to January). We used LMM to investigate if females showed differences in intake of nutrients and time spent in activities such as feeding and resting between the reproductive stages ( $\mathrm{N}=7$ females). Additionally we also used LMM to compare the nutrient intake of females during lactation and pregnancy with the nutrient intake of males in each of those periods. This comparison was relevant due to the lack of sexual dimorphism in sifakas, and was done in order to confirm that differences in diet between the sexes were connected to the high demands of reproduction for females, rather than to the increase of food availability in the forest. All statistical analyses were performed in R. Concerning sample sizes, the comparisons of diet between sexes and seasons were done among focal individuals that were 
present in all seasons, nine adult females and nine adult males. For the comparison between reproductive stages among females our sample size was seven adult females, because one female did not give birth and another female lost the infant shortly after given birth.

\section{Results}

\section{Seasonal differences}

Sifakas in Kirindy spent $47 \%$ of their time feeding. Their diet was composed of 118 species from 44 plant families. During the wet season, sifakas spent $42 \%$ of their time feeding from 88 species, while during the dry season they spent $48 \%$ of their time feeding and included 99 species. They spent less time feeding during the early wet season (15\% vs. $35 \%$ early dry, $28 \%$ late dry, and $20 \%$ late wet) in comparison to the other seasons $\left(\chi^{2}=18.22, \mathrm{df}=4\right.$, $\mathrm{P}=0.001$ ). The time spent resting was also different between seasons (Friedman test: $\chi^{2}=15.8$, $\mathrm{df}=3, \mathrm{P}=0.001)$, being lower ( $14 \%$ vs $21 \%$ early dry, $30 \%$ late dry, and $33 \%$ early wet) during the late wet season compared to the other seasons. The time spent in locomotion was lower during the early dry season ( $20 \%$ vs. $28 \%$ early wet, $29 \%$ late dry, and $23 \%$ late wet) $\left(\chi^{2}=89.78, \mathrm{df}=4, \mathrm{P}<0.001\right)$. Results of Linear Mixed Models and for the Wilcoxon paired tests are available in Supplementary Material (feeding: Table A in SM.I; locomotion: Table B in SM.I; resting Table C in SM.I)

The time spent feeding on different food items was also different between seasons (Figure 1, Table A in SM.II in Supplementary Material). Sifakas spent more time feeding on fruits during the late wet season (Friedman test: $\chi^{2}=92.25$, $\mathrm{df}=4, \mathrm{P}<0.001$ ); on flowers in the transition between late dry and early wet seasons (Friedman test: $\chi^{2}=71$, $\mathrm{df}=4, \mathrm{P}<0.001$ ); on mature leaves during the early dry season (Friedman test: $\chi^{2}=154.84$, $\mathrm{df}=4, \mathrm{P}<0.001$ ), and more time feeding on young leaves during the early wet season (Friedman test: $\chi^{2}=67.73$, $\mathrm{df}=4, \mathrm{P}<0.001)$.. Sifakas spent more time feeding on fruits when this item was highly available $\left(\mathrm{R}^{2}=0.52, \mathrm{df}=10, \mathrm{~F}=13.06, \mathrm{P}=0.005\right.$, Figure 2$)$. However, they did not select their diet based on the availability of young and mature leaves, and flowers. 


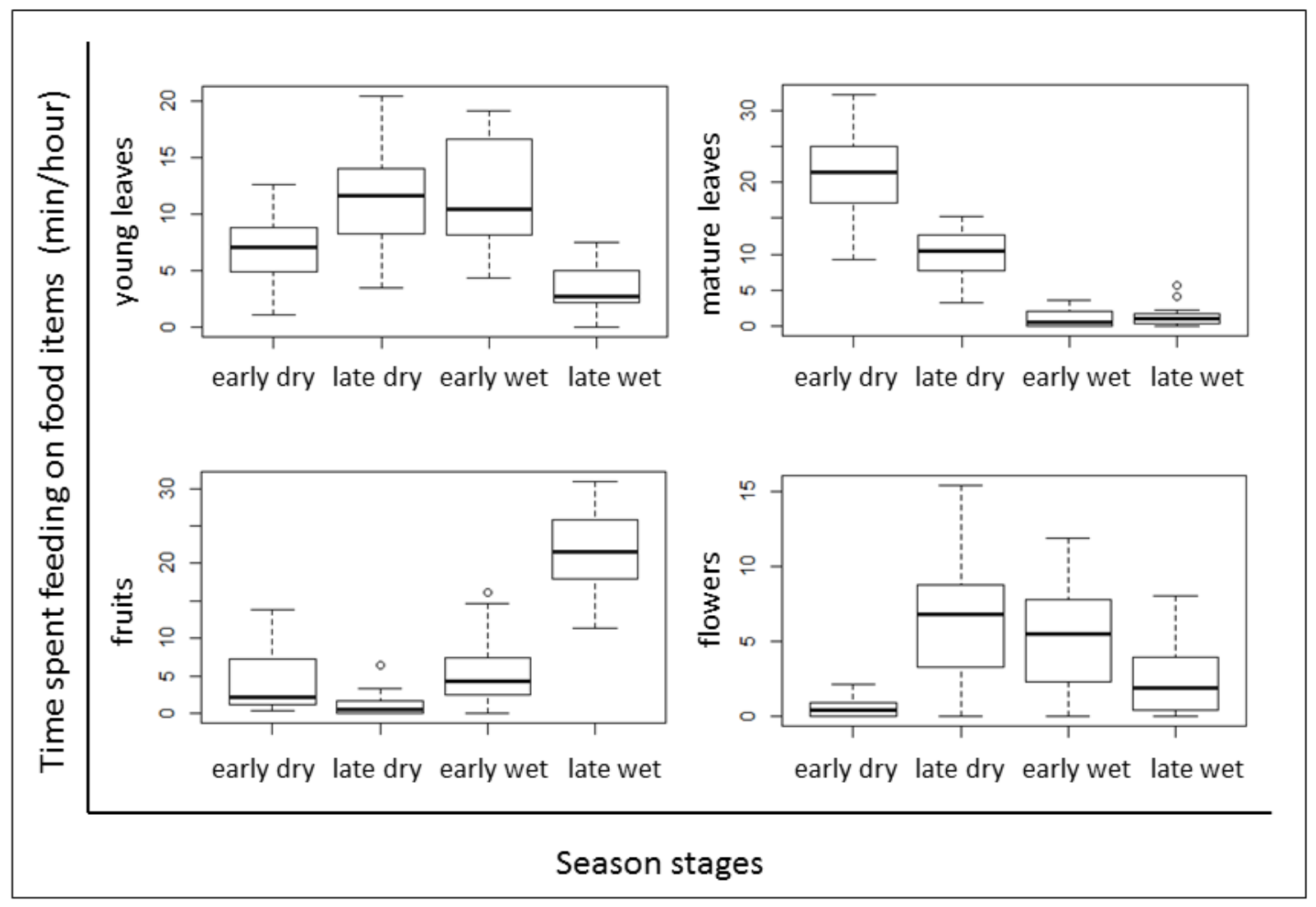

Figure 1. Time sifakas spent feeding (min/feeding hour) on food items between seasons. Early-dry season: from April to July; late-dry season: from August to October; early-wet season: from November to December; and late-wet season: from January to March. 


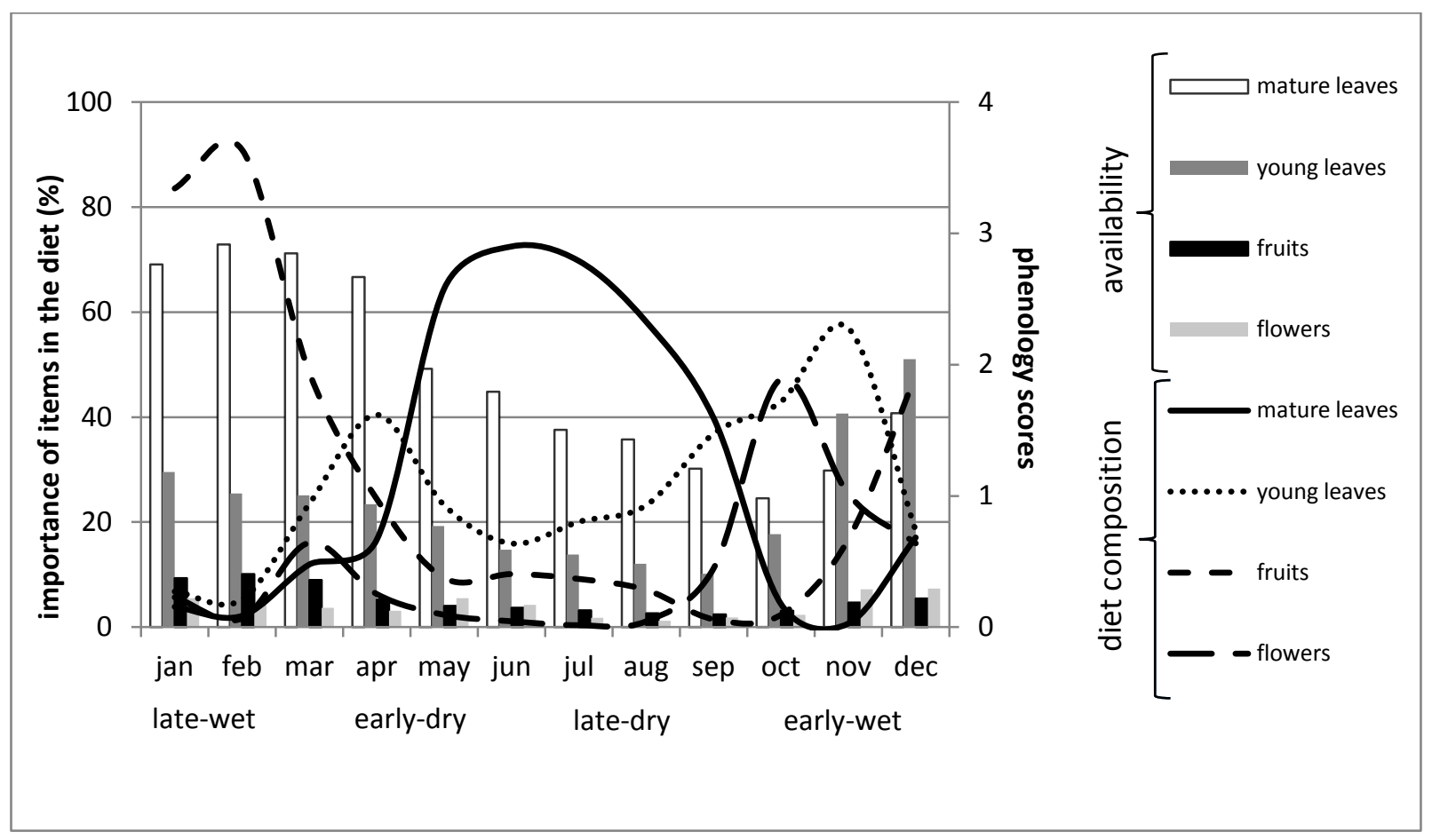

Figure 2. Diet composition and food availability of food items across seasons. Lines indicate the proportion of items included in the diet of sifakas per month, based on time spent feeding. The bars indicate the monthly availability of food items in the forest, based on the phenological scores (0 to 4$)$.

Finally, sifakas had a higher intake of non-structural carbohydrates $\left(\chi^{2}=47.28, \mathrm{df}=4\right.$, $\mathrm{P}<0.001)$, of crude protein $\left(\chi^{2}=35.49, \mathrm{df}=4, \mathrm{P}<0.001\right)$, and also of fibers $\left(\chi^{2}=44.29\right.$, $\mathrm{df}=4$, $\mathrm{P}<0.001$ ) during the late wet season compared to the other seasons (Figure 3 and Figure 4). Results of Linear Mixed Models are available in supplementary material (non-structural carbohydrates: Table A in SM.III; crude protein: Table B in SM.III; and fiber: Table C in SM.III). 


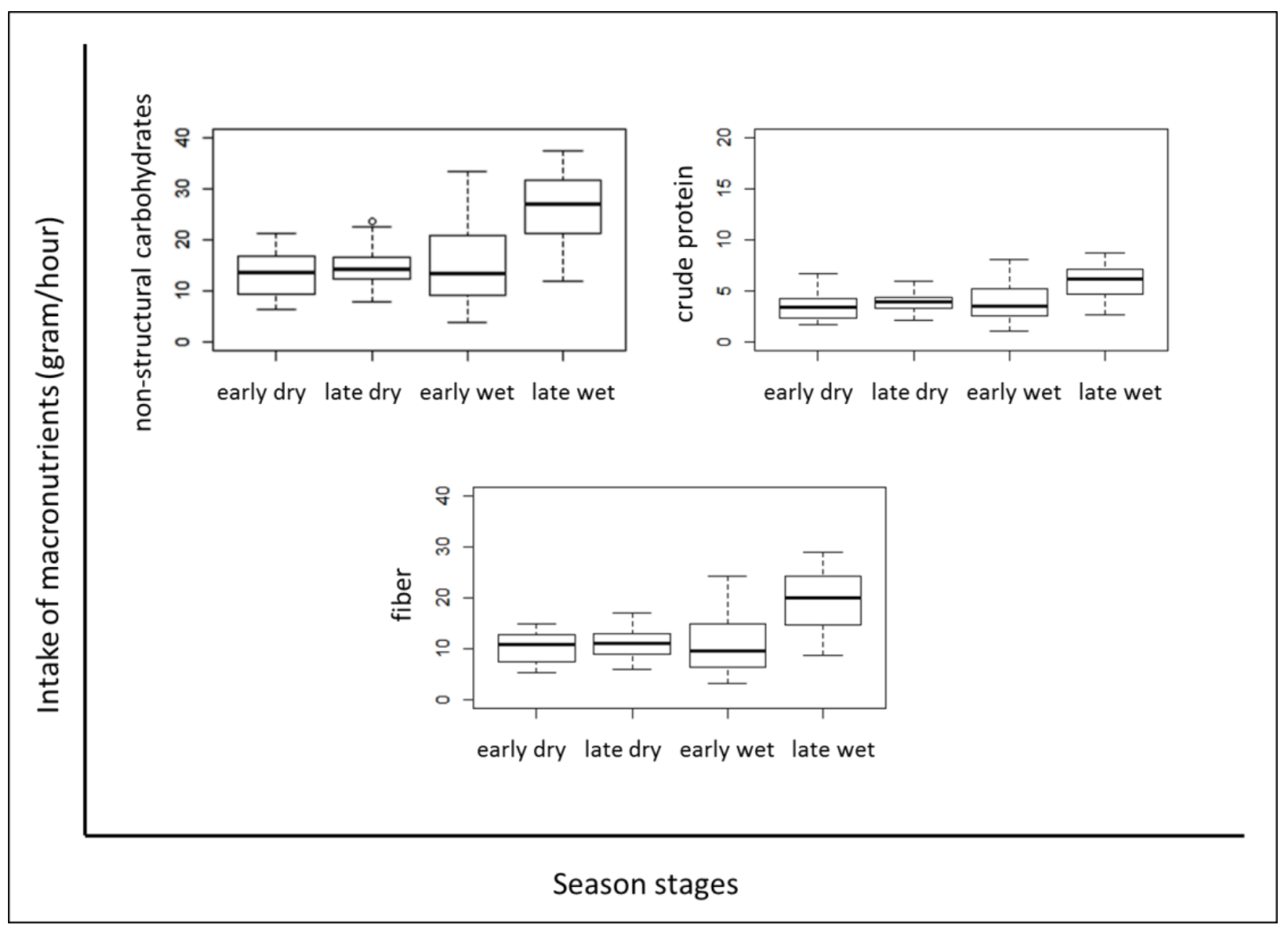

Figure 3. Seasonal intake of non-structural carbohydrates, crude protein, and fiber in grams per hour of feeding time. Early-dry season: from April to July; late-dry season: from August to October; early-wet season: from November to December; and late-wet season: from January to March. 


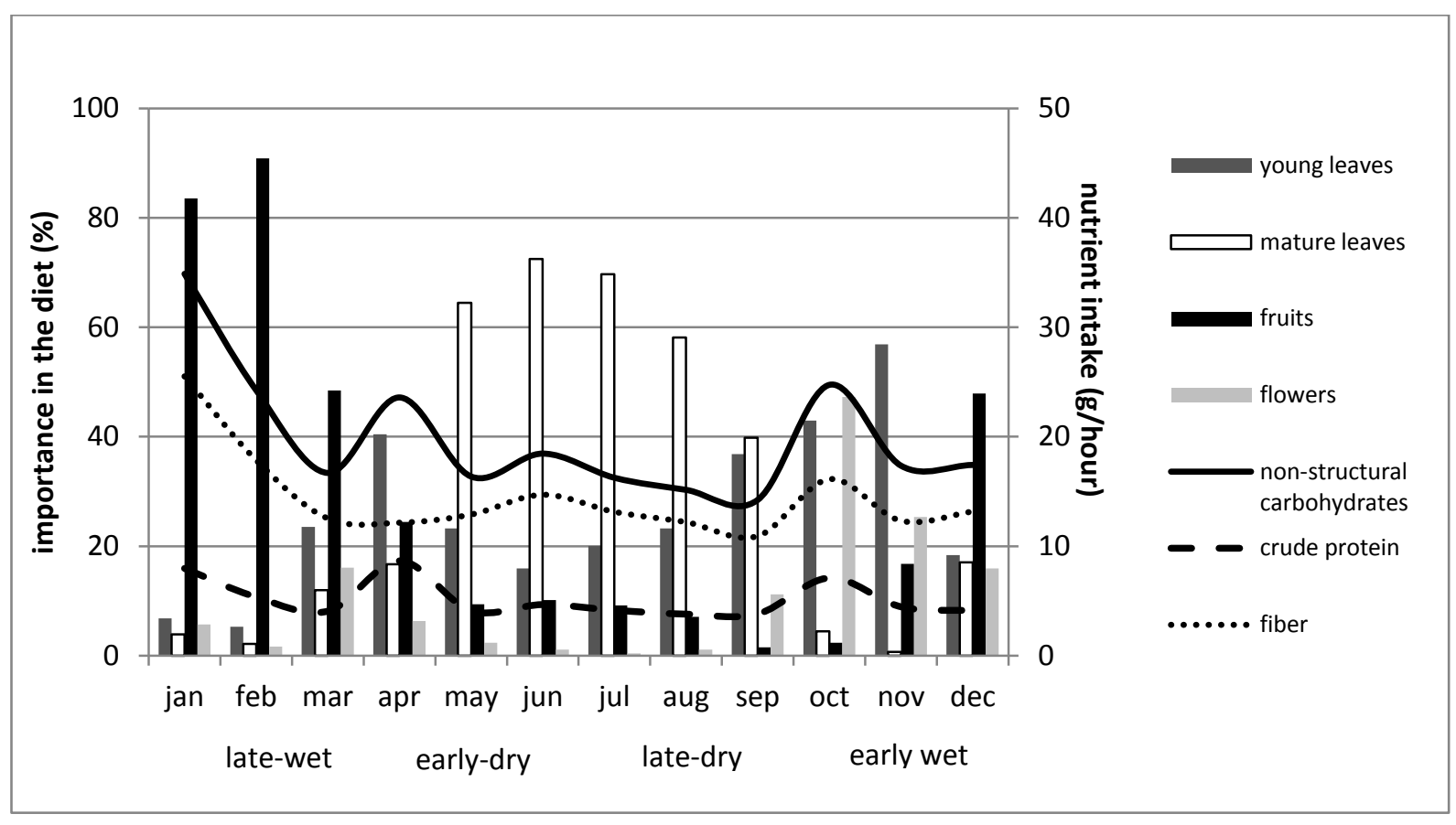

Figure 4. Diet composition and intake of macronutrients across seasons. Lines represent the energy from non-structural carbohydrate (tnc), crude protein, and fiber (ndf) included in the diet of sifakas per month, based on the intake of food. The bars indicate the monthly proportion of items in the diet, based on time spent feeding. The diet composition is based on percentage of time spent feeding on each food item per month per month. The intake of macronutrients is based on the average of grams per hour of feeding time per month.

\section{Sex differences}

There was no difference between males and females ( $\mathrm{N}=18$ individuals) in the time spent resting (Wilcoxon test: $\mathrm{V}=38, \mathrm{P}=0.96$ ). Females spent more time feeding than males $(\mathrm{P}=0.003$, Table $\mathrm{A}$ in SM.I); and males spent more time in locomotion than females $(\mathrm{P}=0.01$, Table B in SM.I). In terms of food items, females spent more time feeding on young leaves $(\mathrm{V}=53, \mathrm{P}=0.002)$, mature leaves $(\mathrm{V}=48, \mathrm{P}=0.04)$, and fruits $(\mathrm{V}=54, \mathrm{P}=0.003)$ than males (Figure 5). There was no sex difference in the time spent feeding on flowers $(\mathrm{V}=40, \mathrm{P}=0.23)$. In relation to the intake of nutrients, females had a higher intake of non-structural carbohydrates $(\mathrm{P}=0.01$, Table A in SM.III), crude protein ( $\mathrm{P}=0.008$, Table B in SM.III), and fiber $(\mathrm{P}=0.03$, Table $\mathrm{C}$ in SM.III) than males. 


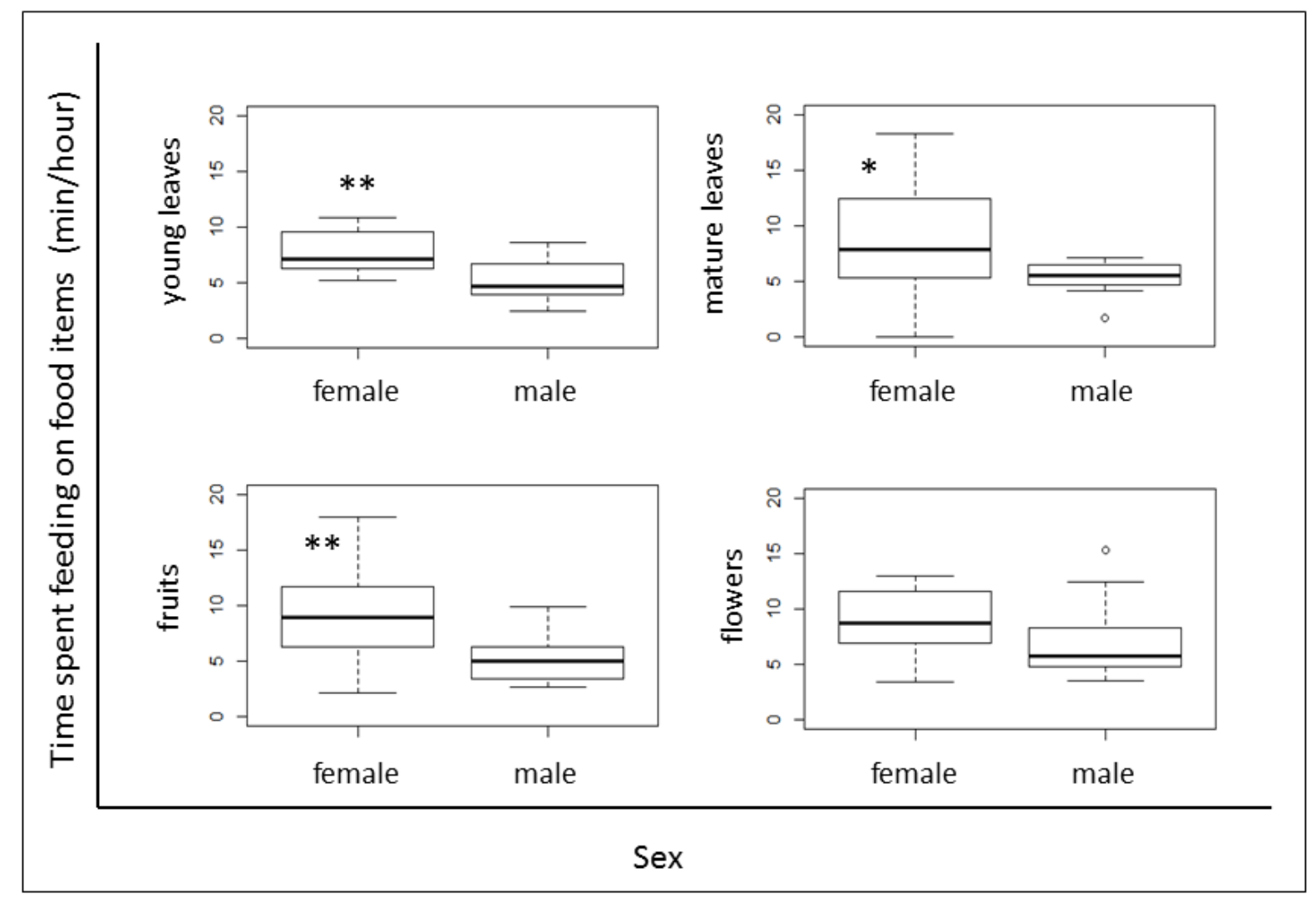

Figure 5. Sex differences on time spent feeding ( $\mathrm{min} /$ hour of feeding time) on fruits, flowers, young leaves and mature leaves. Females spent more time feeding on young leaves, mature leaves and fruits than males. No significant sex differences in the time spent feeding on flowers. 
Table 1. Seasonal intake of macronutrients. Average intake of non-structural carbohydrates, crude protein (nitrogen), and fiber (NDF) per hour from different food items between males and females, including all seasons.

\begin{tabular}{|c|c|c|c|c|c|c|}
\hline \multirow[t]{2}{*}{ Food items } & \multicolumn{2}{|c|}{$\begin{array}{c}\text { Non-structural } \\
\text { carbohydrates } \\
\text { (gram/hour of feeding } \\
\text { time) }\end{array}$} & \multicolumn{2}{|c|}{$\begin{array}{l}\text { Crude protein } \\
\text { (gram/hour of } \\
\text { feeding time) }\end{array}$} & \multicolumn{2}{|c|}{$\begin{array}{c}\text { Fiber } \\
\text { (gram/hour of } \\
\text { feeding time) }\end{array}$} \\
\hline & Females & Males & Females & Males & Females & Males \\
\hline Young leaves & $2.67 \pm 6.87$ & $2.08 \pm 4.90$ & $0.70 \pm 1.77$ & $0.54 \pm 1.21$ & $1.95 \pm 4.79$ & $1.57 \pm 3.53$ \\
\hline Mature leaves & $3.78 \pm 7.53$ & $3.84 \pm 6.77$ & $0.97 \pm 1.77$ & $0.98 \pm 1.62$ & $3.02 \pm 5.94$ & $3.06 \pm 5.25$ \\
\hline Fruits & $6.26 \pm 10.34$ & $5.42 \pm 8.68$ & $1.43 \pm 2.38$ & $1.27 \pm 2.21$ & $4.66 \pm 7.70$ & $4.02 \pm 6.45$ \\
\hline Flowers & $6.05 \pm 10.75$ & $5.73 \pm 9.47$ & $1.65 \pm 2.97$ & $1.55 \pm 2.57$ & $4.01 \pm 6.95$ & $3.90 \pm 6.28$ \\
\hline
\end{tabular}

*Mean, \pm SD

\section{Reproductive stages}

Females did not spend more time feeding or resting in any of the reproductive stages (early lactation, early pregnancy, late lactation, and late pregnancy, $\mathrm{N}=7$ females). However, concerning the nutrient intake in those periods, the intake of non-structural carbohydrates $\left(\chi^{2}=14.76, \mathrm{df}=3, \mathrm{P}=0.002\right)$, crude protein $\left(\chi^{2}=10.21, \mathrm{df}=3, \mathrm{P}=0.02\right)$, and fiber $\left(\chi^{2}=13.69, \mathrm{df}=3\right.$, $\mathrm{P}=0.003$ ) were higher during the stage of late lactation in comparison to the other reproductive stages (Figure 6). Results of Linear Mixed Models are available in supplementary material (non-structural carbohydrates: Table A in SM.IV; crude protein: Table B in SM.IV; and fiber: Table C in SM.IV).

In order to test if the high intake of nutrients observed during lactation was due to the costs of this reproductive stage or because of the general food availability of the period, we compared the intake of nutrients of females during pregnancy and lactation and compared them to the nutrient intake of males in each of those periods ( $\mathrm{N}=16$ individuals: seven females and nine males). Females had indeed a higher intake of non-structural carbohydrates $\left(\chi^{2}=8.11, \mathrm{df}=1, \mathrm{P}=0.004\right)$, crude protein $\left(\chi^{2}=9.75, \mathrm{df}=1, \mathrm{P}=0.001\right)$, and fiber $\left(\chi^{2}=7 ., \mathrm{df}=1\right.$, $\mathrm{P}=0.006$ ) than males during lactation. Results of Linear Mixed Models are available in 
supplementary material (non-structural carbohydrates: Table A in SM.V; crude protein: Table B in SM.V; and fiber: Table C in SM.V). However, there was no difference in nutrient intake in the diet between males and females when females were pregnant (Figure 7).

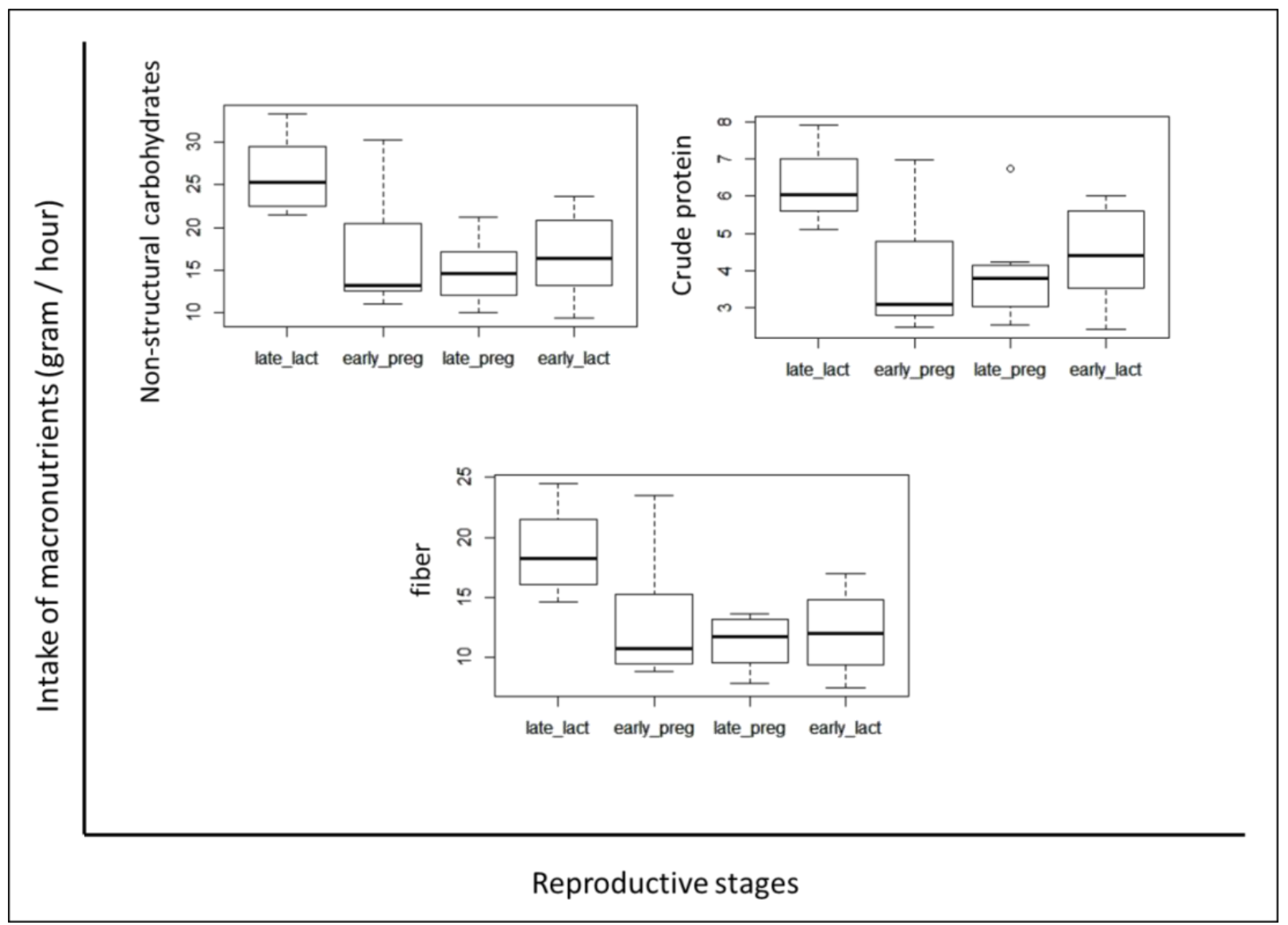

Figure 6. Intake of non-structural carbohydrates, crude protein, and fiber of reproductive females between stages of reproduction. Intake based on grams per hour of feeding time. Late-lact: late lactation (from November to January); early-preg: early pregnancy (from February to March); late-preg: late pregnancy (from April to July); and early-lact: early lactation (from August to October). 


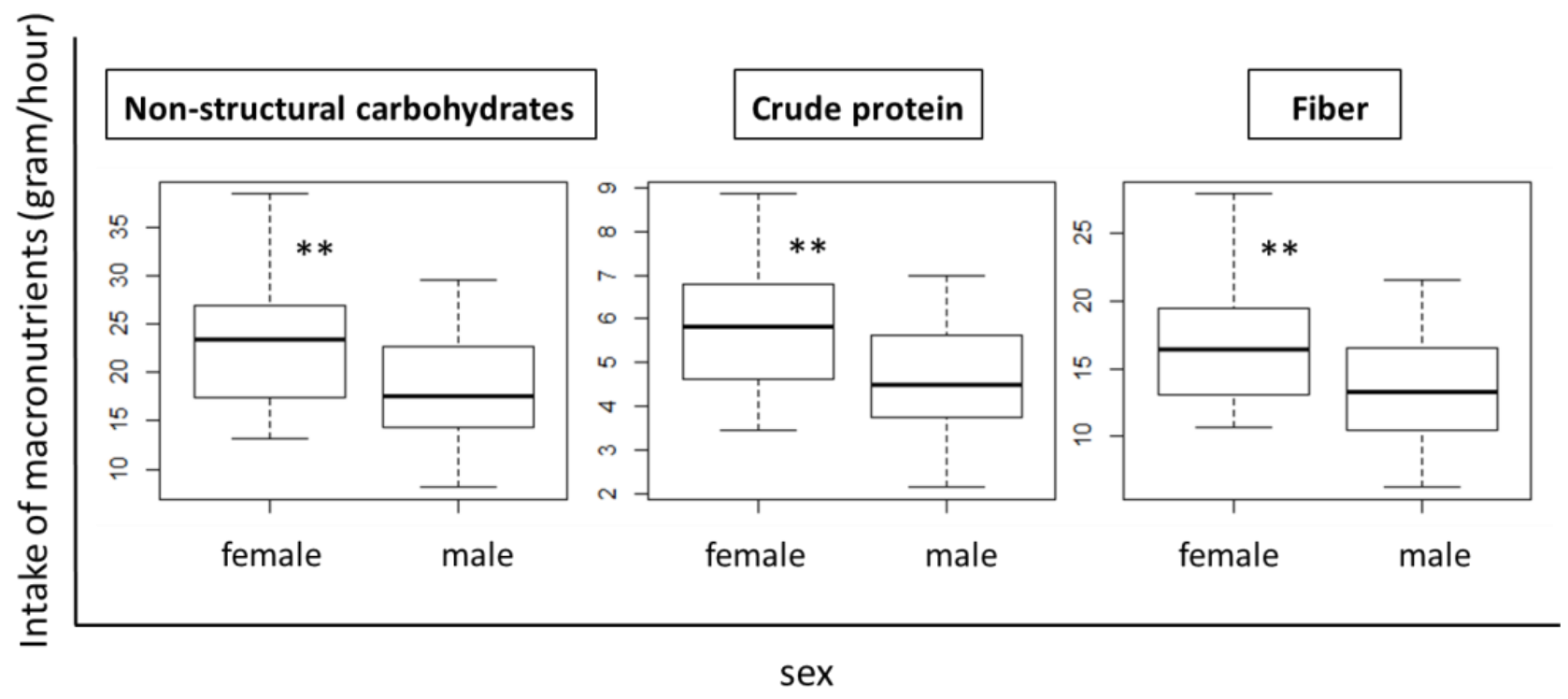

Figure 7. Intake of macronutrients between females and males during the period of lactation for females. Intake based on grams per hour of feeding time.

\section{Discussion}

Our study shows that sex and seasonality influenced feeding patterns of Verreaux's sifakas. The dry season was indeed a period in which the availability of food dropped drastically, and both males and females had lower intake of nutrients in comparison to the wet season. The comparison of dietary patterns between sexes showed that females accessed a higher quality diet than males, a pattern that got more extreme in the late wet season (from January to March), when the availability of fruits peaked. We discuss each of these main results in detail below.

Reproduction is a highly demanding period for mammals, particularly for females (Gittleman and Thompson 1988). For example, in white-faced capuchins (Cebus capucinus), lactating females ingested food of all types than do cycling or pregnant females, suggesting that lactation is the most costly period of reproduction (McCabe and Fedigan 2007). The same pattern has been observed in howler monkeys (Alouatta palliata), in which reproductive females had higher intake of energy than non-reproductive ones (Serio-Silva et al. 1999). Moreover, reproduction for female lemurs is even more costly than for other 
primates due to the highly seasonal climate of Madagascar (reviewed in Wright 1999), in addition to other factors such as altricial infants and low basal metabolic rates (Jolly 1984). In that sense, females are under higher energetic pressure than males, to adapt the demands of reproduction and their own survival to the variability of food availability.

Our results show sex differences in activity patterns, composition and quality of diet that indicate that females indeed accessed a better diet than males. Females spent more time feeding across all seasons, and had higher intake of macronutrients, such as crude protein, non-structural carbohydrates, and fiber, than males. One possible explanation for sex differences in nutrient intake can be the different requirements for body maintenance (Key and Ross 1999). However, that is not the case for sifakas since there is no sex dimorphism in size (Kappeler 1991), or any other physical or physiological difference between males and females, other than reproduction, that could justify differences in nutrient intake. Therefore, we suggest that the sex differences observed in our study are due to the high costs of reproduction for females.

Furthermore, despite the fact that we did not include measurements of body mass, previous studies already showed that both male and female sifakas lose weight during the dry season and gain weight during the wet season (Richard et al. 2000; Lewis and Kappeler 2005a). This pattern of seasonal oscillation in body mass is even more accentuated in females (Meyers and Wright 1993; Richard et al. 2000; Richard et al. 2002). Richard and collaborators (Richard et al. 2002) suggest that the higher oscillation of body mass in females is due to the necessity of storing nutrients from the wet season to pay for the costs of reproduction. Our findings indeed show that females had a higher intake of non-structural carbohydrates than males during the late wet season. Carbohydrates can be stored as glycogen or fat for later use (NRC 2003). Therefore, the recovery of body condition and the successful storage of nutrients are major factors in the reproduction of sifaka females. "Bad" recovery after gestation and lactation, in terms of body mass, has a negative effect on the reproductive success of female sifakas. Females that have a better body condition (higher body mass) around the mating season have higher chances of giving birth, and were more successful in caring for their infant (Richard et al. 2000; Lewis and Kappeler 2005a).

Reproductive stages require different amounts of energy from females. Since the availability of high quality items (fruits and young leaves) is concentrated in a short period of 
the year in Madagascar (Wright 1999; Janson and Verdolin 2005), large lemurs, such as sifakas, have to strategically distribute the reproductive stages across periods of low availability of food (Wright 1999; Richard et al. 2000). It has been suggested that mid/late lactation is the most demanding stage for female mammals (Payne and Wheeler 1968; Coelho 1974). We could see differences between and within reproductive stages concerning the intake of nutrients in our study. Comparing gestation and lactation, reproductive females had a higher intake of nutrients during the lactation period than during gestation. The quality became higher towards the second half of lactation, in comparison to the first half of this stage.

With respect to the timing of reproductive stages with the availability of resources, animals can adopt different reproductive strategies according to their life histories, in order to adapt the energy requirements of reproduction to the environmental conditions. In that sense animals can be classified as income or capital breeders (Drent and Daan 1980; Stearns 1989; Stearns 1992). Income breeders synchronize the most demanding period of their reproduction with the period when the availability of food is high. While capital breeders rely on nutrient stored previously to pay for the costs of their reproduction. In this regard, we could see that females accessed more nutrients (including storable ones) than males, despite the lack of sexual dimorphism. Moreover, there was no synchronization between the most demanding reproductive stage (mid/late lactation) and the period of highest food availability. Therefore, our results indicate that sifakas are using a capital breeding strategy, which is in agreement with what Richard and collaborators (Richard et al. 2000) suggested for Verreaux's sifakas in the southwest of Madagascar.

The improvement in diet observed during the late lactation indicates that the amount of nutrients stored by female sifakas is probably not enough to pay for all the costs of reproduction. For that reason, it has been debated if sifakas are following a capital or an income breeder strategy, and there is no consensus among them up to this date (Wright 1999; Richard et al. 2000; Janson and Verdolin 2005; Lewis and Kappeler 2005a; van Schaik and Brockman 2005; Lewis and Kappeler 2005b). Our results show that by the time of the peak of abundance of food (late wet season), infants were already weaned (total length of lactation period was around 5 months, based on our observations, and unpublished data from C. Fichtel). Additionally, the comparison between the diet of males and reproductive females 
showed that differences were more pronounced during lactation than gestation. This result indicates that the improvement in the diet of females during lactation is connected to the high costs of reproduction and not only to the rise in availability of food that period.

Although not connected to the peak of food availability, the improvement in the quality of diet observed towards mid/late lactation, certainly helped reproductive females to deal with the high costs of late lactation. With regard to the timing of weaning the infants, the synchronization with the period of high availability of food seems a good strategy for two reasons: first from the perspective of the infants that will have plenty of high quality food to explore and to get prepared for the harsh dry season; second from the perspective of females that can concentrate all their energy in recovering the body condition and storing enough nutrients for their next reproduction (Richard et al. 2000; Janson and Verdolin 2005).

The mechanisms used by female sifakas to ensure their access to a better diet are probably connected to their priority to access to food, which is guaranteed by their social dominance over males (Jolly 1966). In addition, the capacity of storing nutrients and the synchronization of their reproductive stages to the seasonal availability of food, also contribute for the reproductive success of females.

In conclusion, our study demonstrated that the seasonal decrease in availability of food observed in Kirindy Forest had negative implications for the quality of the diet of sifakas. In addition, the high amount of macronutrients ingested during the rich season suggests that the survival of sifakas in such seasonal environment is highly dependent on the quality of diet accessed during periods of high and not so much during periods of low abundance of food. The capacity to store energy during the abundant season is probably crucial for their survival, and this phenomenon has been also described for red-tailed sportive lemurs (Lepilemur ruficaudatus), another folivorous lemur species in the same forest (Ganzhorn 2002). Likewise, storage capacity is one prerequisite for hibernation in gray mouse lemurs (Microcebus murinus, Schmid 2000) and fat-tailed dwarf lemurs (Cheirogaleus medius, Dausmann 2014). Thus, this might be a basic trait of lemur biology that requires reconsideration of the importance of lean and rich seasons for lemur evolution. Since we can exclude different costs of body maintenance between sexes, we suggest that the high costs of reproduction drive the superior quality of diet of females in this species. The social dominance is probably within the mechanisms that allow females to access a high 
quality diet (Richard et al. 2000). Hence, factors such as social organization, reproductive strategy, and storage capacity are supporting the successful permanence of sifakas in extreme seasonal environments. 
Appendix A. Model performance of NIRS-models used to estimate concentrations of nitrogen, NDF, fat and ash.

\begin{tabular}{|c|c|c|c|c|}
\hline Plant part & Component & Validation* & $\mathbf{R}^{\mathbf{2}}$ & $\begin{array}{c}\text { RMSEP } / \\
\text { RMSECV } * *\end{array}$ \\
\hline \multirow{3}{*}{ Fruits } & Nitrogen & cross & 98.63 & 0.123 \\
\cline { 2 - 5 } & NDF & cross & 99.35 & 1.140 \\
\cline { 2 - 5 } & Fat & cross & 99.29 & 0.560 \\
\hline \multirow{3}{*}{ Flowers } & Nitrogen & test-set & 94.78 & 0.151 \\
\cline { 2 - 5 } & NDF & cross & 95.41 & 1.600 \\
\cline { 2 - 5 } & Fat & cross & 98.11 & 0.115 \\
\hline \multirow{2}{*}{ Mature leaves } & Nitrogen & test-set & 96.15 & 0.144 \\
\cline { 2 - 5 } & NDF & cross & 80.29 & 3.440 \\
\hline \multirow{2}{*}{ Young leaves } & Nitrogen & test-set & 96.15 & 0.144 \\
\cline { 2 - 5 } & NDF & cross & 90.32 & 2.800 \\
\hline All parts & Ash & test-set & 89.79 & 0.941 \\
\hline
\end{tabular}

${ }^{*}$ Cross $=$ cross validation; test-set $=$ test-set validation

**RMSEP: root of the mean square error of the prediction based on the test-set validation; RMSECV: root of the mean square error of the prediction of cross validation (Stolter et al., 2006). 


\section{SUPPLEMENTARY MATERIAL (SM): \\ CHAPTER 3}

SM.I

SM.I Table A. LMM: time spent feeding between sexes and season stages.

\begin{tabular}{llllll}
\hline Fixed effects & Estimate & Std. Error & df & t value & $\operatorname{Pr}(>|\mathbf{z}|)$ \\
\hline (Intercept) & 22.83 & 1.53 & 35.00 & 14.93 & 0.001 \\
Males & -3.92 & 1.25 & 66.96 & -3.13 & $0.003 * *$ \\
Early dry season & 4.07 & 1.65 & 61.33 & 2.47 & $0.02 *$ \\
Early wet season & -10.93 & 1.65 & 61.33 & 2.29 & $0.02 *$ \\
Late dry season & -11.20 & 1.65 & 61.33 & 3.04 & $0.003 * *$ \\
\hline
\end{tabular}

SM.I Table B. LMM: time spent for locomotion between sexes and season stages.

\begin{tabular}{llllll}
\hline Fixed effects & Estimate & Std. Error & $\mathbf{d f}$ & $\mathbf{t}$ value & $\operatorname{Pr}(>|\mathbf{z}|)$ \\
\hline (Intercept) & 0.59 & 0.03 & 37.24 & 19.85 & 0.001 \\
Males & 0.07 & 0.02 & 66.99 & 2.65 & $0.01 *$ \\
Early wet season & 0.41 & 0.03 & 60.83 & 12.64 & $0.001 * * *$ \\
Late dry season & 0.24 & 0.03 & 60.83 & 7.33 & $0.001 * * *$ \\
Late wet season & 0.30 & 0.03 & 60.83 & 9.24 & $0.001^{* * *}$ \\
\hline
\end{tabular}

SM.I Table C. Results of the Wilcoxon paired test comparing the time spend resting between season stages.

\begin{tabular}{l|cccccc}
\hline \multirow{4}{*}{ Resting } & $\begin{array}{c}\text { Early dry } \\
\text { Early wet }\end{array}$ & $\begin{array}{c}\text { Early dry } \\
\text { Late wet }\end{array}$ & $\begin{array}{c}\text { Late dry } \\
\text { Late wet }\end{array}$ & $\begin{array}{c}\text { Late dry } \\
\text { Early dry }\end{array}$ & $\begin{array}{c}\text { Late dry } \\
\text { Early wet }\end{array}$ & $\begin{array}{c}\text { Late wet } \\
\text { Early wet }\end{array}$ \\
\cline { 2 - 7 } & $\mathrm{V}=46$, & $\mathrm{V}=143$, & $\mathrm{V}=155$, & $\mathrm{V}=65$, & $\mathrm{V}=77$, & $\mathrm{V}=15$, \\
& $\mathrm{P}=0.54$ & $\mathrm{P}=0.06$ & $\mathrm{P}=0.008$ & $\mathrm{P}=1$ & $\mathrm{P}=1$ & $\mathrm{P}=0.006$ \\
\hline
\end{tabular}


SM.II Table A. Results of the Wilcoxon paired tests comparing the time spent feeding on each food item per season stages.

\begin{tabular}{c|cccccc}
\hline \multirow{2}{*}{ Food items } & $\begin{array}{c}\text { Early dry } \\
\text { Early wet }\end{array}$ & $\begin{array}{c}\text { Early dry } \\
\text { Late wet }\end{array}$ & $\begin{array}{c}\text { Late dry } \\
\text { Late wet }\end{array}$ & $\begin{array}{c}\text { Late dry } \\
\text { Early dry }\end{array}$ & $\begin{array}{c}\text { Late dry } \\
\text { Early wet }\end{array}$ & $\begin{array}{c}\text { Late wet } \\
\text { Early wet }\end{array}$ \\
\hline \multirow{2}{*}{ Young leaves } & $\mathrm{V}=13$, & $\mathrm{V}=162$, & $\mathrm{V}=171$, & $\mathrm{V}=16$, & $\mathrm{V}=77$, & $\mathrm{V}=0$, \\
& $\mathrm{P}=0.004$ & $\mathrm{P}=0.001$ & $\mathrm{P}<0.001$ & $\mathrm{P}=0.007$ & $\mathrm{P}=1$ & $\mathrm{P}<0.001$ \\
Mature & $\mathrm{V}=171$, & $\mathrm{V}=171$, & $\mathrm{V}=170$, & $\mathrm{V}=171$, & $\mathrm{V}=171$, & $\mathrm{V}=92$, \\
leaves & $\mathrm{P}<0.001$ & $\mathrm{P}<0.001$ & $\mathrm{P}<0.001$ & $\mathrm{P}=0.007$ & $\mathrm{P}=0.95$ & $\mathrm{P}=1$ \\
\multirow{3}{*}{ Fruits } & $\mathrm{V}=43$, & $\mathrm{V}=0$, & $\mathrm{V}=0$, & $\mathrm{V}=151$, & $\mathrm{V}=4$, & $\mathrm{V}=171$, \\
& $\mathrm{P}=0.4$ & $\mathrm{P}<0.001$ & $\mathrm{P}<0.001$ & $\mathrm{P}=0.02$ & $\mathrm{P}=0.002$ & $\mathrm{P}<0.001$ \\
& $\mathrm{~V}=1$, & $\mathrm{V}=20$, & $\mathrm{V}=148$, & $\mathrm{V}=2$, & $\mathrm{V}=107$, & $\mathrm{V}=11$, \\
& $\mathrm{P}<0.001$ & $\mathrm{P}=0.02$ & $\mathrm{P}=0.03$ & $\mathrm{P}=0.001$ & $\mathrm{P}=0.95$ & $\mathrm{P}=0.002$ \\
\hline
\end{tabular}


SM.III Table A. LMM: intake of non-structural carbohydrates per sex and season stages.

\begin{tabular}{llllll}
\hline Fixed effects & Estimate & Std. Error & df & t value & $\operatorname{Pr}(>|\mathrm{z}|)$ \\
\hline (Intercept) & 5.28 & 1.21 & 26.10 & 25.03 & 0.001 \\
Males & -0.41 & 1.16 & 65.50 & -2.52 & $0.01 *$ \\
Early dry season & -1.46 & 1.21 & 60.31 & -6.84 & $0.001 * * *$ \\
Early wet season & -1.29 & 1.21 & 60.31 & -6.03 & $0.001 * * *$ \\
Late dry season & -1.24 & 1.21 & 60.31 & -5.80 & $0.001 * * *$ \\
\hline
\end{tabular}

SM.III Table B. LMM: intake of crude protein per sex and season stages.

\begin{tabular}{llllll}
\hline Fixed effects & Estimate & Std. Error & df & t value & $\operatorname{Pr}(>|\mathbf{z}|)$ \\
\hline (Intercept) & 2.53 & 0.10 & 26.05 & 24.32 & 0.001 \\
Males & -0.22 & 0.08 & 66.49 & -2.72 & $0.008 * *$ \\
Early dry season & $-0-58$ & 0.10 & 60.29 & -5.52 & $0.001 * * *$ \\
Early wet season & -0.50 & 0.10 & 60.29 & -4.83 & $0.001 * * *$ \\
Late dry season & -0.45 & 0.10 & 60.29 & -4.24 & $0.001 * * *$ \\
\hline
\end{tabular}

SM.III Table C. LMM: intake of fiber per sex and season stages.

\begin{tabular}{llllll}
\hline Fixed effects & Estimate & Std. Error & df & t value & $\operatorname{Pr}(>|\mathbf{z}|)$ \\
\hline (Intercept) & 4.52 & 0.18 & 29.62 & 25.25 & 0.001 \\
Males & -0.33 & 0.14 & 66.82 & -2.27 & $0.03 *$ \\
Early dry season & -1.18 & 0.18 & 60.36 & -6.25 & $0.001 * * *$ \\
Early wet season & -1.15 & 0.19 & 60.36 & -6.12 & $0.001 * * *$ \\
Late dry season & -1.07 & 0.19 & 60.36 & -5.70 & $0.001 * * *$ \\
\hline
\end{tabular}


SM.IV Table A. LMM: the intake of non-structural carbohydrates of reproductive females $(\mathrm{N}=7$ females) during reproductive stages.

\begin{tabular}{|c|c|c|c|c|}
\hline Fixed effects & Estimate & Std. Error & t value & $\operatorname{Pr}(>|z|)$ \\
\hline (Intercept) & 5.38 & 0.25 & 19.34 & 0.001 \\
\hline Early lactation & -0.92 & 0.30 & 18.00 & $0.006 * *$ \\
\hline Early pregnancy & -1.05 & 0.30 & 18.00 & $0.002 * *$ \\
\hline Late pregnancy & -1.10 & 0.30 & 18.00 & $0.001 * *$ \\
\hline
\end{tabular}

SM.IV Table B. LMM: the intake of crude protein of reproductive females ( $\mathrm{N}=7$ females) during reproductive stages.

\begin{tabular}{|c|c|c|c|c|c|}
\hline Fixed effects & Estimate & Std. Error & df & t value & $\overline{\operatorname{Pr}(>|z|)}$ \\
\hline (Intercept) & 2.64 & 0.13 & 21.00 & & 0.001 \\
\hline Early lactation & -0.34 & 0.17 & 18.00 & & 0.058 . \\
\hline Early pregnancy & -0.48 & 0.17 & 18.00 & & $0.01 *$ \\
\hline Late pregnancy & -0.50 & 0.17 & 18.00 & & $0.008 * *$ \\
\hline
\end{tabular}

SM.IV Table B. LMM: the intake of fiber of reproductive females ( $\mathrm{N}=7$ males) during reproductive stages.

\begin{tabular}{|c|c|c|c|c|c|}
\hline Fixed effects & Estimate & Std. Error & df & t value & $\operatorname{Pr}(>|z|)$ \\
\hline (Intercept) & 4.56 & 0.20 & 19.69 & & 0.001 \\
\hline Early lactation & -0.76 & 0.24 & 18.00 & & $0.006 * *$ \\
\hline Early pregnancy & -0.87 & 0.24 & 18.00 & & $0.002 * *$ \\
\hline Late pregnancy & -0.76 & 0.24 & 18.00 & & $0.006 * *$ \\
\hline
\end{tabular}

SM.V 
SM.V Table A. LMM: intake of non-structural carbohydrates between males ( $N=9$ males) and lactating females ( $\mathrm{N}=7$ females).

\begin{tabular}{llllll}
\hline Fixed effects & Estimate & Std. Error & df & t value & $\operatorname{Pr}(>|\mathbf{z}|)$ \\
\hline (Intercept) & 4.97 & 0.19 & 17.44 & 25.52 & 0.001 \\
Males & -0.71 & 0.24 & 29.73 & -2.93 & $0.006 * *$ \\
\hline
\end{tabular}

SM.V Table B. LMM: intake of crude protein between males ( $\mathrm{N}=9$ males) and lactating females $(\mathrm{N}=7$ females $)$.

\begin{tabular}{llllll}
\hline Fixed effects & Estimate & Std. Error & df & t value & $\operatorname{Pr}(>|\mathbf{z}|)$ \\
\hline (Intercept) & 2.46 & 0.09 & 15.38 & 27.83 & 0.001 \\
Males & -0.35 & 0.11 & 29.37 & -3.27 & $0.002 * *$ \\
\hline
\end{tabular}

SM.V Table C. LMM: intake of fiber (NDF) between males ( $\mathrm{N}=9$ males) and lactating females $(\mathrm{N}=7$ females $)$.

\begin{tabular}{llllll}
\hline Fixed effects & Estimate & Std. Error & df & t value & $\operatorname{Pr}(>|\mathbf{z}|)$ \\
\hline (Intercept) & 4.17 & 0.16 & 18.75 & 26.00 & 0.001 \\
Males & -0.58 & 0.21 & 29.85 & -2.79 & $0.009 * *$ \\
\hline
\end{tabular}




\section{GENERAL DISCUSSION}

In this section I will give a brief summary of the main results of each of my chapters. I will also discuss the use of different methods for the investigation of participation and outcome, and I will integrate some of the most relevant results of my dissertation in more detail.

\section{Brief summary of main findings}

\section{Chapter 1}

I investigated the factors that influence the participation in group encounters. I used data from empirical observations of direct encounters for the analyses in this chapter. My results showed no difference in the probability of participation between sexes. Dominant individuals participated more often than subordinates. The number of opponents active in the encounter was the main factor influencing the participation of both sexes in group encounters. The presence of free-riders was common, with males free-riding according to social status, and females according to the presence of dependent infants. The results also indicated a dynamic aspect of participation that followed the escalation of encounters: encounters with long duration had more participants than shorter ones and the number of participants in one group increased in response to the number of participants in the opponent group.

\section{Chapter 2}

I investigated the effect of numerical advantage and location of the encounter in the chances of winning a group encounter. I used data from GPS loggers for the analyses in this chapter. The results show that rather than the numerical advantage, the location of the encounter, in terms of proximity to intensively used areas, was the main predictor for the outcome. In this chapter I also investigated the short and long-term costs of losing an encounter. In this study short-term costs referred to the alteration in travelling patterns (distance, speed and sinuosity) that potentially increase the energy spent by losers after defeat. Long-term costs referred to the impossibility to use the encounter area after defeat. According to my results, sifakas paid 
short-term costs instead of long ones. Therefore, losers used the encounter area less often than winners in the month after the encounter.

\section{Chapter 3}

I investigated sex and seasonal differences in diet and nutritional intake in sifakas. I also explored the impact of seasonality in different reproductive stages of females, and compared the diet of females in each of these reproductive stages with the diet of males. In this study I showed that seasonality had a negative impact on the nutritional intake of males and females concerning the intake of crude proteins, non-structural carbohydrates, and fibers. As expected, females had a higher intake of all macronutrients than males during lactation.

\section{Distinguished methods for the investigation of participation and outcome in group encounters}

The understanding of how gregarious animals achieve collective action has been a main question in the study of intergroup relationships. However, because intergroup encounters are considerably rare and difficult to be observed in the wild, the knowledge in this topic is still limited, and often based on small sample sizes. The recent implementation of technologies such as playback experiments and radio telemetry in studies on intergroup relationships have been changing considerably the research in the field, providing new opportunities to investigate some critical questions that were logistically not addressable before (Kitchen and Beehner 2007; Crofoot and Wrangham 2010).

The simulation of group encounters with the use of playback experiments can for instance provide information on potential individual participation in group defense. Wilson and collaborators (2001) used this technique to show that chimpanzees rely on numerical advantage in order to decide their participation in group encounters. Moreover, this method has been used also to investigate the factors that influence individual participation, such as the presence of dependent infants (McComb et al. 1994; Kitchen et al. 2004). Similarly, the use of radio telemetry has been very promising in the study of intergroup relationships. This approach can provide information hard to obtain otherwise, including details about the 
specific location of encounters, and the simultaneous access of the patterns of home range use in multiple groups.

Despite the many advantages, the use of these technologies has some limitations. The individual participation in group defense inferred from playback experiments has to be taken with some caution, since the response to vocal stimuli does not necessarily imply an active participation in an actual encounter. Therefore, the probability of participation revealed by playback experiments can in fact differ from what is observed in actual encounters, since the risks involved in vocal contests are lower than the ones in encounters in which the groups are in closer proximity and in visual contact with the opponents. For example, in chimpanzees (Pan troglodytes), females are known as "vocal helpers" since they join in vocal contests against other groups, but they rarely participate in actual encounters (Williams et al. 2004).

Although radio telemetry provides detailed information at the spatial level, it does not allow the inference of individual participation in encounters between groups. For instance, one of the possible hypotheses to explain the lack of effect of numerical advantage in the outcome of group encounters is the presence of free-riders (Crofoot et al. 2008). In this sense, the actual number of participants would be a better proxy for the power of a group and therefore a better predictor for the chances of a positive outcome. Nevertheless, direct observation of encounters is necessary to test the effect of the number of participants in the outcome, information that radio telemetry cannot provide.

Thus, in order to take advantage of the various strengths of different methods and to be able to investigate intergroup encounters at both the group and the individual level, in the present study I combined two methods: radio telemetry and direct observations. I used radio telemetry to explore the intergroup encounters at the group level and to acquire detailed information about the location of the encounters and its potential influence in the outcome. I also used the empirical approach of direct observations to investigate intergroup encounters at the individual level. This method provided the chance of investigating the effect of individual characteristics (e.g., sex, age, rank) on the probability of participating in actual group encounters. Another important difference between the two approaches was the overall sample size: while the empirical approach resulted in the observation of 71 direct encounters, radio telemetry allowed for a much larger sample size, including 624 encounters inferred from GPS data. 


\section{The presence of free-riders and the numerical odds in group encounters}

The overlap between the two main aspects of intergroup encounters, participation and outcome, is evident and intuitive. Groups in which individuals are collaborative with each other have higher chances to succeed in encounters with other groups (Hölldobler 1981; Cheney 1987; Mosser and Packer 2009; Bonanni et al. 2010). Additionally, larger groups have more potential participants than smaller ones, and thereby more chances of winning encounters (Black and Owen 1989; McComb et al. 1994; Wilson et al. 2001a; Nunn and Deaner 2004; Benson-Amram et al. 2011; Markham et al. 2012). However, if there is a connection between the participation and the chances of winning an encounter, then why is cooperation among individuals usually affected by collective action problems? And why does numerical advantage not necessarily guarantee the victory of large groups over smaller ones?

The variability in individual participation is mainly connected to individual characteristics, such as sex, age, rank, physical condition, body mass, and previous experiences. These individual characteristics influence the balance between costs and benefits for each group member in each encounter. As a consequence, for some individuals the encounter can bring more costs than benefits, and the option of free-riding can be taken (Nunn and Deaner 2004; Cords 2007). For instance, males and females have different interests in the outcome of encounters, since males' reproductive success is mainly affected by the availability of mating opportunities, while females are more affected by food availability (Trivers 1972). Based on the nature of encounters and the disputed resource, one of the sexes can have higher motivation in participating than the other (Wrangham 1980; reviewed in Fashing 2001).

The difficulties in cooperation within groups that usually lead to collective action problem can vary with group size, tending to be more accentuated in large groups. This is because large groups offer more opportunities for free-riding than smaller ones (Nunn 2000; Nunn and Deaner 2004; Bonanni et al. 2010). Additionally, the need to be collaborative might be more extreme in small groups, since they are in principle less powerful than larger ones (Nunn 2000; Bonanni et al. 2010). 
In this study, I investigated the role of numerical odds in participation and outcome of group encounters, and how sifakas estimate the power of opponent groups. Despite the fact that sifakas live in relatively small group size (average six individuals), there were free-riders in the majority of encounters observed in my study. It is likely that the unbalanced access to resources that follows the social status of each individual leads to a high incidence of freeriding (Kappeler et al. 2009). In sifakas, dominants of both sexes have higher access to resources than subordinates (Richard and Nicoll 1987; Kappeler and Schäffler 2008; Mass et al. 2009), and for that reason they are expected to have higher interest in participating in disputes with other groups in comparison to subordinates. The presence of free-riders in relatively small groups was also observed in howler monkeys (Allouatta pigra): similarly to sifakas they have unbalanced access to resources according to individual social status, which was the factor suggested as the cause for free-riding (van Belle et al. 2014).

Other studies have previously showed that the presence of free-riders decreases the power of large groups, and it is one of the factors why groups with numerical advantage are not necessarily the winners of encounters (Nunn and Deaner 2004; Crofoot and Gilby 2012; van Belle et al. 2014). In my study, advantage in total group size did not affect the chances of participation and winning an encounter. On the contrary, I could see that the number of freeriders increased with the size of the group. Interestingly, I observed that the participation of males and females was affected by the effective size of the opponent group (number of participants in the encounter without the free-riders).

Despite the fact I could not infer individual participation using data from GPS loggers in chapter 2, the results from the empirical observations in chapter 1 showed the presence of free-riders, which is likely one of the reasons for the lack of effect of numerical advantage in the outcome of encounters. For instance, in a study in white-faced capuchins (Cebus capucinus), Crofoot and collaborators (2008) also did not find the effect of total group size on the outcome in group encounters. Similarly to my study, the number of actual participants in the encounter is a better predictor for the power of a group and its chances of winning a encounter (Crofoot et al. 2008).

Gregarious animals often use numerical asymmetry in power (the information of relative number of individuals between their own group and their opponents) to infer the chances of winning the encounter (Parker 1974). The lack of effect of numerical advantage 
based on total group size and the strong influence of effective group size observed in my study indicates that sifakas estimated their chances of winning and the power of opponents based on the number of actual participants in the encounter (effective group size). In contrast to total group size, effective group size can be more variable across encounters. This variance in the number of participants affects the anticipated estimation of the opponent's power, which brings unpredictability to the costs of the encounters. Moreover, if the outcome of encounters is influenced by effective group size, then the relations of dominance between groups tend to vary across encounters. The impact of variability in numerical odds in intergroup relationships can be observed in fission-fusion societies, in which the number of individuals within subgroups is variable, and individuals cannot estimate the power of their opponents before an interaction (Wilson et al. 2001; Boesch et al. 2008).

The power of opponents can also change within the encounter itself, since the number of participants can increase with the escalation of the encounters. According to theoretical studies based on the sequential assessment game (Enquist and Leimar 1983; Leimar and Enquist 1984), agonistic encounters involve a series of interactions in which individuals attempt to assess their opponent's power (Payne 1998). The costs in terms of energy and time allocated in the contest tend to be lower at the beginning, and as the encounter proceeds, it progressively gets more costly (Jennions and Backwell 1996). In the case of gregarious animals, the escalation of encounters can have two consequences: 1) more individuals join the encounter as the costs of the dispute increase to be able to overcome the power of the opponent, or 2) individuals retreat when the costs of the encounter increase, since the compensation based on the value of the resource disputed loses relevance.

The dynamic aspect in the participation pointed in this study refers to the fact that not all individuals start participating in an encounter at the same time. In that sense, the final number of participants accounted at the end is probably the result of a "buildup" in participation that occurs in response to the progressive escalation of the encounter. Based on the results of my work (chapter 2), two main aspects indicate this dynamic situation during intergroup encounters (Appendix A):

1) Long encounters had higher number of participants than shorter ones. This indicates the adoption of a "waiting strategy" in which some group members waited to decide their participation according to the escalation of the encounter in terms of increase in 
duration or the effective size of the opponent. Long encounters are more demanding than shorter ones in terms of time and energy (Maynard Smith and Parker 1976). The increase in the duration of an encounter is usually connected to two factors: 1) the high interest of both groups in the resource in contest, and 2) the lack of asymmetries in the power of groups (Enquist and Leimar 1987; Jennions and Backwell 1996). A study on wild dogs for instance showed a correlation between individual participation and the duration of encounters, demonstrating that participation increased with the difficulties of the fight (Bonanni et al. 2010).

2) The effective group size of one group increased as a response to the effective group size of their opponents. Individuals joined the encounter in response to the increase in costs and difficulties to win, as more opponents were joining. In addition to the duration patterns I discussed above, these results suggest the presence of a dynamic aspect in the decision in joining group encounters.

\section{High participation of females}

Another interesting aspect in my study was the fact that females participated as often as males in group encounters. This pattern is quite rare in primates since, in the majority of the species, males are the main participants in group encounters (Table 6 available in chapter 1). The higher participation of males observed in many species of primates is mainly connected to two aspects: mating competition and physical power. In sifakas, however, there is no strong mating competition and males and females have similar size and physical power (Kappeler 1991; Kappeler and Schäffler 2008; Mass et al. 2009). The high participation of sifaka females can then be attributed to the combination of multiple factors, including food defense, philopatry, female dominance, lack of sexual dimorphism, leadership in group movements, and the relatively small group size.

According to the socioecological model, philopatric females participate in disputes between groups when food resources are economically defendable in terms of quality and distribution (Wrangham 1980) or availability (Isbell 1991). Therefore, the investigation of the patterns of availability and distribution of food is crucial to establish any further 
connection between intergroup competition and food. Taking into account the impact of food availability on the reproductive success of females (Trivers 1972; Wrangham 1980), I investigated in detail the impact of the seasonal fluctuation in availability of food on the diet of males and females, in order to check if food could be a resource of which groups, in particular females, would compete for due to its high economic value during periods of low availability (Isbell 1991).

\section{Food defense}

Studies on intergroup relationships often present the participation of females in group defense as the main predictor to relate the nature of the encounter to food defense (reviewed in Fashing 2001). An additional indication for food defense has been attributed to the fact that encounters often happen when individuals are feeding, or in proximity to important feeding resources (for instance in van Belle 2015). However, this interpretation requires caution. First of all, food defense can occur in group encounters without the participation of females, since males can also directly defend food resources as an indirect form of mating defense (Emlen and Oring 1977). Second, taking into account that feeding is a common behavior, there is a high chance that group encounters are observed when individuals are feeding. Thus, the interpretation of the nature of encounters can be very challenging (Harris 2007; Hanya and Chapman 2012).

Madagascar has a highly seasonal climate that brings extreme variance in the availability and quality of food (reviewed in Wright 1999). In fact, many lemur characteristics, including female dominance and the lack of sexual dimorphism, have been attributed to be an adaptation to such a harsh environment (Jolly 1966; Wright 1999). Since females, particularly in mammals, are under higher energetic pressure than males due to reproductive costs, it is expected that they are highly affected by variance in food availability (Trivers 1972; Wrangham 1980).

Generally, sifakas include a large amount of leaves in their diet (Richard 1974). Folivores are expected to have lower intergroup competition for food than frugivores, because leaves are not considered an economically defendable resource (Wrangham 1980). However, the scarcity of resources can increase their economic value (Isbell 1991). Therefore, in a deciduous forest such as the one where I conducted the present study, $90 \%$ of 
trees lose their leaves during the dry season (Sorg and Rohner 1996), and, in these conditions, food can be a limiting resource even for a folivore primate.

Studies already show that the extreme seasonality present in Madagascar has negative impact in the diet of sifakas (Richard 1974; Hemingway 1999; Norscia et al. 2006; Yamashita 2008; Simmen et al. 2012; Irwin et al. 2014). However, this seasonality is highly variable across years, for instance in terms of production of flowers and fruits that can follow asynchronous or alternate year cycles (reviewed in Wright 1999). I investigated in detail the seasonal patterns of availability and quality of food in Kirindy (chapter 3 ) to see if food was a limiting resource for female sifakas during my study period and it could justify their high participation in group encounters. I also took into account the differences of diet across reproductive stages in order to explore how females cope with the variation in food availability and the demands of reproduction.

My results show that seasonality had a considerable impact on the diet of both sexes. However, overall, females had a better diet than males, with a higher intake of macronutrients, especially during lactation. Because males and females have similar body size, the differences in diet quality observed are likely connected to the high energetic demands of reproduction for females. Moreover, according to my results, food was a limiting resource for sifakas in Kirindy Forest. Therefore, there was potential for food competition between groups, and it is likely that the high participation of females observed in my study is connected to disputes over food.

Given the absence of sexual dimorphism, females are physically as powerful as males and this can be an incentive for the participation of females in group encounters. Indeed, in the presence of high levels of sexual dimorphism, individuals of the larger sex are expected to be the main participants in group defense (Packer and Pusey 1979). For instance in baboons, the high degree of sexual dimorphism in favor of males, among other factors, has been attributed as a cause for the extreme low degree of participation of females in group encounters (Altmann et al. 1993). 


\section{Conclusion}

Consistent with the findings of other studies on gregarious animals, I demonstrated that despite the fact that groups are social units and often appear to possess a single mind, individual differences affected collective action and therefore the workability of groups as units. As with the majority of primates, the fact that sifakas live in complex, hierarchical and heterogeneous groups contributes to the diversity in individual differences that can lead to collective action problems. In fact, the disproportion in individual contribution based on the access to the benefits of group living is widespread in most groups of animals from different taxa and under different levels of complexity. From the collective movements of shoals of fish or flocks of birds, to the time spent for group vigilance, to the participation in intergroup encounters, collective behaviors are the result of the action of few individuals that will lead, protect and/or defend their groups according to the profitability of those actions.

Therefore, the inclusion of individual characteristics and differences in the investigation of gregarious animals is critical for the understanding of collective behaviors. In addition to the fact that group competition can affect the fitness of all members of the groups involved, the understanding of how group living animals coordinate their actions is fundamental for our comprehension of sociality. 


\section{APPENDIX: GENERAL DICUSSION}

Appendix A. Individual participation in group encounters. 2a) relation between the number of active individuals in the focal group and the duration of the encounter. The number of participants increased with the duration of the encounter. $2 \mathrm{~b}$ ) relation between the number of individuals active in the focal group and the number of individuals active in the opponent group. The number of participants in one group tends to increase with the number of participants in the opponent group.

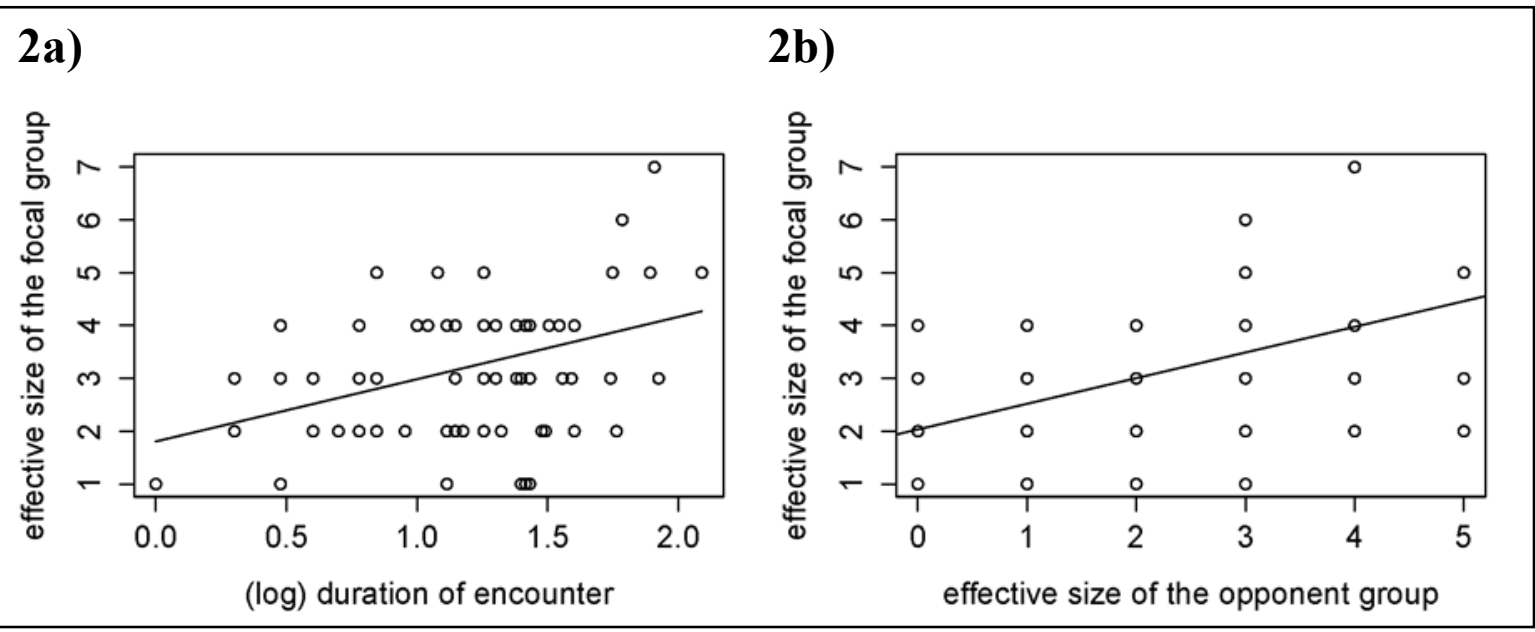




\section{REFERENCES}

Altmann J (1974) Observational study of behavior: sampling methods. Behaviour 49:227267.

Altmann J, Schoeller D, Altmann SA, et al (1993) Body size and fatness of free-living baboons reflect food availability and activity levels. Am J Primatol 30:148-161.

Altmann SA (2009) Fallback foods, eclectic omnivores, and the packaging problem. Am J Phys Anthropol 140:615-29.

Armitage KB (1988) Resources and social organization of ground-dwelling squirrels. In: Slobodchikoff CN (ed) The ecology of social behavior. Academic Press Inc, San Diego, pp 131-155.

Arnott G, Elwood RW (2008) Information gathering and decision making about resource value in animal contests. Anim Behav 76:529-542.

Baayen RH, Davidson DJ, Bates DM (2008) Mixed-effects modeling with crossed random effects for subjects and items. J Mem Lang 59:390-412.

Bartlett TQ (2003) Intragroup and intergroup social interactions in white-handed gibbons. Int J Primatol 24:239-259.

Bates D, Maechler M, Bolker B, Walker S (2014) lme4: Linear mixed-effects models using Eigen and S4.

Bauchop T, Martucci RW (1968) Ruminant-like digestion of the langur monkey. Science 161:698-700.

Benadi G, Fichtel C, Kappeler P (2008) Intergroup relations and home range use in verreaux's sifaka (Propithecus verreauxi). Am J Primatol 70:956-965. 
Benson-Amram S, Heinen VK, Dryer SL, Holekamp KE (2011) Numerical assessment and individual call discrimination by wild spotted hyaenas, Crocuta crocuta. Anim Behav $82: 743-752$.

Bercovitch FB (1987) Female Weight and reproductive condition in a population of olive baboons (Papio anubis). Am J Primatol 12:189-195.

Black JM, Owen M (1989) Agonistic behaviour in barnacle goose flocks: assessment, investment and reproductive success. Anim Behav 37:199-209.

Boesch C, Boesch H (1989) Hunting behavior of wild chimpanzees in the Taï national park. Am J Phys Anthropol 78:547-573.

Boesch C, Crockford C, Herbinger I, et al (2008) Intergroup conflicts among chimpanzees in Tai National Park: Lethal violence and the female perspective. Am J Primatol 70:519532.

Boinski S (1988) Sex differences in the foraging behavior of squirrel monkeys in a seasonal habitat. Behav Ecol Sociobiol 23:177-186.

Bonanni R, Valsecchi P, Natoli E (2010) Pattern of individual participation and cheating in conflicts between groups of free-ranging dogs. Anim Behav 79:957-968.

Borries C (1997) Infanticide in seasonally breeding multimale groups of hanuman langurs (Presbytis entellus) in Ramnagar (south Nepal). Behav Ecol Sociobiol 41:139-150.

Borries C (1993) Ecology of female social relationships: hanuman langurs (Presbytis entellus) and the van Schaik model. Folia Primatol 61:21-30.

Boydston EE, Morelli TL, Holekamp KE (2001) Sex differences in territorial behavior exhibited by the spotted hyena (Hyaenidae, Crocuta crocuta). Ethology 107:369-385.

Brockman DK (1999) Reproductive behavior of female Propithecus verreauxi at Beza Mahafaly, Madagascar. Int J Primatol 20:375-398. 
Brockman DK, Whitten PL, Richard AF, Schneider A (1998) Reproduction in free-ranging male Propithecus verreauxi: the hormonal correlates of mating and aggression. Am J Phys Anthropol 105:137-151.

Brown M (2011) Intergroup encounters in grey-cheeked mangabeys (Lophocebus albigena) and redtail monkeys (Cercopithecus ascanius): form and function. $\mathrm{PhD}$ thesis, Columbia University.

Brown M (2013) Food and range defence in group-living primates. Anim Behav 85:807-816.

Campbell JL, Eisemann JH, Glander KE, Crissey SD (1999) Intake, digestibility, and passage of a commercially designed diet by two Propithecus species. Am J Primatol 48:237-246.

Cant MA, Otali E, Mwanguhya F (2002) Fighting and mating between groups in a cooperatively breeding mammal, the banded mongoose. Ethology 108:541-555.

Caro TM (1989) Determinants of asociality in felids. In: Standen V, Foley RA (eds) Comparative socioecology: the behavioural ecology of humans and other mammals. Blackwell Scientific Publications, Oxford, pp 41-74.

Carrai V, Borgognini-Tarli SM, Huffman MA, Bardi M (2003) Increase in tannin consumption by sifaka (Propithecus verreauxi verreauxi) females during the birth season: a case for self-medication in prosimians? Primates 44:61-66.

Chapman CA, Chapman LJ, Rode KD, et al (2003) Variation in the nutritional value of primate foods: among trees, time periods, and areas. Int J Primatol 24:317-333.

Cheney DL (1987) Interactions and relations between groups. In: Smuts BB, Cheney DL, Seyfarth RM, et al. (eds) Primate Societies. University of Chicago Press, Chicago, pp $267-281$.

Cheney DL (1981) Intergroup encounters among free-ranging vervet monkeys. Folia Primatol 35:124-146. 
Cheney DL (1992) Intragroup cohesion and intergroup hostility: the relation between grooming distributions and intergroup competition among female primates. Behav Ecol 3:334-345.

Cheney DL, Seyfarth RM (1987) The influence of intergroup competition on the survival and reproduction of female vervet monkeys. Behav Ecol Sociobiol 21:375-386.

Coelho AM (1974) Socio-bioenergetics and sexual dimorphism in primates. Primates 15:262-269.

Cooper M, Aureli F, Singh M (2004) Between-group encounters among bonnet macaques (Macaca radiata). Behav Ecol Sociobiol 56:217-227.

Cords M (2007) Variable participation in the defense of communal feeding territories by blue monkeys in the Kakamega Forest, Kenya. Behaviour 144:1537-1550.

Cowlishaw G (1995) Behavioural patterns in baboon group encounters: the role of resource competition and male reproductive strategies. Behaviour 132: 75-86.

Crofoot M (2007) Mating and feeding competition in white-faced capuchins (Cebus capucinus): the importance of short- and long-term strategies. Behaviour 144:14731495.

Crofoot MC (2013) The cost of defeat: capuchin groups travel further, faster and later after losing conflicts with neighbors. Am J Phys Anthropol 152:79-85.

Crofoot MC, Gilby IC (2012) Cheating monkeys undermine group strength in enemy territory. Proc Natl Acad Sci USA 109:501-5.

Crofoot MC, Gilby IC, Wikelski MC, Kays RW (2008) Interaction location outweighs the competitive advantage of numerical superiority in Cebus capucinus intergroup contests. Proc Natl Acad Sci USA 105:577-81. 
Crofoot MC, Wrangham RW (2010) Intergroup aggression in primates and humans : the case for a unified theory. In: Kappeler PM, Silk JB (eds) Mind the gap: tracing the origins of human universals. Springer, New York, pp 175-196.

Dausmann KH (2014) Flexible patterns in energy savings: heterothermy in primates. J Zool 292:101-111.

Davies CR, Ayres JM, Dye C, Deane LM (1991) Malaria infection rate of Amazonian primates increases with body weight and group size. Funct Ecol 5:655-662.

Decanini DP, Macedo RH (2008) Sociality in Callithrix penicillata: II. Individual strategies during intergroup encounters. Int J Primatol 29:627-639.

Dewar RE, Richard AF (2007) Evolution in the hypervariable environment of Madagascar. Proc Natl Acad Sci USA 104:13723-13727.

Doake S, Elwood RW (2011) How resource quality differentially affects motivation and ability to fight in hermit crabs. Proc Biol Sci 278:567-73.

Donati G, Baldi N, Morelli V, et al (2009) Proximate and ultimate determinants of cathemeral activity in brown lemurs. Anim Behav 77:317-325.

Doran D (1997) Influence of seasonality on activity patterns, feeding behavior, ranging, and grouping patterns in Tai chimpanzees. Int J 18:183-206.

Drent R, Daan S (1980) The prudent parent: energetic adjustments in avian breeding. Ardea 68:225-252.

Dugatkin LA. (1998) Breaking up fights between others: a model of intervention behaviour. Proc R Soc B Biol Sci 265:433-437.

Dunbar RIM (1988) Primate social systems. Croom Helm, London.

Dunham AE (2008) Battle of the sexes: cost asymmetry explains female dominance in lemurs. Anim Behav 76:1435-1439. 
Emlen ST, Oring LW (1977) Ecology, sexual selection, and the evolution of mating systems. Science 197:215-223.

Enquist M, Leimar O (1983) Evolution of fighting behaviour: decision rules and assessment of relative strength. J Theor Biol 102:387-410.

Enquist M, Leimar O (1987) Evolution of fighting behaviour: the effect of variation in resource value. J Theor Biol 127:187-205.

Erhart EM, Overdorff DJ (1998) Infanticide in Propithecus diadema edwardsi: an evaluation of the sexual selection hypothesis. Int J Primatol 19:73-81.

Erkert HG, Kappeler PM (2004) Arrived in the light: diel and seasonal activity patterns in wild verreaux's sifakas (Propithecus v. verreauxi; Primates: Indriidae). Behav Ecol Sociobiol 57:174-186.

Esteban J, Raz D (2001) Collective action and the group size paradox. Am Polit Sci Rev 95:663-672.

Fashing P (2001) Male and female strategies during intergroup encounters in guerezas (Colobus guereza): evidence for resource defense mediated through males and a comparison with other primates. Behav Ecol Sociobiol 50:219-230.

Fichtel C, Kappeler PM (2002) Anti-predator behavior of group-living Malagasy primates: mixed evidence for a referential alarm call system. Behav Ecol Sociobiol 51:262-275.

Fichtel C, Van Schaik CP (2006) Semantic differences in sifaka (Propithecus verreauxi) alarm calls: a reflection of genetic or cultural variants? Ethology 112:839-849.

Foley WJ, McIlwee A, Lawler I, et al (1998) Ecological applications of near infrared reflectance spectroscopy - a tool for rapid, cost-effective prediction of the composition of plant and animal tissues and aspects of animal performance. Oecologia 116:293-305. 
Fournier LA (1974) Un método cuantitativo para la medición de caracteristicas fenológicas en árboles. Turrialba 24:422-423.

Furrer RD, Kyabulima S, Willems EP, et al (2011) Location and group size influence decisions in simulated intergroup encounters in banded mongooses. Behav Ecol 22:493500.

Ganzhorn J (2002) Distribution of a folivorous lemur in relation to seasonally varying food resources: integrating quantitative and qualitative aspects of food characteristics. Oecologia 131:427-435.

Ganzhorn JU, Arrigo-Nelson S, Boinski S, et al (2009) Possible fruit protein effects on primate communities in Madagascar and the neotropics. PLoS One 4:e8253.

Ganzhorn JU, Klaus S, Ortmann S, Schmid J (2003) Adaptations to seasonality: some primate and nonprimate examples. In: Kappeler PM, Pereira ME (eds) Primate life histories and socioecology. Chicago University Press, Chicago, pp 132-144

Garber PA, Pruetz JD, Isaacson J (1993) Patterns of range use, range defense, and intergroup spacing in moustached tamarin monkeys (Saguinus mystax). Primates 34:11-25.

Gese EM (2001) Territorial defense by coyotes (Canis latrans) in Yellowstone national park, Wyoming: who, how, where, when, and why. Can J Zool 79:980-987.

Gittleman JL, Thompson SD (1988) Energy allocation in mammalian reproduction. Integr Comp Biol 28:863-875.

Gursky S (2000) Effect of seasonality on the behavior of an insectivorous primate, Tarsius spectrum. Int J Primatol 21:477-495.

Haley MP (1994) Resource-holding power asymmetries, the prior residence effect, and reproductive payoffs in male northern elephant seal fights. Behav Ecol Sociobiol $34: 427-434$. 
Hanya G, Chapman CA (2012) Linking feeding ecology and population abundance: a review of food resource limitation on primates. Ecol Res 28:183-190.

Hardin G (1968) The Tragedy of the Commons. Science (80- ) 162:1243-1248.

Harris T (2007) Testing mate, resource and infant defence functions of intergroup aggression in non-human primates: issues and methodology. Behaviour 144:1521-1535.

Harris TR (2005) Within- and among-male variation in roaring by black and white colobus monkeys (Colobus guereza): what does it reveal about function? Behaviour 143:197218.

Harris TR (2010) Multiple resource values and fighting ability measures influence intergroup conflict in guerezas (Colobus guereza). Anim Behav 79:89-98.

Harrison MJS (1983) Age and sex differences in the diet and feeding strategies of the green monkey, Cercopithecus sabaeus. Anim Behav 31:969-977.

Heinsohn R, Packer C (1995) Complex cooperative strategies in group-territorial African lions. Science 269:1260-1261.

Hemingway CA (1999) Time budgets and foraging in a Malagasy primate: do sex differences reflect reproductive condition and female dominance? Behav Ecol Sociobiol 45:311322.

Hill CM (1994) The role of female diana monkeys, Cercopithecus diana, in territorial defence. Anim Behav 47:425-431.

Hill WCO (1953) Primates: comparative anatomy and taxonomy, Vol. 8. University Press.

Hinde RA (1956) The biological significance of the territories of birds. Ibis 107:466-492.

Hölldobler B (1981) Foraging and spatiotemporal territories in the honey ant Myrmecocystus mimicus Wheeler (Hymenoptera: Formicidae). Behav Ecol Sociobiol 9:301-314. 
Hölldobler B, Wilson EO (1990) The Ants. Harvard University Press

Hoogland JL (1979) Aggression, ectoparasitism, and other possible costs of prairie dog (Sciuridae, Cynomys spp.) coloniality. Behaviour 69:1-35.

Hoogland JL (1985) Infanticide in prairie dogs: lactating females kill offspring of close kin. Science 230:1037-1040.

Horiuchi S (2008) Horiuchi S (2008) High population density promotes the evolution of ownership. Ecol Res 23:551-556.

Irwin MT, Raharison JL, Raubenheimer D, et al (2014) Nutritional correlates of the "lean season": effects of seasonality and frugivory on the nutritional ecology of diademed sifakas. Am J Phys Anthropol 153:78-91.

Isbell LA (1991) Contest and scramble competition: patterns of female aggression and ranging behavior among primates. Behav Ecol 2:143-155.

Janson CH (1985) Aggressive competition and individual food consumption in wild brown capuchin monkeys (Cebus apella). Behav Ecol Sociobiol 18:125-138.

Janson CH, Verdolin J (2005) Seasonality of primate births in relation to climate. In: Brockman DK, van Schaik CP (eds) Seasonality in primates: studies of living and extinct human and non-human primates. Cambridge University Press, New York, pp $307-350$.

Janson CH, Boinski S (1992) Morphological and behavioral adaptations for foraging in generalist primates: the case of the cebines. Am J Phys Anthropol 88:483-98.

Janson CH, van Schaik CP (1988) Recognizing the many faces of primate food competition: methods. Behaviour 105:165-186.

Jennions MD, Backwell PRY (1996) Residency and size affect fight duration and outcome in the fiddler crab Uca annulipes. Biol J Linn Soc 57:293-306. 
Jolly A (1984) The puzzle of female feeding priority. In: Small M (ed) Female primates: studies by women primatologists. A.R.Liss, New York, pp 197-215.

Jolly A (1966) Lemur behavior. Chicago press, Chicago.

Jolly A, Pride E (1999) Troop histories and range inertia of Lemur catta at Berenty, Madagascar: a 33-year perspective. Int J Primatol 20:359-373.

Jolly A, Rasamimanana HR, Kinnaird MF, et al (1993) Territoriality in Lemur catta groups during the birth season at Berenty Madagascar. In: Kappeler PM, Ganzhorn JU (eds) Lemur social systems and their ecological basis. Springer, New York, pp 85-109

Jolly A, Dobson A, Rasamimanana H, et al (2002) Demography of Lemur catta at Berenty Reserve, Madagascar: effects of troop size, habitat and rainfall. Int J Primatol 23:327353.

Kao AB, Couzin ID (2014) Decision accuracy in complex environments is often maximized by small group sizes. Proc Biol Sci 281:20133305.

Kappeler PM (1990) The evolution of sexual size dimorphism in prosimian primates. Am J Primatol 21:201-214.

Kappeler PM (1991) Patterns of sexual dimorphism in body weight among prosimian primates. Folia Primatol 57:132-146.

Kappeler PM, Fichtel C (2012) A 15-year perspective on the social organization and life history of sifaka in Kirindy Forest. In: Kappeler PM, Watts DP (eds) Long-term field studies of primates. Springer, Berlin, pp 21-45.

Kappeler PM, Mass V, Port M (2009) Even adult sex ratios in lemurs: potential costs and benefits of subordinate males in verreaux's sifaka (Propithecus verreauxi) in the Kirindy Forest. Am J Phys Anthropol 497:487-497. 
Kappeler PM, Schäffler L (2008) The lemur syndrome unresolved: extreme male reproductive skew in sifakas (Propithecus verreauxi), a sexually monomorphic primate with female dominance. Int J Primatol 62:1007-1015.

Kappeler PM, Schaik CP Van (2002) Evolution of Primate Social Systems. Int J Primatol 23:707-740.

Kelly RC (2005) The evolution of lethal intergroup violence. Proc Natl Acad Sci USA 102:15294-15298.

Key C, Ross C (1999) Sex differences in energy expenditure in non-human primates. Proc R Soc Biol Sci 266:2479-85.

Kinnaird MF (1992) Variable resource defense by the tana river crested mangabey. Behav Ecol Sociobiol 31:115-122.

Kitchen D, Beehner J (2007) Factors affecting individual participation in group-level aggression among non-human primates. Behaviour 144:1551-1581.

Kitchen D, Horwich RH, James RA (2004) Subordinate male black howler monkey (Alouatta pigra) responses to loud calls: experimental evidence for the effects of intra-group male relationships and age. Behaviour 141:703-723.

Kitchen D, Seyfarth RM, Fischer J, Cheney DL (2003) Loud calls as indicators of dominance in male baboons (Papio cynocephalus ursinus). Behav Ecol Sociobiol 53:374-384.

Kitchen DM (2004) Alpha male black howler monkey responses to loud calls: effect of numeric odds, male companion behaviour and reproductive investment. Anim Behav 67:125-139.

Kitchen DM (2006) Experimental test of female black howler monkey (Alouatta pigra) responses to loud calls from potentially infanticidal males: effects of numeric odds, vulnerable offspring, and companion behavior. Am J Phys Anthropol 131:73-83. 
Knott CD (1998) Changes in orangutan caloric intake, energy balance, and ketones in response to fluctuating fruit availability. Int J Primatol 19:1061-1079.

Korstjens AH, Nijssen EC, Noe R (2005) Intergroup relationships in western black-andwhite colobus, Colobus polykomos polykomos. Int J Primatol 26:1267-1289.

Krebs JR, Davies NB (1997) Behavioral ecology: an evolutionary approach. Blackwell, Oxford.

Kuznetsova A, Brockhoff PB, Bojesen Christensen RH (2013) lmerTest: Tests for random and fixed effects for linear mixed effect models (lmer objects of lme4 package).

Lambert JE (2007) Seasonality, fallback strategies, and natural selection: a chimpanzee and Cercopithecoid model for interpreting the evolution of the hominin diet. In: Ungar PS (ed) Evolution of the human diet: the known, the unknown, and the unknowable. Oxford University Press, Oxford, pp 324-343.

Landau HG (1951) On dominance relations and the structure of animal societies: effect of inherent characteristics. Bull Math Biophys 13:1-19.

Lee PC (1984) Early infant development and maternal care in free-ranging vervet monkeys. Primates 25:36-47.

Lee PC (1994) Social structure and evolution. In: Slate PJB, Halliday TR (eds) Behaviour and Evolution. Cambridge University Press, Cambridge, pp 266-303.

Leimar O, Enquist M (1984) Effects of asymmetries in owner-intruder conflicts. J Theor Biol 111:475-491.

Lewis RJ (2005) Sex differences in scent-marking in sifaka: Mating conflict or male services? Am J Phys Anthropol 128:389-398.

Lewis RJ, Kappeler PM (2005a) Seasonality, body condition, and timing of reproduction in Propithecus verreauxi verreauxi in the Kirindy Forest. Am J Primatol 67:347-364. 
Lewis RJ, Kappeler PM (2005b) Are Kirindy sifaka capital or income breeders? It depends. Am J Primatol 67:365-369.

Lewis RJ, Razafindrasamba SM, Tolojanahary JP (2003) Observed infanticide in a seasonal breeding prosimian (Propithecus verreauxi verreauxi) in Kirindy Forest, Madagascar. Folia Primatol 74:101-103.

Lott DF (1991) Intraspecific variation in the social systems of wild vertebrates. Cambridge University Press, Cambridge.

Macdonald DW, Carr GM (1989) Food security and the rewards of tolerance. In: Standen V, Foley RA (eds) Comparative Socioecology: the behavioural ecology of humans and other mammals. Blackwell Scientific Publications, Oxford, pp 75-99.

Majolo B, Ventura R, Koyama NF (2005) Sex, Rank and Age Differences in the Japanese Macaque (Macaca fuscata yakui) Participation in Inter-Group Encounters. Ethology $111: 455-468$.

Mares R, Young a. J, Clutton-Brock TH (2012) Individual contributions to territory defence in a cooperative breeder: weighing up the benefits and costs. Proc R Soc B Biol Sci 279:3989-3995.

Markham A, Alberts S, Altmann J (2012) Intergroup conflict: ecological predictors of winning and consequences of defeat in a wild primate population. Anim Behav 82:399403.

Marshall AJ, Boyko CM, Feilen KL, et al (2009) Defining fallback foods and assessing their importance in primate ecology and evolution. Am J Phys Anthropol 140:603-614.

Marshall AJ, Wrangham RW (2007) Evolutionary consequences of fallback foods. Int J Primatol 28:1219-1235.

Mass V, Heistermann M, Kappeler PM (2009) Mate-guarding as a male reproductive tactic in Propithecus verreauxi. Int J Primatol 30:389-409. 
Maynard Smith J, Parker GA (1976) The logic of asymmetric contests. Anim Behav 24:159175.

McCabe GM, Fedigan LM (2007) Effects of reproductive status on energy intake, ingestion rates, and dietary composition of female Cebus capucinus at Santa Rosa, Costa Rica. Int J Primatol 28:837-851.

McComb K, Packer C, Pusey A (1994) Roaring and numerical assessment in contests between groups of female lions, Panthera leo. Anim Behav 47:379-387.

Mehlman PT, Parkhill RS (1988) Intergroup interactions in wild barbary macaques (Macaca sylvanus), Ghomaran Rif mountains, Morocco. Am J Primatol 15:31-44.

Meyers DM, Wright PC (1993) Resource tracking: food availability and Propithecus seasonal variation. In: Kappeler PM, Ganzhorn JU (eds) Lemur social systems and their ecological basis. Plenum Press, New York, pp 179-192.

Milton K (1980) The foraging strategy of howler monkeys. A study in primate economies. Columbia University Press, New York.

Milton K (1998) Physiological ecology of howlers (Alouatta): energetic and digestive considerations and comparison with the Colobinae. Int J Primatol 19: 513-548.

Mitani JC, Watts DP, Amsler SJ (2010) Lethal intergroup aggression leads to territorial expansion in wild chimpanzees. Curr Biol 20:507-508.

Mitani JC, Watts DP, Lwanga JS (2002) Ecological and social correlates of chimpanzee party size and composition. In: Boesch C, Hohmann G, Marchant LF (eds) Behavioural diversity in chimpanzees and bonobos. Cambridge University Press, Cambridge, pp $102-111$.

Moler AP, Birkhead T (1993) Cuckoldry and sociality: a comparative study of birds. Am Nat 142:118-140. 
Morelli TL, Wright P, King S, Pochron S (2009) The rules of disengagement: takeovers, infanticide, and dispersal in a rainforest lemur, Propithecus edwardsi. Behaviour 146:499-523.

Mosser A, Packer C (2009) Group territoriality and the benefits of sociality in the African lion, Panthera leo. Anim Behav 78:359-370.

Nakamichi M, Koyama N (1997) Social relationships among ring-tailed lemurs (Lemur catta) in Two Free-Ranging Troops at Berenty Reserve, Madagascar. Int J Primatol 18:73-93.

Naumann C, Bassler R (1976) Die Chemische Untersuchung von Futtermitteln. VDLUFAVerlag, Darmstadt, Germany.

Nicholson AJ (1954) An outline of the dynamics of animal populations. Autralian J Zool 2:9-65.

Nievergelt CM, Mutschler T, Feistner A TC (1998) Group encounters and territoriality in wild alaotran gentle lemurs (Hapalemur griseus alaotrensis). Am J Primatol 46:251258.

Norscia I, Carrai V, Borgognini-Tarli SM (2006) Influence of dry season and food quality and quantity on behavior and feeding strategy of Propithecus verreauxi in Kirindy, Madagascar. Int J Primatol 27:1001-1022.

NRC (2003) National Research Council. Nutrient requirements of nonhuman primates. The National Academies Press, Washington, D.C.

Nunn CL (2000) Collective benefits, free-riders, and male extra-group conflict. In: Kappeler PM (ed) Primate males: causes and consequences of variation in group composition. Cambridge University Press, Cambridge, pp 192-204.

Nunn CL, Deaner RO (2004) Patterns of participation and free riding in territorial conflicts among ringtailed lemurs (Lemur catta). Behav Ecol Sociobiol 57:50-61. 
Oftedal OT (1985) Pregnancy and lactation. In: Hudson R, White R (eds) Bioenergetics of wild herbivores. CRC, Florida, pp 215-218.

Okamoto K, Matsumura S (2002) Intergroup encounters in wild moor macaques (Macaca maurus). Primates 43:119-125.

Olson M (1965) The logic of collective action: public goods and the theory of groups.

Ortmann S, Bradley B, Stolter C, Ganzhorn JU (2006) Estimating the quality and composition of wild animal diets: a critical survey of methods. In: Hohmann G, Robbins MM, Boesch C (eds) Feeding ecology in apes and other primates: ecological, physical and behavioral aspects. Cambridge University Press, Cambridge, pp 396-420.

Ostfeld RS (1990) The ecology of territoriality in small mammals. Trends Ecol Evol 5:411415.

Owen-Smith N (1977) On territoriality in ungulates and an evolutionary model. Q Rev Biol $52: 1-38$.

Packer C, Pusey AE (1979) Female aggression and male membership in troops of Japanese macaques and olive baboons. Folia Primatol 31:212-218.

Palombit RA, Seyfarth RM, Cheney DL (1997) The adaptive value of "friendships" to female baboons: experimental and observational evidence. Anim Behav 54:599-614.

Parker GA (1974) Assessment strategy and the evolution of fighting behaviour. J Theor Biol 47:223-43.

Parrish JK, Hamner WM, Prewitt CT (1997) From individuals to aggregations: unifying properties, global framework, and the holy grails of congregation. In: Parrish JK, Hamner WM (eds) Animal groups in three dimensions. Cambridge University Press, Cambridge, pp 1-13. 
Payne HFP, Lawes MJ, Henzi SP (2003) Competition and the exchange of grooming among female samango monkeys (Cercopithecus mitis erythrarchus). Behaviour 140:453-471.

Payne PR, Wheeler EF (1968) Comparative nutrition in pregnancy and lactation. Proc Nutr Soc 27:129-138.

Payne R (1998) Gradually escalating fights and displays: the cumulative assessment model. Anim Behav 56:651-662.

Perry S (1996) Intergroup encounters in wild white-faced capuchins (Cebus capucinus). Int J Primatol 17:309-330.

Peters C, O’Brien E (1994) Potential hominid plant foods from woody species in semi-arid versus sub-humid Africa. In: Chivers DJ, Langer PJ (eds) The digestive system in mammals: food and function. Cambridge University Press, Cambridge, pp 166-192.

Port M, Johnstone RA., Kappeler PM (2012) The evolution of multimale groups in verreaux's sifaka, or how to test an evolutionary demographic model. Behav Ecol 23:889-897.

Port M, Kappeler PM, Johnstone RA. (2011) Communal defense of territories and the evolution of sociality. Am Nat 178:787-800.

Pride ER (2005) Optimal group size and seasonal stress in ring-tailed lemurs (Lemur catta). Behav Ecol Sociobiol 16:550-560.

Pride RE, Felantsoa D, Randriamboavonjy R (2006) Resource defense in Lemur catta: the importance of group size. In: Jolly A, Sussman RW, Koyama N, Rasamimanana H (eds) Ringtailed lemur biology. Springer US, pp 208-232.

R Development Core Team (2015) A language and environment for statistical computing. R Foundation for statistical computing, Vienna, Austria. http:/www.R-project.org/.

Ralls K (1976) Mammals in which females are larger than males. Q Rev Biol 51:245-276. 
Rankin DJ, Bargum K, Kokko H (2007) The tragedy of the commons in evolutionary biology. Trends Ecol Evol 22:643-651.

Richard AF, Dewar RE, Schwartz M, Ratsirarson J (2000) Mass change, environmental variability and female fertility in wild Propithecus verreauxi. J Hum Evol 39:381-91.

Richard AF, Rakotomanga P, Schwartz M (1993) Dispersal by Propithecus verreauxi at Beza Mahafaly, Madagascar: 1984-1991. Am J Primatol 30:1-20.

Richard AF (1985) Social boundaries in a Malagasy prosimian, the sifaka (Propithecus verreauxi). Int J Primatol 6:553-568.

Richard AF (1992) Aggressive competition between males, female-controlled polygyny and sexual monomorphism in a Malagasy primate, Propithecus verreauxi. J Hum Evol 22:395-406.

Richard AF (1974) Intra-specific variation in the social organization and ecology of Propithecus verreauxi. Folia Primatol 22:178-207.

Richard AF, Dewar RE, Schwartz M, Ratsirarson J (2002) Life in the slow lane? Demography and life histories of male and female sifaka (Propithecus verreauxi verreauxi). J Zool 256:421-436.

Richard AF, Nicoll ME (1987) Female social dominance and basal metabolism in a Malagasy primate, Propithecus verreauxi. Am J Primatol 12:309-314.

Riechert SE (1979) Games spiders play, II Resource assessment strategies. Behav Ecol Sociobiol 6:121-125.

Robbins M, Sawyer S (2007) Intergroup encounters in mountain gorillas of Bwindi impenetrable national park, Uganda. Behaviour 144:1497-1519.

Robinson JG (1988) Group size in wedge-capped capuchin monkeys Cebus olivaceus and the reproductive success of males and females. Behav Ecol Sociobiol 23:187-197. 
Rood JP (1986) Ecology and social evolution in the mongooses. In: Rubenstein DI, Wrangham RW (eds) Ecological aspects of social evolution: Birds and Mammals. Princeton University Press, Princeton, New Jersey, pp 131-152.

Rothman JM, Chapman CA., Soest PJ (2011) Methods in primate nutritional ecology: a user's guide. Int J Primatol 33:542-566.

Rothman JM, Dierenfeld ES, Hintz HF, Pell AN (2008) Nutritional quality of gorilla diets: consequences of age, sex, and season. Oecologia 155:111-122.

Rubenstein DI (1986) Ecology and sociality in horses and zebras. In: Rubenstein DI, Wrangham RW (eds) Ecology and social evolution: birds and mammals. Princeton University Press, Princeton, New Jersey, pp 282-302.

Rubenstein DI, Wrangham RW (1986) Ecological aspects of social evolution: birds and mammals. Princeton University Press, Princeton.

Saito C, Sato S, Suzuki S, et al (1998) Aggressive Intergroup encounters in two populations of Japanese macaques (Macaca fuscata). Primates 39:303-312.

Scarry CJ (2013) Between-group contest competition among tufted capuchin monkeys, Sapajus nigritus, and the role of male resource defence. Anim Behav 85:931-939.

Scarry CJ, Tujague MP (2012) Consequences of lethal intragroup aggression and alpha male replacement on intergroup relations and home range use in tufted capuchin monkeys (Cebus apella nigritus). Am J Primatol 74:804-810.

Schmid J (2000) Daily torpor in the gray mouse lemur (Microcebus murinus) in Madagascar: energetic consequences and biological significance. Oecologia 123:175-183.

Schmid J, Kappeler PM (1998) Fluctuating sexual dimorphism and differential hibernation by sex in a primate, the gray mouse lemur (Microcebus murinus). Behav Ecol Sociobiol $43: 125-132$. 
Serio-Silva JC, Hernández-Salazar LT, Rico-Gray V (1999) Nutritional composition of the diet of Alouatta palliata mexicana females in different reproductive states. Zoo Biol 513:507-513.

Shaffer CA. (2013) Activity patterns, intergroup encounters, and male affiliation in freeranging bearded sakis (Chiropotes sagulatus). Int J Primatol 34:1190-1208.

Shultz S, Opie C, Atkinson QD (2011) Stepwise evolution of stable sociality in primates. Nature 479:219-222.

Sicotte P (1993) Inter-group encounters and female transfer in mountain gorillas: influence of group composition on male behavior. Am J Primatol 30:21-36.

Sicotte P, Macintosh AJ (2004) Inter-group encounters and male incursions in colobus vellerosus in central Ghana. Behaviour 141:533-553.

Signer J, Balkenhol N (2015) Reproducible home ranges (rhr): a new user-friendly R package for analyses of wildlife telemetry data. Wildl Rep Bull 39:358-363.

Silk J (2002) Using the "F"-word in primatology. Behaviour 139:421-446.

Simmen B, Tarnaud L, Hladik A (2012) Leaf nutritional quality as a predictor of primate biomass: further evidence of an ecological anomaly within prosimian communities in Madagascar. J Trop Ecol 28:141-151.

Sorg J, Rohner U (1996) Climate and tree phenology of the dry deciduous forest of Kirindy forest. Primate Rep 46:57-81.

Springer A, Razafimanantsoa L, Fichtel C, Kappeler PM (2015) Comparison of three shortterm immobilization regimes in wild verreaux's sifakas (Propithecus verreauxi): ketamine-xylazine, ketamine-xylazine-atropine, and tiletamine-zolazepam. J Zoo Wildl Med 46:482-490. 
Stanford CB, Nkurunungi JB (2003) Behavioral ecology of sympatric chimpanzees and gorillas in Bwindi impenetrable national park, Uganda: diet. Int J Primatol 24:901-918.

Stearns SC (1989) Trade-offs in life-history evolution. Funtional Ecol 3:259-268.

Stearns SC (1992) The evolution of life histories. Oxford University Press, New York.

Steenbeek R (1999) Tenure related changes in wild thomas's langurs I: between-group interactions. Behaviour 136:595-625.

Sterck EHM, Watts DP, van Schaik CP (1997) The evolution of female social relationships in nonhuman primates. Behav Ecol Sociobiol 41:291-309.

Stolter C, Julkunen-Tiitto R, Ganzhorn JU (2006) Application of near infrared reflectance spectroscopy (NIRS) to assess some properties of a sub-arctic ecosystem. Basic Appl Ecol 7:167-187.

Strier KB (1992) Atelinae adaptations: behavioral strategies and ecological constraints. Am J Phys Anthropol 88:515-524.

Sumpter DJT (2006) The principles of collective animal behaviour. Philos Trans R Soc Lond B Biol Sci 361:5-22.

Takahata Y, Koyama N, Ichino S, et al (2008) The relationship between female rank and reproductive parameters of the ringtailed lemur: a preliminary analysis. Primates 49:135-138.

Thompson CL, Norconk MA, Whitten PL (2012) Why fight? Selective forces favoring between-group aggression in a variably pair-living primate, the white-faced saki (Pithecia pithecia). Behaviour 149:795-820.

Trillmich J, Fichtel C, Kappeler PM (2004) Coordination of group movements in wild Verreaux's sifakas (Propithecus verreauxi). Behaviour 141:1103-1120. 
Trivers RL (1972) Parental investment and sexual selection. In: P.Campbell (ed) Sexual selection and the descent of man, first. IL:Aldine, Chicago, pp 136-179.

Van Belle S (2015) Female participation in collective group defense in black howler monkeys (Alouatta pigra). Am J Primatol 77:595-604.

Van Belle S, Garber PA., Estrada A, Di Fiore A (2014) Social and genetic factors mediating male participation in collective group defence in black howler monkeys. Anim Behav 98:7-17.

Van Schaik CP (1989) The ecology of social relationships amongst female primates. In: V. S, R.A. F (eds) Comparative socioecology: the behavioural ecology of humans and other mammals. Blackwell, Oxford, UK, pp 195-218.

Van Schaik CP (1983) Why are diurnal primates living in groups? Behaviour 87: 120-144.

Van Schaik CP (1996) Social evolution in primates: the role of ecological factors and male behaviour. Proc Br Acad 88:9-31.

Van Schaik CP, Assink PR, Salafsky N (1992) Territorial behavior in Southeast Asian langurs: resource defense or mate defense ? Am J Primatol 26:233-242.

Van Schaik CP, Brockman DK (2005) Seasonality in primate ecology, reproduction, and life history: an overview. In: Seasonality in primates: studies of living and extinct human and non-human primates. pp 3-20.

Van Schaik CP, Kappeler PM (1993) Life history, activity period and lemur social systems. In: Kappeler PM, Ganzhorn JU (eds) Lemur social systems and their ecological basis. Plenum Press, New York, pp 241-260.

Van Schaik CP, van Noordwijk M (1988) Scramble and contest in feeding competition among female long-tailed macaques (Macaca fascicularis). Behaviour 105: 77-98. 
Van Soest P (1996) Allometry and ecology of feeding behavior and digestive capacity in herbivores : A Review. Zoo Biol 15:455-479.

Van Vuren D (1996) Ectoparasites, fitness, and social behaviour of yellow-bellied marmots. Ethology 102:686-694.

Vogel ER, Haag L, Mitra-Setia T, et al (2009) Foraging and ranging behavior during a fallback episode: Hylobates albibarbis and Pongo pygmaeus wurmbii compared. Am J Phys Anthropol 140:716-726.

Voigt FA, Bleher B, Fietz J, et al (2004) A comparison of morphological and chemical fruit traits between two sites with different frugivore assemblages. Oecologia 141:94-104.

Watts DP, Mitani JC (2001) Boundary patrols and integroup encounters in wild chimpanzees. Behaviour 138:299-327.

Wich S, Nunn C (2002) Do male "long-distance calls" function in mate defense? A comparative study of long-distance calls in primates. Behav Ecol Sociobiol 52:474-484.

Wich S, Sterck E (2007) Familiarity and threat of opponents determine variation in thomas langur (Presbytis thomasi) male behaviour during between-group encounters. Behaviour 144:1583-1598.

Willems EP, Hellriegel B, Schaik CP Van (2013) The collective action problem in primate territory economics The collective action problem in primate territory economics. Proc R Soc B Biol Sci 280:20130081.

Willems EP, van Schaik CP (2015) Collective action and the intensity of between-group competition in nonhuman primates. Behav Ecol 26:625-631.

Williams JM, Oehlert GW, Carlis JV., Pusey AE (2004) Why do male chimpanzees defend a group range? Anim Behav 68:523-532. 
Wilson ML, Hauser MD, Wrangham RW (2001) Does participation in intergroup conflict depend on numerical assessment, range location, or rank for wild chimpanzees? Anim Behav 61:1203-1216.

Wilson ML, Wrangham RW (2003) Intergroup relations in chimpanzees. Annu Rev Anthropol 32:363-392.

Worton BJ (1989) Kernel methods for estimating the utilization distribution in home-range studies. Ecology 70:164-168.

Wrangham RW (1980) An ecological model of female-bonded primate groups. Behaviour 75: $262-300$.

Wrangham RW, Chapman CA, Clark-Arcadi AP, Isabirye-Basuta G (1996) Social ecology of Kanyawara chimpanzees: implications for understanding the costs of great ape groups. In: Marchant LF, Nishida T (eds) Great Ape Societies. Cambridge University Press, Cambridge, pp $45-57$.

Wright PC (1999) Lemur traits and Madagascar ecology: coping with an island environment. Am J Phys Anthropol Suppl 29:31-72.

Yamashita N (2008) Chemical properties of the diets of two lemur species in southwestern Madagascar. Int J Primatol 29:339-364.

Young AL, Richard AF, Aiello LC (1990) Female dominance and maternal investment in strepsirhine primates. Am Nat 135:473-488.

Zhao QK (1997) Intergroup interactions in Tibetan macaques at Mt. Emei, China. Am J Phys Anthropol 104:459-470. 


\section{ACKNOWLEDGEMENTS}

During my PhD I had opportunity to meet wonderful people that contributed in many different ways to the development of this dissertation. I was very fortunate to work with Claudia Fichtel and Peter Kappeler. Claudia was the one with whom I exchanged and discussed all details of this dissertation. I will be always thankful for her kindness, patience, and support in each step of this work. I learned so much with Peter in each seminar and during the work through each of the chapters of this dissertation. He was also always very helpful and supportive with all the logistics of the project. Thank you so much, Claudia and Peter for all that. I also would like to thank Stefan Scheu for his support and collaboration. I am also thankful to the other committee members, Julia Ostner, Oliver Schülke and Carel van Schaik for evaluating my thesis, and for all the inspiring talks over these years in Göttingen.

I would like to say thanks to all employees of the German Primate Center for the kindness and help during my time there. I am also grateful for the support by the Département de Biologie Animale, Université d'Antananarivo, the CNFEREF and the Commission Tripartite and the CAFF of the Direction des Eaux et Forêts. This work counted on financial support from the German Primate Center (DPZ), and from the German Research Foundation (DFG). A special thanks to Christina, Ulli, Henning, and Anja for all the administrative and technical work that actually makes our work in the Behavioral Ecology and Sociobiology unit possible.

I am very grateful to the people in Kirindy Forest. Thanks to Léon for managing all logistics in camp, but more than that, for all the very nice dinners and talks on the weekendsoff, and for the support when I was missing home so badly. To Mamy, Pata, and Remy my amazing field assistants, deep thanks for helping me to collect the data for this project. To Majebati, the best band in Kirindy forest, thanks for the great music and the wonderful veloma parties. I would like to say a special thanks to Tina, one of the kindest people I know, his smile and positive energy in every breakfast in the forest for sure helped me to keep going during the long field work. Here I also want to say thanks to Femke, Momo, Falk, Hanitra, and Roberta, with whom I shared amazing moments in the field that I will never forget. 
To my colleagues and friends, the ones that are still in Göttingen, Andrea, Franzi, Matze, Eva, Klara, Thiago, Tiziana, Darja, Anna, Tilman and the ones that are already doctors and far from here, I want to say thanks to all of you for the time we spent together and for all the interesting things I learned from you. In special I would like to say thanks to Omer and Josué for their friendship and for sharing their statistics knowledge with me.

I would like to thank the researchers I had the privilege to work with in this dissertation. To Jörg Ganzhorn, thanks for the nutritional analyses of all plant samples, and for support and advice. I want to thank Irene Tomaschewski and Kain Irretier for their help with the nutritional analyses in the lab at the University of Hamburg. I am also grateful for the opportunity to visit the labs of Jessica Rothman at Hunter College and of Colin Chapman at McGill University. Finally, I want to say a very special thanks to Johannes Signer for the collaboration with the spatial analyses, but most of all for the inspiring uncountable hours we spent in the library exploring the GPS data until we finally decided what to do with it (and even after that).

Thanks a lot to Chris Young, Chris Haunhorst, Rebecca, Susanne, Pascal, Anni, Marlies, Selly, Frederic, Josi, Cedric, Anna Gamero, Christin, and Steffi, for the great moments we spent together in Göttingen. I would like to say thanks to Paul Garber for all his encouraging words along these years, since we met in Brazil a while ago, he has been my mentor and an inspiration to me. I would like to say thanks to Angela and Carina for being the best friends I could ever have. To my dear friend Luca, I wish I had the right words to express my gratitude for all the things I learned from him, for all his support during the difficult times, and for all the fun we had together.

I would like to say thanks to my family for giving me all support, for helping me to cope with all the missing, and for their understanding of my absence in so many important moments since I left Brazil. There is not even one day that I do not think and miss you guys, saudade sem fim! In special, actually in the most special way possible, thanks to my mother, for all her support since the beginning, and for being my best friend. Finally, I would like to say thanks to my partner, Mo Lefever, for her support, understanding, help with English in all chapters of this dissertation, but most of all, for making me the happiest person in this planet. 


\section{CURRICULUM VITAE}

\section{$\underline{\text { Personal information }}$}

Name: Flávia Koch de Vasconcellos

Address: Emilienst. 9, 37075, Goettingen, Germany

Phone: +49015759235978

Email: biokoch@gmail.com

Date of birth: 06.10.1981

Place of birth: Porto Alegre/ Rio Grande do Sul/ Brazil

Family status: Single

Nationality: Brazilian

$\underline{\text { Basic Education }}$

1987 - $1995 \quad$ Basic Primary school

1996 - 1998 High School, João Paulo I, Porto Alegre, Rio Grande do Sul, Brazil

$\underline{\text { Academic education }}$ 
Graduation: Bachelor in Biology Federal University of Rio Grande do Sul, UFRGS, Porto Alegre, Rio Grande do Sul, Brazil.

Bachelor's thesis: "Ecology and Behavior of Alouatta guariba clamitans."

Volunteer at Ubatuba Aquarium

Aim: Conservation and education)

Duration: one month

Ubatuba, Sao Paulo, Brazil.

Volunteer at National Park of Ilha Anchieta

Aim: conservation and education

Duration: one month

Ubatuba, Sao Paulo, Brazil

Volunteer at Project TAMAR for Conservation of Sea Turtles

Aim: conservation and education

Duration: 3 months

Ubatuba, Sao Paulo, Brazil

Workshop: Observational Methods for Primates Behavioral Studies

Eleonora Setz, PhD (UNICAMP, Campinas / SP, Brazil)

$\mathrm{X}$ Brazilian Congress of Primatology

UFPa, Belém do Pará / PA, Brazil

Field course: Techniques and Theories in Primatological Studies

Gabriel Zunino, PhD (Argentian Museum of Natural History, Argentina)

Argentian Museum of Natural History - Corrientes Biological Reserve Corrientes, Argentina 
Master's in Zoology - Including 1 year of field work and one year of theoretical approach

Catholic University of Rio Grande do Sul, PUCRS, Brazil

Master's thesis: "Diet and behaviour of Alouatta guariba clamitans: a cause and effect relation?"

Field assistance for Dr. Josia Razafindramanana

Ringtailed and Brown Lemur's Behavior

Duration: 3 months

Berenty Private Reserve

Fort Dauphin, Madagascar

Preliminary data collection for $\mathrm{PhD}$ project "Intergroup relationships inVerreaux's sifaka (Propithecus verreauxi). Characterization of habitat and forest structure in Kiri; behavior and diet of Propithecus verreauxi, at Kirindy Forest/CNFEREF, western Madagascar.

German Primate Center, Göttingen, Germany

$2012-2015$

PhD candidate Biology Program (GAUSS)

University of Goettingen

German Primate Center (DPZ)

Goettingen, Germany

Publications:

Koch, F.; Bicca-Marques, J.C. (in press) Callithrix kuhlii. In: The Pictorial Guide of Living Primates, vol. 2. Rowe N., Mittermeier R. (eds.), Pogonias Press, East Hampton, NY, USA. 
Koch, F.; Bicca-Marques, J.C. (2005) Activity budget and diet of Alouatta guariba clamitans: A sex-age assessment. In: The Primatology in Brazil 10, v. 10, 2005.

Koch, F.; Bicca-Marques, J.C. (2005) Substrate manipulation by Alouatta guariba clamitans in solving a locomotor problem. Neotropical primates, v. 13, 2005.

Koch, F.; Pereira, T.S. (2014) Os Bugios e o mico. In: Mamíferos do Rui Grande do Sul. Goncalves, G.S.; Quintela, F.; Freitas, T.O. (eds.), Pacartes Press, Porto Alegre, RS, Brazil.

Koch, F.; Ganzhorn, J.U.; Rothman, J.M.; Chapman, C.A.; Fichtel, C. (submitted) Sex and seasonal differences in diet and nutrient intake in Verreaux's sifakas (Propithecus verreauxi).

Koch, F.; Signer, J.; Kappeler, P.M.; Fichtel, C. (submitted) Intergroup encounters in Verreaux's sifakas (Propithecus verreauxi): who fights and why?

Koch, F.; Signer, J.; Kappeler, P.M.; Fichtel, C. (submitted) Group encounters in Verreaux's sifakas: the importance of location as a predictor for outcome.

Ganzhorn, J.U.; Arrigo-Nelson, S.J.; Carrai, V.; Chalise, M.K.; Donati, G.; Droescher, I.; Eppley, T.M.; Irwin, M.T.; Koch, F.; Koenig, A.; Kowalewski, M.M.; Mowry, C.B.; Patel, E.R.; Pichon, C.; Ralison, J.; Reisdorff, C.; Simmen, B.; Stalenberg, E.; Terboven, J.; Wright, P.C.; Foley, W.J. (Submitted). The importance of protein in leaf selection of folivorous primates. 
Funding:

$\underline{2002}$

3000 R\$ (1300€) -FAPERGS- Fundação de Amparo a Pesquisa do Rio Grande do Sul. Brazil.

$\underline{2006}$

$11400 \mathrm{R} \$(5000 €)-$ CAPES-Brazil

"Diet and behavior of Alouatta guariba clamitans: a cause and effect relation?"

2009-2012

Scholarship from German Primate Center, Goettingen, Germany.

2012-2015

$\mathrm{PhD}$ project "Intergroup relationships in Verreaux's sifakas (Propithecus verreauxi)" funded by German Research Foundation (DFG).

\section{$\underline{\text { Scientific Exchange }}$}

Visitor student:

Prof. Dr. Jessica M. Rothman

Departmnet of Anthropology - Nutritional Ecology Lab.

Hunter College Of The City University Of New York

New York, United States of America

From $01 / 07 / 2014$ to $05 / 08 / 2014$

Visitor student:

Prof. Dr. Colin A. Chapman

Department of Anthropology \& McGill School of Environment 
McGill University

Montreal, Quebec, Canada

From 25/07/2014 to 28/09/2014

Conferences:

2001

V Congresso Brasileiro de Ecologia

Porto Alegre, Rio Grande do Sul, Brazil, 4-9 November

2003

II Congresso Brasileiro de Mastozoologia

Belo horizonte, Minas Gerais, Brazil, 23-29 June

2002

X Congresso Brasileiro de Primatologia

Porto Alegre, Rio Grande do Sul, Brazil

2005

XI Congresso Brasileiro de Primatologia

Porto Alegre, Rio Grande do Sul, Brazil, 13-18 February

2007

XII Congresso Brasileiro de Primatologia

Belo Horizonte, Minas Gerais, Brazil, 22-27 July

2011

4th Congress of the European Federation for Primatology (EFP)

Almada, Portugal. 14-17 August

2014

15th International Behavioral Ecology Congress (ISBE)

New York, United States of America. 31-5 July

Poster: Intergroup encounters in Verreaux's sifakas: factors influencing individual participation 


\section{Hanoi, Vietnam. 11-16 August}

Talk: Intergroup encounters in Verreaux's sifakas: who is the winner?

2014

37th Meeting of the American Society of Primatologists (ASP)

Decatur, Atlanta, United States of America. 12-15 September

Talk: Dietary differences in neighboring groups in Verreaux's sifakas

2015

Conference of the Gesellschaft für Primatologie (GFP)

Leipzig, Germany. 11-13 February

Talk: Intrgeoup encounters in Verreaux's sifakas: the role of female participation in group defense

2015

6th Congress of the European Federation for Primatology (EFP)

Rome, Italy. 25-28 August

Talk: Intergroup encounters in Verreax's sifakas

(Propithecus verreauxi)

\section{$\underline{\text { Languages }}$}

Portuguese (native speaker)

English (advanced)

Spanish (intermedium)

French (basic) 


\section{DECLARATION}

I hereby declare that I have written this thesis entitled "Intergroup relationships in Verreaux's sifakas (Propithecus verreauxi)" independently and with no other aids or sources than quoted.

Flávia Koch

Göttingen, 20.10.2015 